SYDNEI MARSSAL DE OLIVEIRA

\title{
UM MODELO DE DECISÃO PARA PRODUÇÃO E COMERCIALIZAÇÃO DE PRODUTOS AGRÍCOLAS DIVERSIFICÁVEIS
}


SYDNEI MARSSAL DE OLIVEIRA

\section{UM MODELO DE DECISÃO PARA PRODUÇÃO E COMERCIALIZAÇÃO DE PRODUTOS AGRÍCOLAS DIVERSIFICÁVEIS}

Tese apresentada à Escola Politécnica da Universidade de São Paulo

Área de Concentração: Engenharia de Produção

Orientadora: Prof ${ }^{a}$. Dr ${ }^{a}$. Celma de Oliveira Ribeiro 


\section{FICHA CATALOGRÁFICA}

Oliveira, Sydnei Marssal de

Um modelo de decisão para produção e comercialização de produtos agrícolas diversificáveis / S.M. de Oliveira. -- São Paulo, 2012.

$128 \mathrm{p}$.

Tese (Doutorado) - Escola Politécnica da Universidade de São Paulo. Departamento de Engenharia de Produção.

1. Engenharia de produção 2. Engenharia financeira 3. Produção agrícola 4. Portfólios (Seleção) 5. Estoques 6. Otimização estocástica I. Universidade de São Paulo. Escola Politécnica. Departamento de Engenharia de Produção II. t. 


\section{AGRADECIMENTOS}

À $\operatorname{Prof}^{a}$. $\operatorname{Dr}^{\mathrm{a}}$. Celma de Oliveira Ribeiro, pela orientação e pelo constante estímulo, pelos conhecimentos que tantas portas abriram, pela tolerância e compreensão, pelos momentos juntos, pelas oportunidades oferecidas em diversas áreas e pela amizade.

Ao prof. Dr. Ricardo Humberto Rocha, membro da banca, pela colaboração, conselhos e oportunidades em minha carreira como docente.

Ao prof. Dr. Oswaldo L. V. Costa, membro da banca, pelos ajustes que permitiram alcançarmos a excelência necessária para uma tese de Doutorado.

A minha querida esposa Pollyanna Celso Felipe de Castro pela parceria e companhia em todos os instantes.

Aos amigos, familiares e a todos que colaboraram direta ou indiretamente, na execução deste trabalho.

Por fim, ao pessoal da Secretaria, Comissão de Pós-Graduação e Bibliotecas da Escola Politécnica. 


\section{RESUMO}

A ascensão de um grande número de pessoas em países em desenvolvimento para a classe média, no inicio do século XXI, aliado ao movimento político para transferência de base energética para os biocombustíveis vêm aumentando a pressão sobre os preços das commodities agrícolas e apresentando novas oportunidades e cenários administrativos para os produtores agrícolas dessas commodities, em especial aquelas que podem se diversificar em muitos subprodutos para atender diferentes mercados, como o de alimentos, químico, têxtil e de energia.

Nesse novo ambiente os produtores podem se beneficiar dividindo adequadamente a produção entre os diferentes subprodutos, definindo o melhor momento para a comercialização através de estoques, e ainda controlar sua exposição ao risco através de posições no mercado de derivativos.

A literatura atual pouco aborda o tema da diversificação e seu impacto nas decisões de produção e comercialização agrícola e portanto essa tese tem o objetivo de propor um modelo de decisão fundado na teoria de seleção de porttólios capaz de decidir a divisão da produção entre diversos subprodutos, as proporções a serem estocadas e o momento mais adequado para a comercialização e por fim as posições em contratos futuros para fins de proteção ou hedge. Adicionalmente essa tese busca propor que esse modelo seja capaz de lidar com incerteza em parâmetros, em especial parâmetros que provocam alto impacto nos resultados, como é o caso dos retornos previstos no futuro.

Como uma terceira contribuição, esse trabalho busca ainda propor um modelo de previsão de preços mais sofisticado que possa ser aplicado a commodities agrícolas, em especial um modelo híbrido ou hierárquico, composto de dois modelos, um primeiro modelo fundado sob a teoria de processos estocásticos e do Filtro de Kalman e um segundo modelo, para refinar os resultados do primeiro modelo de previsão, baseado na teoria de redes neurais, com a finalidade de considerar variáveis exógenas.

O modelo híbrido de previsão de preços foi testado com dados reais do mercado sucroalcooleiro brasileiro e indiano, gerando resultados promissores, enquanto o modelo de decisão de parâmetros de produção, comercialização, estocagem e hedge se mostrou uma ferramenta útil para suporte a decisão após ser 
testado com dados reais do mercado sucroalcooleiro brasileiro e do mercado de milho, etanol e biodiesel norte-americano.

Palavras-chave: Commodity. Filtro de Kalman. Previsão de Preços. Hedge. Otimização Robusta. 


\section{ABSTRACT}

The rise of a large number of people in developing countries for the middle class at the beginning of the century, combined with the political movement to transfer the energy base for biofuels has been increasing pressure on prices of agricultural commodities and presenting new opportunities and administrative scenarios for agricultural producers of these commodities, especially those who may diversify into many products to meet different markets such as food, chemicals, textiles and energy.

In this new environment producers can achieve benefits properly dividing production between different products, setting the best time to market through inventories, and still control their risk exposure through positions in the derivatives market.

The literature poorly addresses the issue of diversification and its impact on agricultural production and commercialization decisions and therefore this thesis aims to propose a decision model based on the theory of portfolio selection able to decide the division of production between different products, the proportions to be stored and timing for marketing and finally the positions in futures contracts to hedge.

Additionally this thesis attempts to propose that this model is capable of dealing with uncertainty in parameters, especially parameters that cause high impact on the results, as is the case of expected returns in the future.

As a third contribution this paper seeks to also propose a model more sophisticated to forecast prices that can be applied to agricultural commodities, especially a hybrid or hierarchical model, composed of two models, a first one based on the theory of stochastic processes and Kalman filter and a second one to refine the results of the first prediction model, based on the theory of neural networks in order to consider the exogenous variables.

The hybrid model for forecasting prices has been tested with real data from the Brazilian and Indian sugar ethanol market, generating promising results, while the decision model parameters of production, commercialization, storage and hedge proved a useful tool for decision support after being tested with real data from Brazilian sugar ethanol market and the corn, ethanol and biodiesel market in U.S.A. 
Keywords: Commodity. Kalman Filter. Price Forecasting. Hedge. Robust Optimization. 


\section{LISTA DE FIGURAS}

Figura 1.2.1 - Estrutura do Modelo Proposto......................................................10

Figura 2.2.1 - Processo Produtivo da Cana-de-açúcar ..........................................23

Figura 2.3.1 - Produção de Milho - EUA, 1930-2010 ........................................28

Figura 2.3.2 - Milho Destinado a Produção de Etanol - EUA, 1985-2010 ……….....29

Figura 2.3.3 - Produção de Biodiesel - EUA, 2005-2010 ....................................29

Figura 2.3.4 - Processo Produtivo do Milho - Moagem Úmida ….............................30

Figura 2.3.5 - Processo Produtivo do Milho - Moagem Seca ....................................31

Figura 3.2.1 - Preço real do açúcar e preço estimado pelo Filtro de Kalman para o mercado sucroalcooleiro Brasileiro 44

Figura 3.2.2 - Preço real do açúcar e preço estimado pelo Filtro de Kalman para o mercado sucroalcooleiro Indiano.........................................................................44

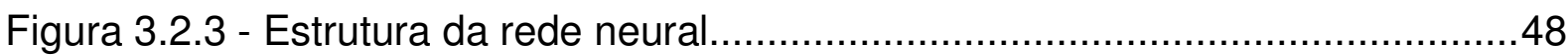

Figura 3.2.4 - Resultados do modelo por redes neurais com taxa de câmbio como

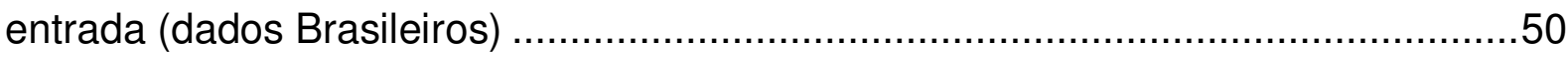

Figura 4.3.1 - Margens de lucro previstas e momentos escolhidos.........................77

Figura 4.3.2 - Fronteira eficiente no momento 1 - dados reais EUA..........................79

Figura 4.3.3 - Relação risco e retorno no momento 1 - dados EUA ..........................80

Figura 4.3.4 - Relação incerteza e retorno no momento 1 - dados EUA ....................80

Figura 4.3.5 - Proporção a produzir de Etanol no momento 1 - dados EUA...............81

Figura 4.3.6 - Proporção a produzir de Biodiesel no momento 1 - dados EUA .........81

Figura 4.3.7 - Proporção a estocar de Milho no momento 1 - dados EUA .................82

Figura 4.3.8 - Proporção a vender de Milho no momento 1 - dados EUA ..................82

Figura 4.3.9 - Proporção a estocar de Etanol no momento 1 - dados EUA................82

Figura 4.3.10 - Proporção a estocar de Biodiesel no momento 1 - dados EUA ........82

Figura 4.3.11 - Razão de hedge para o Etanol no momento 1 - dados EUA..............83

Figura 4.3.12 - Razão de hedge para o Biodiesel no momento 1 - dados EUA .........83

Figura 4.3.13 - Razão de hedge para o Milho no momento 1 - dados EUA ...............84

Figura 4.3.14 - Fronteira eficiente no momento 2 - dados reais EUA........................85

Figura 4.3.15 - Relação risco e retorno no momento 2 - dados EUA ..........................85

Figura 4.3.16 - Relação incerteza e retorno no momento 2 - dados EUA ..................85

Figura 4.3.17 - Proporção a produzir de Etanol no momento 2 - dados EUA............86 
Figura 4.3.18 - Proporção a produzir de Biodiesel no momento 2 - dados EUA .......86

Figura 4.3.19 - Proporção a estocar de Milho no momento 2 - dados EUA ...............86

Figura 4.3.20 - Proporção a vender de Milho no momento 2 - dados EUA .................86

Figura 4.3.21 - Proporção a estocar de Etanol no momento 2 - dados EUA.............87

Figura 4.3.22 - Proporção a estocar de Biodiesel no momento 2 - dados EUA ........87

Figura 4.3.23 - Razão de hedge para o Etanol no momento 2 - dados EUA.............88

Figura 4.3.24 - Razão de hedge para o Biodiesel no momento 2 - dados EUA ........88

Figura 4.3.25 - Razão de hedge para o Milho no momento 2 - dados EUA ...............88

Figura 4.3.26 - Margens de lucro previstas e momentos históricos escolhidos..........90

Figura 4.3.27 - Fronteira eficiente no momento 1 - dados Brasil ............................92

Figura 4.3.28 - Relação risco e retorno no momento 1 - dados Brasil .......................93

Figura 4.3.29 - Relação incerteza e retorno no momento 1 - dados Brasil ................93

Figura 4.3.30 - Proporção a produzir de Açúcar no momento 1 - dados Brasil .........93

Figura 4.3.31 - Proporção a produzir de Etanol no momento 1 - dados Brasil ..........93

Figura 4.3.32 - Proporção a estocar de Açúcar no momento 1 - dados Brasil ...........94

Figura 4.3.33 - Proporção a estocar de Etanol no momento 1 - dados Brasil ............94

Figura 4.3.34 - Razão de hedge no momento 1 - dados Brasil ................................95

Figura 4.3.35 - Fronteira eficiente no momento 2 - dados Brasil ..............................95

Figura 4.3.36 - Relação risco e retorno no momento 2 - dados Brasil .......................96

Figura 4.3.37 - Relação incerteza e retorno no momento 2 - dados Brasil ................96

Figura 4.3.38 - Proporção a produzir de Açúcar no momento 2 - dados Brasil .........96

Figura 4.3.39 - Proporção a produzir de Etanol no momento 2 - dados Brasil ..........96

Figura 4.3.40 - Proporção a estocar de Açúcar no momento 2 - dados Brasil ..........97

Figura 4.3.41 - Proporção a estocar de Etanol no momento 2 - dados Brasil ............97

Figura 4.3.42 - Razão de hedge no momento 2 - dados Brasil ................................98 


\section{LISTA DE TABELAS}

Tabela 2.2.1 - Dez maiores produtores de cana de açúcar - 2008..........................20

Tabela 2.3.1 - Dez maiores produtores de milho - 2009..................................27

Tabela 3.2.1 - Resultado do modelo por processos estocásticos e Filtro de Kalman para a previsão do preço à vista do açúcar um mês a frente ..................................43 Tabela 3.2.2 - Variáveis exógenas usadas no modelo de redes neurais (Dados Brasileiros) 45

Tabela 3.2.3 - Variáveis exógenas usadas no modelo de redes neurais (Dados Indianos).

Tabela 3.2.4 - Resultados do modelo por redes neurais para cada variável exógena (dados Brasileiros)

Tabela 3.2.5 - Resultados do modelo por redes neurais para cada variável exógena (dados Indianos) .50

Tabela A.1 - Fatores de transformação em bushels de milho 112

Tabela A.2 - Resultado do modelo por processos estocásticos e Filtro de Kalman para os dados do mercado de milho, etanol e biodiesel dos Estados Unidos. 112

Tabela A.3 - Matriz $\boldsymbol{r}$ de retornos esperados (EUA) 112

Tabela A.4 - Matriz $s$ de níveis de incerteza (EUA) 113

Tabela A.5 - Quantidades e Capacidade de Estoque (EUA). 114

Tabela A.6 - Fatores de transformação em equivalentes ATR 114

Tabela A.7 - Custos de Produção do Setor Sucroalcooleiro 115

Tabela A.8 - Resultado do modelo por processos estocásticos e Filtro de Kalman para os dados do mercado Sucroalcooleiro Brasileiro 115

Tabela A.9 - Matriz $\boldsymbol{r}$ de retornos esperados (Brasil) 115

Tabela A.10 - Matriz $\boldsymbol{s}$ de níveis de incerteza (Brasil) 115

Tabela A.11 - Quantidades e Capacidade de Estoque (Brasil) 116 


\section{SUMÁRIO}

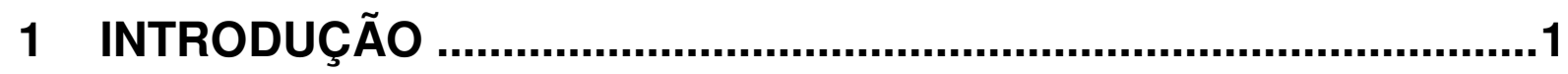

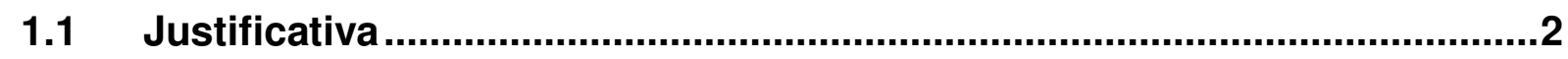

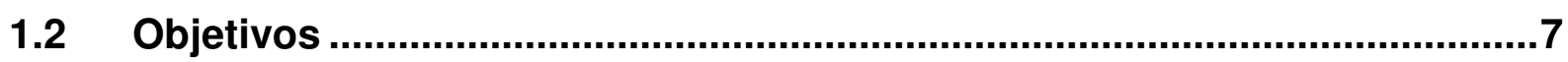

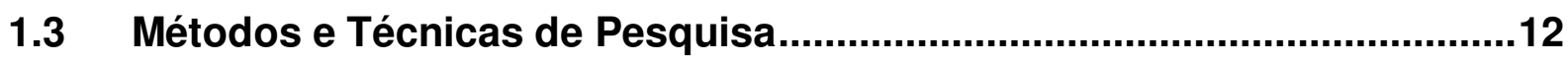

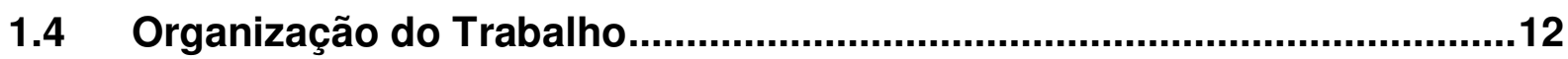

2 FUNDAMENTAÇÃO TEÓRICA ..................................................13

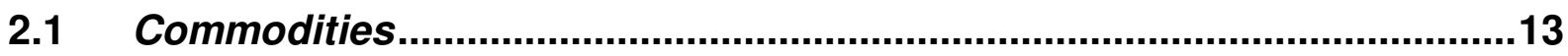

2.1.1 Negociação e hedging de commodities agrícolas .....................................14

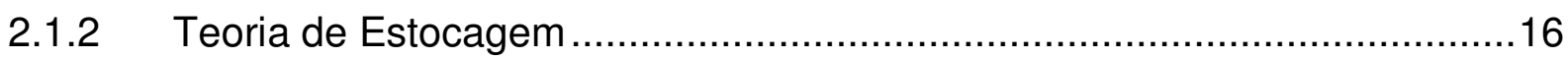

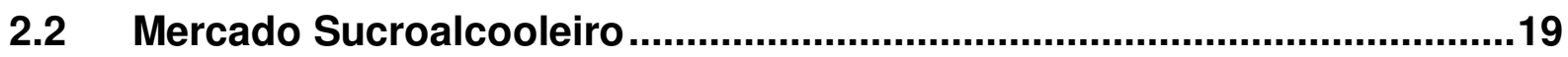

2.2.1 Cenário Atual e Perspectivas para o Futuro ……………........................19

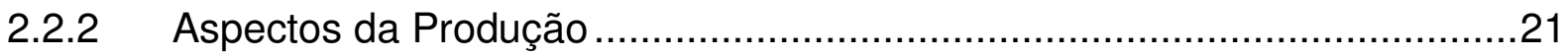

2.2.3 Preços no Mercado Sucroalcooleiro …………...................................24

2.3 Mercado de Milho, Etanol e Biodiesel nos Estados Unidos ......................27

2.3.1 Cenário Atual e Perspectivas para o Futuro ...............................................27

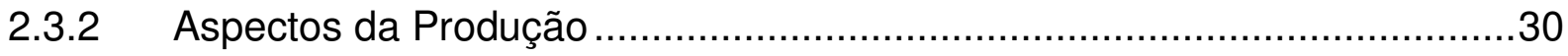

2.3.3 Preços no Mercado de Milho, Etanol e Biodiesel .......................................31

3 PREVISÃO DE PREÇOS DE COMMODITIES................................33

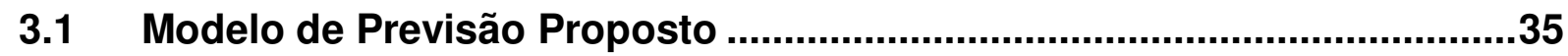

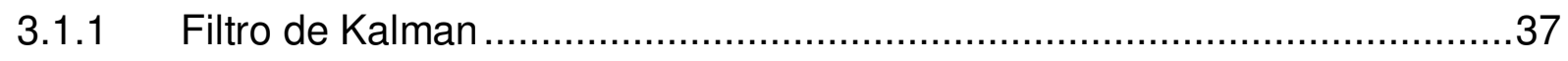

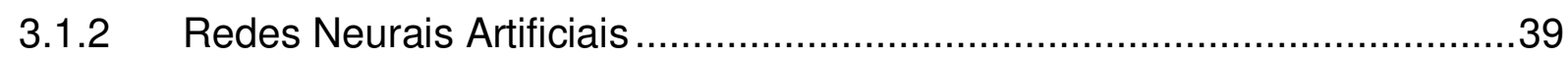

3.2 Resultados do Modelo de Previsão de Preços …………...........................41

3.2.1 Processos Estocásticos e Filtro de Kalman ...........................................42

3.2.2 Correção por Redes Neurais Artificiais .................................................45

3.3 Conclusões do Modelo de Previsão de Preços ..........................................51 


\section{MODELO DE DECISÃO DE MIX DE PRODUÇÃO,}

COMERCIALIZAÇÃO, HEDGE E ESTOCAGEM

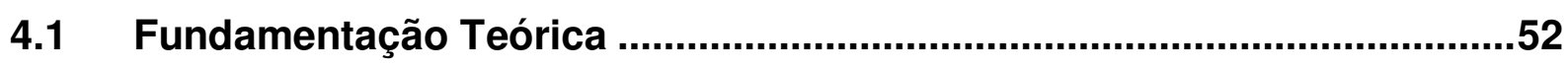

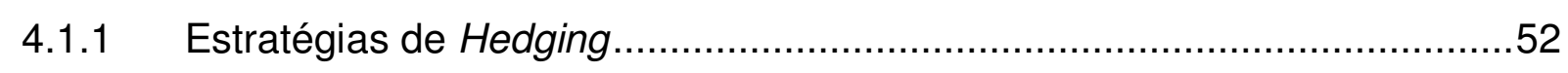

4.1.2 Seleção de Portfólio ........................................................................56

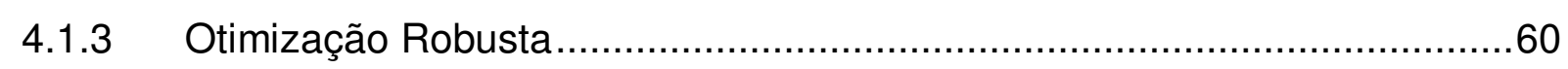

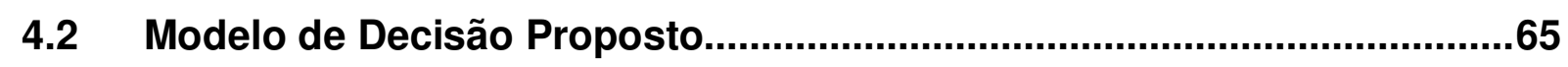

4.2.1 Modelo de Otimização Não Robusto.......................................................65

4.2.2 Modelo de Otimização Robusta ............................................................

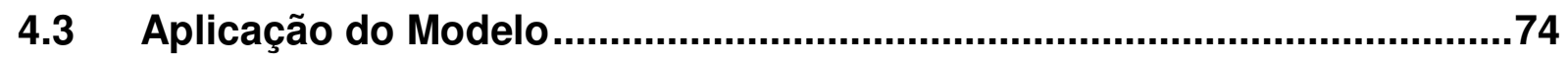

4.3.1 Resultados com dados reais do mercado de milho, etanol e biodiesel dos

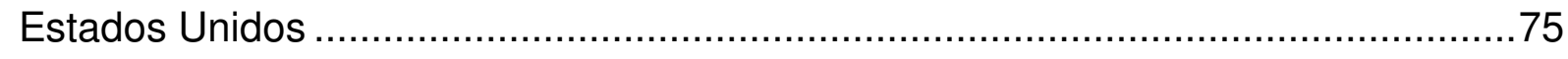

4.3.2 Resultados com dados reais do mercado sucroalcooleiro Brasileiro ..........88

4.4 Conclusões Acerca do Modelo de Decisão............................................99

5 CONCLUSÕES ....................................................................100

6 REFERÊNCIAS BIBLIOGRÁFICAS.........................................103

7 ANEXO 1: TABELAS .................................................................112 


\section{INTRODUÇÃO}

Atualmente muitos produtos agrícolas podem gerar inúmeros subprodutos, atendendo a diversos mercados com dinâmicas peculiares. Essa flexibilidade ou capacidade intrínseca de diversificação está presente em commodities agrícolas, como a soja, o milho e a cana de açúcar. O milho, por exemplo, é capaz de gerar subprodutos para o setor de alimentos, têxtil, cosméticos e energia.

Com o avanço da demanda por biocombustíveis a capacidade de diversificação de determinadas commodities agrícolas passou a ser fator de grande relevância nas decisões do produtor.

A inserção dos produtos agrícolas na matriz energética possui desdobramentos ainda desconhecidos e que tem sido objeto de estudo pela comunidade científica.

Além disso, a possibilidade de escolha entre diferentes produtos, associada a formação de grandes grupos empresariais no setor agrícola, em conjunto com novos instrumentos financeiros, como futuros e opções, fez com que o interesse por novos modelos de previsão de preços e tomada de decisões para gerenciamento do binômio risco-retorno se intensificasse.

Essa nova realidade levou à proposição, no presente trabalho, de um modelo de decisão capaz de orientar o produtor agrícola e garantir sua capacidade de definir estratégias de produção, comercialização, hedge e estocagem, considerando o balanceamento entre risco e retorno.

Este trabalho tem como objetivo desenvolver um modelo de decisão para produção, comercialização, hedge e estocagem para os produtores de commodities agrícolas, em especial as commodities que podem ser transformadas em diversos produtos, tanto alimentícios quanto de energia ou ainda de uso industrial.

Como as decisões para produção, comercialização, hedge e estocagem dependem da previsão de variáveis no futuro, como é o caso dos preços à vista, um segundo objetivo do trabalho é a proposição de um modelo híbrido para previsão de preços. 


\subsection{Justificativa}

Com a crescente preocupação mundial com aspectos ambientais de sustentabilidade, com a escassez de combustíveis fósseis e com o aquecimento global, inúmeros países adotaram a questão dos biocombustíveis em seus programas de governo.

Graças a essas forças político-econômicas, em 2005, as maiores economias do mundo, incluindo o G8 e cinco nações em desenvolvimento (México, Índia, Brasil, China e África do Sul), e também as Nações Unidas e a União Européia se uniram em uma parceria global pela bioenergia (GBEP - Global Bioenergy Partnership, 2005). Um dos principais objetivos do GBEP é de discutir e promover a produção de biocombustíveis ao redor do mundo. Recentemente a Comissão Europeia traçou um ambicioso programa (Diretiva 2003/30/CE) para apoiar a penetração dos biocombustíveis no mercado dos combustíveis convencionais através da fixação de uma quota mínima obrigatória de mistura de etanol na gasolina que deve chegar a 10\% até 2020 (Mas et al., 2010).

Iniciativas desse tipo aquecem os mercados de biocombustíveis e levam a produção agrícola a novas direções em que os produtos agrícolas extrapolam sua função básica de alimentação e passam a fazer parte das matrizes energéticas de diversos países.

Os novos destinos para produtos agrícolas vêm gerando diversas discussões a respeito do impacto do mercado de biocombustíveis nos preços dos alimentos, o que geraria um desbalanceamento entre a seguridade alimentar e a de energia, o que afetaria as parcelas mais pobres da população mundial. Em 2004 uma crise afetou os preços das commodities agrícolas, e os preços começaram a acelerar em função principalmente da entrada de novos consumidores em países emergentes como China e Índia, embora muitos discutam a adoção de bicombustíveis como causa desse processo inflacionário.

Zhang et al. (2010) concluem que os últimos choques de volatilidade nos preços das commodities agrícolas não podem ser atribuídos ao impacto da adoção dos biocombustíveis. Adicionalmente, Gauder et al. (2011) afirma que a produção de etanol no Brasil não deve representar, nos próximos 10 anos, ameaça a produção de alimentos, uma vez que não existem restrições a expansão das áreas de cultivo até o ano de 2020. Por outro lado, em um estudo recente, Cha e Bae (2011) 
apontam para uma correlação positiva entre os preços do milho e dos combustíveis nos Estados Unidos. Esmaeili e Shokoohi (2011), Bafes (2007) e Nazlioglu e Soytas (2010) apontam que existe influência indireta do preço do petróleo no preço de uma série de alimentos. Em resumo ainda não é possível atribuir o aumento no preço dos alimentos ao aumento da adoção de biocombustíveis, mas é possível apontar o aumento do preço do petróleo como uma das causas do encarecimento dos alimentos.

A despeito de todas as implicações sociais da adoção de biocombustíveis em grande escala, um novo conjunto de variáveis econômicas e operacionais se apresentaram para os produtores agrícolas, que passaram a considerar não só o setor de alimentos, como também o setor de energia.

Como se não bastasse toda a incerteza em relação as condições meteorológicas, a gestão da produção agrícola, com a consideração de dois setores, cada vez mais enfrenta impactos em sua cadeia de suprimentos, na armazenagem, na comercialização, nas técnicas financeiras de proteção e na gestão de capital de giro.

Por outro lado, a complexidade da gestão da produção agrícola vêm acompanhada da capacidade de diversificação da produção, ou seja, a capacidade de gerar subprodutos de acordo com a melhor estratégia de retorno. No caso de um produtor de milho alguns dos subprodutos são a farinha de milho, o milho em grão, o óleo de milho ou o etanol. No caso de um produtor de cana de açúcar, existe a possibilidade de gerar diferentes tipos de açúcar, etanol, fertilizantes, bebidas alcoólicas e até plástico.

É possível encontrar na literatura alguns trabalhos que buscam otimizar parâmetros relacionados a produção, comercialização e gestão financeira de commodities. Contudo as características únicas das commodities agrícolas diversificáveis ainda não foram consideradas nos modelos propostos pela literatura.

Os principais modelos de gestão financeira e operacional de commodities, envolvem:

1. estratégia de aquisição de matéria prima e insumos,

2. estratégia de expansão da malha produtiva,

3. níveis de estoque,

4. divisão da produção entre diversos subprodutos,

5. estratégia de venda do produto final, 
6. proteção financeira (hedge).

Alguns trabalhos recentes buscam dar suporte a decisões de longo prazo, como a definição de novas unidades produtivas, sua capacidade e localização. Esse é o caso do trabalho apresentado por Mas et al. (2010), Kostin et al. (2010), Leboleiro e Hilaly (2011) e Corsano et al. (2010).

Mas et al. (2010) otimizam cadeias de suprimentos para produção de biocombustíveis, levando em consideração incertezas de mercado e níveis de aversão ao risco, para prever o efeito do aumento da demanda, em um período superior a dez anos, no espalhamento geográfico da produção de biomassa e de instalações de produção de etanol. O modelo trata a incerteza dos preços através da construção de cenários para os preços de compra do milho e de venda do etanol. Mas et al. (2010) não utilizam modelos estocásticos para definir os preços futuros, assim como não define estratégias de hedge.

Kostin et al. (2010) apresenta um trabalho muito similar ao de Mas et al. (2010), em que também são consideradas incertezas de mercado para definir possíveis expansões de unidades produtivas e de estocagem para açúcar e etanol. Esse estudo determina preços, considerando incertezas através do Método de Monte Carlo. Novamente o modelo proposto não considera estratégias de hedge.

Leboleiro e Hilaly (2011) propõe um modelo baseado em um fator de transporte para avaliar a economia de coleta de biomassa, transporte e armazenamento. Também é investigado o tamanho da planta ideal para biorefinarias de etanol a partir da palha de milho.

Corsano et al. (2010) também propõem um modelo de cadeia de suprimentos ligadas a produção de açúcar e etanol, considerando o tratamento de resíduos para atender restrições ambientais, porém esse modelo não considera explicitamente a natureza incerta de certas variváveis, assim como não propõe a utilização de mecanismos de proteção ou hedge.

Aspectos financeiros, em geral, são negligenciados nos modelos de cadeias de suprimentos ou então buscam apenas modelar o fluxo de caixa e as decisões de investimento e financiamento ligadas a operação, sem considerar a possibilidade de hedge, esse é o caso apresentado por Gupta e Dutta (2010). 
O modelo proposto por esse trabalho atenderá decisões que envolvem os itens de 3 a 6 , ou seja, decisões que se concentram no curto prazo, relacionadas aos níveis de estoque, divisão da produção, comercialização e estratégias de hedge.

Em muitos modelos os níveis de estoque estão relacionados a questões logísticas e não a questões econômicas relacionadas a expectativa de preço. Esse é caso dos trabalhos de Mas et al. (2010) e Kostin et al. (2010).

Outros trabalhos consideram a decisão dos níveis de estoque considerando a possibilidade de conceder descontos em ambiente de concorrência monopolística, ou seja, os produtos possuem grande diferenciação, esse é o caso do trabalho de Chen e Simchi-Levi (2006).

No modelo aqui proposto, os produtos são commodities agrícolas, ou seja, são padronizados e os níveis de estoque estão relacionados a expectativa de preços no futuro e o risco dessa previsão não se concretizar.

A flexibilidade de se escolher em direcionar a produção para um ou outro subproduto agrícola apesar de ser uma decisão antiga para alguns produtores é um processo decisório que ainda possui grande potencial de melhorias, em especial a adoção de modelos capazes de lidar com os diversos parâmetros incertos inerentes a produção, comercialização e gestão financeira.

Não foi encontrada na literatura, tanto nacional como internacional, qualquer proposição de modelo de decisão que considerasse a flexibilidade da diversificação da produção, para determinar parâmetros de produção, negociação e níveis de estoque.

Bastian-Pinto et al. (2009) calculam o valor da opção gerada pela flexibilidade de se produzir açúcar ou etanol, levando em consideração preços do mercado brasileiro, através de um modelo de preços por reversão à média. Contudo esse trabalho não apresenta um modelo de decisão que considere o efeito desse valor nas decisões de produção, estocagem e hedge dos produtores.

Estratégias de hedge de commodities são tratadas em profundidade pela literatura, utilizando instrumentos como contratos futuros e opções. As opções, como instrumentos de hedge para commodities, além de não possuírem a mesma liquidez que o mercado futuro, podem não agregar benefícios em relação as operações com o mercado futuro (Lapan et al., 1991).

Não existem muitos trabalhos que agreguem decisões de hedge e decisões operacionais e de produção, com foco em produtos agrícolas. Entre os trabalhos 
existentes se destaca o de AitSahlia et al. (2009). Os autores investigam o impacto de previsões climáticas no planejamento do plantio e nas estratégias de hedge com contratos futuros. Os autores utilizam o $\mathrm{CVaR}$ (Condicional-Value-at-Risk) como medida de risco e copula gaussiana para modelar cenários com uma distribuição conjunta de retornos e preços. O modelo é aplicado a produção de algodão no sudeste dos Estados Unidos. Esse trabalho apresenta uma característica interessante, pois as decisões de hedge ficam subjugadas a qualidade da previsão climática, porém o trabalho de AitSahlia et al. (2009) não considera decisões que afetam estoques, nem a possibilidade de diversificação.

Alguns pontos são críticos nos modelos de decisão, pois afetam seu desempenho computacional e acuracidade, alguns desses pontos são:

- Técnica de previsão de preços

- Medida de risco

- Incerteza em variáveis

Um dos pontos mais críticos dos modelos de decisão que consideram a incerteza relacionada aos preços de commodities agrícolas é a predição dos preços no futuro. Os modelos de previsão de preços são investigados a décadas, como tratado por Allen (1994), porém mais recentemente diversos autores (Geman, 2005) apontam que a utilização de modelos que considerem o movimento geométrico browniano podem atingir uma excelente aproximação caso o mercado possa ser considerado eficiente. Zunino et al. (2011) apontam o mercado de açúcar como um dos quatro mais eficientes entre as commodities agrícolas, o que permite a utilização de modelos de previsão que se utilizam do movimento geométrico browniano e ainda esperar bons resultados dessa previsão como apresentador por Ribeiro e Oliveira (2011).

Muitos trabalhos que lidam com decisão de seleção de ativos, adotam medidas de risco ineficientes ou incapazes de representar a real natureza dos eventos indesejados, esse é o caso dos modelos que utilizam a variância como medida de risco. Outra medida de risco utilizada é o VaR (Value at Risk), que de acordo com Artzner et al. (1999) não é uma medida coerente de risco. Exemplos de trabalhos que utilizam a variância ou o VaR como medidas de risco são Martínez-deAlbéniz e Simchi-Levi (2006) e Kleindorfer e Li (2005).

Trabalhos como o de Unger (2002) apesar de utilizar o CVaR (Conditional Value at Risk), uma medida de risco coerente, lida com o setor de energia elétrica 
que não possui possibilidade de estocagem e que ainda não possui mecanismos eficientes para hedge.

Modelos que acumulem as tarefas de decisão de produção, investimento, comercialização e proteção financeira de commodities, mesmo as não agrícolas e não diversificáveis são raros na literatura, sendo o trabalho mais notável o de Hélyette Geman (Geman e Ohana, 2008). O modelo proposto por Geman e Ohana (2008), permite gerar uma estratégia ótima de investimento, multi-período, em um portfólio de commodities estocáveis, sendo consistente no tempo, levando em consideração a posse da mercadoria física, e posições em contratos à vista e futuros, além da consideração da função utilidade para modelar a aversão ao risco e elasticidade temporal de substituição. O modelo proposto pelos autores não considera a possibilidade de diversificação da produção, assim como não leva em conta a natureza incerta de algumas variáveis.

No passado recente diversos trabalhos utilizaram a otimização robusta na definição de portfólios, como em Howe et al., (1996), Howe e Rustem, (1997), Costa e Paiva (2002), e mais recentemente alguns modelos de decisão para produção e comercialização lidam com a incerteza de variáveis através da otimização robusta.

Pishvaee et al. (2011) utilizam otimização robusta para considerar a incerteza em variáveis que afetam cadeias de suprimentos, como demanda e custos de transporte. O modelo proposto pelos autores não considera a possibilidade de hedge, assim como não mantém seu foco na comercialização e sim na infraestrutura.

Aouam et al. (2010) utilizam otimização robusta para decidir entre diferentes estratégias de compra de gás, por uma empresa de distribuição local, com o objetivo de garantir a oferta com o máximo de retorno das operações. O modelo proposto por considera que os preços obedecem um processo com reversão à média, porém a medida de risco considerada é a variância.

\subsection{Objetivos}

O objetivo central do trabalho é propor um modelo para suporte a tomada de decisão dos produtores de produtos agrícolas que possuem a capacidade de diversificação, em especial os mercados de alimentos e energia. O modelo suporta 
decisões de como dividir a matéria prima entre os diversos subprodutos possíveis, além de definir a estratégia comercial, de estocagem e de hedge que maximiza o retorno e protege o produtor contra oscilações indesejadas.

O trabalho também conta com três objetivos intermediários que deverão contribuir para se alcançar o objetivo central. O primeiro objetivo intermediário se concentra na proposição de um modelo híbrido ou hierárquico de previsão de preços de commodities agrícolas baseado no filtro de Kalman e em redes neurais.

A principal contribuição gerada pelo modelo híbrido de previsão de preços proposto é a possibilidade de avaliar o potencial de desempenho desse tipo de modelo, raro na bibliografia aplicada a commodities agrícolas, em sua aplicação no mercado sucroalcooleiro.

O segundo objetivo se concentra na proposição de um modelo para definição do mix de produção, da comercialização dos subprodutos no mercado à vista, além de posição dos estoques desses mesmos subprodutos e de estratégias proteção ou hedge considerando o mercado futuro e de opções para isso. A definição do mix de produção é feita utilizando para isso um modelo de seleção de portfólio. O modelo de otimização busca minimizar a risco levando em consideração uma medida de risco coerente, no caso o CVaR (Conditional Value at Risk).

O terceiro objetivo intermediário é dar a capacidade de o modelo de decisão de produção, comercialização, estocagem e hedge de lidar com a incerteza inerente a previsão de preços que afeta a determinação dos retornos que são entradas do modelo. Isso é feito através de técnicas de otimização robusta, que apesar de não serem inéditas, sua aplicação nesse contexto e seu efeito nas decisões de produtores de commodities agrícolas diversificáveis ainda não foram investigadas.

O modelo de decisão proposto considera a produção e comercialização de produtos agrícolas que dão origem a diversos subprodutos. O modelo deve subsidiar decisões do produtor, como:

1. Definir a partir da quantidade disponível de matéria prima, qual proporção deve ser destinada a produção de cada subproduto.

2. Definir a partir da quantidade disponível de cada subproduto qual proporção deve ser comercializada imediatamente e qual proporção deve ser estocada.

3. Tendo em vista que o produtor não deve ficar demasiadamente exposto aos riscos, qual deve ser seu posicionamento no mercado futuro para fins de hedge. 
Nesse trabalho são avaliados produtos que se diversifiquem em subprodutos negociados no mercado de alimentos e no mercado de energia, com o intuito de atender um espaço em aberto na literatura como já discutido na seção 1.1. As contribuições do modelo de decisão de produção, comercialização, estocagem e hedge são abordadas em detalhes na seção 4.4 e no capítulo 5 .

No modelo proposto é considerado que as decisões ocorrem para apenas um período, de $t_{0}$ a $t_{1}$. O modelo é dividido em dois grandes blocos: no primeiro ocorre a previsão dos preços à vista de cada subproduto um período a frente. $A$ partir dessa previsão são obtidas informações importantes como a média e o desvio padrão do erro de previsão. O segundo bloco pode ser entendido como um modelo expandido para determinação de portfólio. Esse bloco considera restrições de produção, a utilização de instrumentos financeiros negociados no mercado de derivativos, a utilização do CVaR como medida de risco e a incerteza da previsão de preços do primeiro bloco através da contrapartida robusta do problema de seleção de portfólio.

Um modelo sem a contrapartida robusta é utilizado para permitir a comparação de resultados entre a solução robusta e a não robusta. Desse modo o estudo realizado pode ser representado pela Figura 1.2.1. 


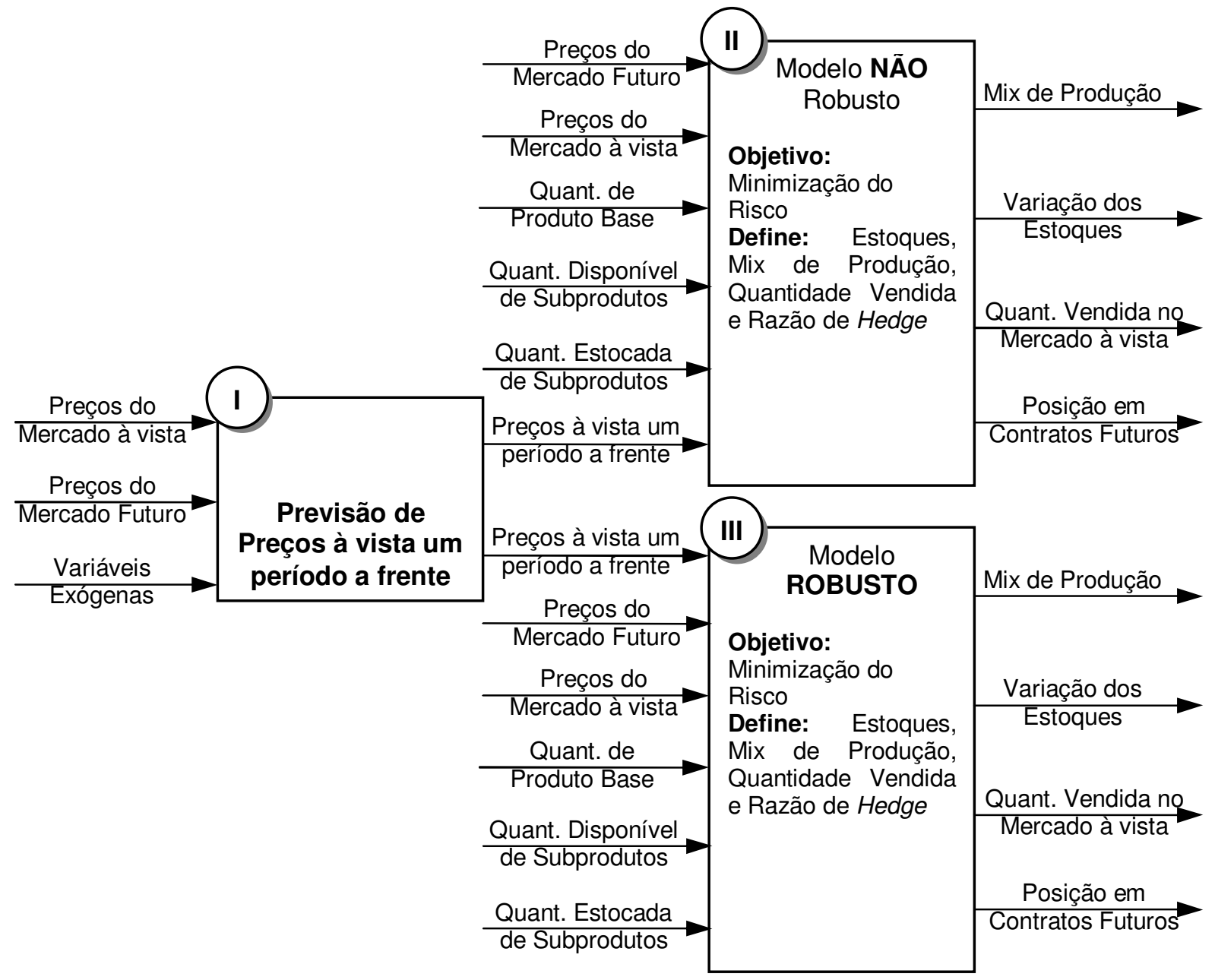

Figura 1.2.1 - Estrutura do Modelo Proposto

O modelo de previsão de preços é um modelo híbrido, ou seja, é composto de dois modelos de previsão em série, sendo que a saída do primeiro modelo é utilizada como entrada no segundo modelo. O primeiro modelo de previsão de preços recebe apenas duas variáveis de entrada para cada subproduto: os preços no mercado à vista e o preço no mercado futuro para o primeiro vencimento. Já o segundo modelo de previsão recebe as saídas do primeiro modelo, ou seja, a previsão de preços um período a frente e variáveis exógenas que possibilitem a consideração de não linearidades.

Os modelos representados pelos blocos II e III, da Figura 1.2.1, consideram como variáveis de entrada: a previsão de preços à vista um período a frente para cada subproduto oriunda do bloco I, os preços de cada subproduto no mercado futuro para o primeiro vencimento, assim como o número de dias úteis até 0 vencimento, a quantidade de produto base disponível, a quantidade de cada 
subproduto disponível no final do processo produtivo, e a quantidade disponível em estoque de cada subproduto. 


\subsection{Métodos e Técnicas de Pesquisa}

Como é comum em trabalhos de gestão financeira, o método de pesquisa adotado partirá de dados reais dos mercados em análise e através de simulações auxiliadas por computador serão gerados e comparados os resultados da aplicação dos diferentes modelos.

São seguidas orientações para desenvolvimento de pesquisa, com modelagem quantitativa axiomática normativa e simulação, extraídas de Bertrand e Fransoo (2002). Seguindo os critérios de classificação o presente trabalho se enquadra obviamente como uma pesquisa quantitativa, uma vez que explicita matematicamente as relações entre as variáveis dos modelos propostos, de modo não ambíguo e verificável. Além de quantitativo o trabalho pode ser classificado como axiomático normativo, por focar na modelagem, porém também possui aspectos de uma pesquisa empírica por abordar a validação e a implementação com dados reais. E por propor um modelo de decisão para produção de produtos agrícolas diversificáveis pode ser considerado normativo.

\subsection{Organização do Trabalho}

O trabalho se divide em 4 capítulos principais. No capitulo 2 a fundamentação teórica utilizada para a proposição do modelo é apresentada. São apresentadas as características dos mercados de commodities agrícolas, do mercado sucroalcooleiro, e do mercado de milho, etanol e biodiesel que serão os mercados empregados para teste do modelo proposto.

O capítulo 3 apresenta o modelo híbrido para previsão de preços à vista e seu teste com dados reais do mercado sucroalcooleiro brasileiro e indiano.

O capítulo 4 apresenta o modelo de decisão de produção, comercialização, estocagem e hedge de commodities agrícolas diversificáveis, assim como seu teste com dados reais do mercado sucroalcooleiro brasileiro e do mercado de milho, etanol e biodiesel norte-americano, sempre dentro da perspectiva do produtor dos subprodutos principais da cana-de-açúcar ou do milho respectivamente. 


\section{FUNDAMENTAÇÃO TEÓRICA}

A fim de apresentar os fundamentos sobre os quais os modelos propostos se baseiam este capítulo foi dividido em 3 seções.

A seção 2.1 apresenta os fundamentos do mercado de commodities, tratando dos tipos de mercados de negociação e dos ambientes de negociação mais ativos no mundo. A seção também trata das peculiaridades das commodities agrícolas e da teoria de estocagem.

O mercado sucroalcooleiro é discutido na seção 2.2. Este mercado possui características já apresentadas na seção anterior, porém possui um grande número peculiaridades de seu processo produtivo e mercado.

Do mesmo modo os mercados de milho, etanol e biodiesel são apresentados na seção 2.3, onde as peculiaridades do processo produtivo e de mercado são abordadas considerando a realidade norte-americana.

\subsection{Commodities}

Para Geman (2005), uma commodity pode ser definida como um ativo físico que possui características padronizadas, de ampla negociação em diversas localidades, que pode ser transportado e armazenado por um longo período de tempo.

O termo commodity costuma ser atribuído aos insumos, ou matérias-primas, uma vez que esses ainda não foram industrialmente transformados, o que facilita a padronização. As commodities, por sua padronização, fazem com que não exista preferência, em termos de qualidade, por parte dos compradores do produto, de uma região ou outra. Essa ausência de preferência simplifica a negociação adicionando liquidez aos mercados em que são negociadas.

É possível destacar dois tipos de commodities, as renováveis, que incluem as commodities agrícolas e a energia elétrica proveniente de hidrelétricas, e as nãorenováveis que incluem os produtos de mineração e derivados de petróleo.

No caso das commodities agrícolas os estoques sofrem uma redução de seu valor com o passar do tempo. Produtos agrícolas perdem valor por processos naturais de degradação e contaminação. Essa redução de valor é chamada de 
depreciação primária e impacta a decisão de manter estoques. As commodities agrícolas estão sujeitas a sazonalidade, devido aos períodos de safra e entressafra, o que dificulta a regularidade de fornecimento e costuma afetar os preços. Estas ainda estão sujeitas a riscos de redução de produtividade devido ao clima, o que também afeta a regularidade de fornecimento bem como os preços.

\subsubsection{Negociação e hedging de commodities agrícolas}

Commodities podem ser negociadas no mercado à vista, no mercado a termo ou ainda no mercado futuro, sendo que a entrega física da mercadoria costuma se dar com mais freqüência no mercado à vista.

O mercado à vista, por envolver a entrega física do produto, presume uma série de cuidados, como documentações para transporte, contratação de frete, estocagem, seguros ou ainda procedimentos aduaneiros, no caso de comércio internacional. Apesar de a entrega ser entendida como imediata, o processo de transporte provoca alguma defasagem entre o fechamento da negociação e a entrega. Contudo, o mercado à vista exige dos vendedores a disponibilidade de estoque no local e na quantidade negociada, o que dificulta o planejamento tanto de compradores quanto de vendedores, o que por sua vez dificulta a continuidade e estabilidade de fornecimento.

Para facilitar o planejamento e garantir a continuidade do fluxo de mercadorias, o mercado a termo permite realizar negociações do mesmo modo que o mercado à vista, porém com entrega física em data futura a um preço pré-definido. No mercado a termo, assim como no mercado à vista, a negociação é feita diretamente entre as partes e o risco de crédito pode ser assumido pelas partes ou ainda transferidos via seguro de crédito ou através de uma câmara de liquidação.

O mercado a termo exige uma grande afinidade de interesses, seja pela quantidade negociada, pelas características do produto, pela data de entrega e até o interesse de negociar no mesmo momento e no mesmo local. Ambas as partes de um contrato a termo estão expostas ao risco de liquidação, seja de entrega da mercadoria, seja de pagamento.

Com o intuito de simplificar os encontros dos negociadores, o processo de negociação e até tratar o risco de crédito de modo mais padronizado, o mercado 
futuro pode ser utilizado. Para Schouchana e Miceli (2004) nos contratos futuros constam especificações de qualidade dos produtos negociados, cotação, variação mínima de apregoação, oscilação máxima diária, unidade de negociação, meses de vencimento, data de vencimento, local de formação do preço e de entrega da mercadoria, período e procedimentos de entrega e retirada da mercadoria, liquidação financeira, arbitramento, ativos aceitos como margens de garantia e custos operacionais. Os contratos futuros são padronizados, de modo que no pregão, sejam negociados o preço e a quantidade de contratos, uma vez que todos se referem ao mesmo produto, mesmo local de entrega e mesma quantidade por contrato.

A negociação de contratos futuros ocorre em bolsas e é esperado que esses contratos sejam negociados em maior volume do que os contratos a termo. Essa maior liquidez facilita a construção de estratégias financeiras. Ao contrário do mercado a termo o mercado futuro divulga as cotações de suas transações, o que acaba por servir como referência na formação dos preços. E apesar de os contratos futuros também permitirem liquidação física, normalmente os negociadores utilizam apenas a liquidação financeira, em especial a liquidação por diferença. No mercado futuro a garantia de liquidação é dada por uma câmara de liquidação, que por sua vez exige depósitos de garantia dos participantes do mercado. Esses depósitos de garantia, também chamados de depósitos de margem, podem ser executados caso uma das partes não cumpra com suas obrigações.

Para que os depósitos de margem exigidos não sejam muito elevados, as câmaras de liquidação utilizam uma política de ajuste diário, ou liquidação por diferença, e diariamente a câmara transfere valores da conta de um negociador para o outro de acordo com a oscilação dos preços no pregão do dia. Diferentemente do mercado a termo, as partes não chegam a se conhecer e os negócios são fechados anonimamente.

No Brasil a bolsa de maior expressão na negociação de contratos futuros é a BM\&FBOVESPA, criada a partir da integração da Bolsa de Valores de São Paulo, e da Bolsa de Mercadorias e Futuros. 


\subsubsection{Teoria de Estocagem}

Os preços de uma commodity tem relação com o volume global estocado, uma vez que o detentor da mercadoria física pode estocar o produto quando o preço de está baixo e vendê-lo quando o preço no mercado à vista for mais favorável.

Para que seja tomada a decisão de manter estoques é preciso que o ganho marginal do aumento de preços exceda o custo de estocagem. E para que ocorra um aumento nos preços é preciso que exista escassez no fornecimento, ou seja, se diversos produtores decidirem estocar imaginando um aumento nos preços, esse estoque pode ter a capacidade de garantir o fornecimento não gerando escassez.

O possível benefício em manter estoques interfere nos preços do mercado futuro, por exemplo, pode ocorrer de o preço à vista estar acima do preço no mercado futuro, isso devido à escassez de estoques.

A diferença entre preço futuro e preço à vista, ou a diferença entre dois contratos futuros com vencimentos distintos foi chamada de preço de estocagem, de acordo com Working (1948).

Se o preço de estocagem for negativo, isso indica a possibilidade de escassez no fornecimento da commodity. Segundo Fama e French (1987), o preço de estocagem, representado por $F_{t}-S_{t}$, pode ser definido pela equação 2.1.1.

$$
F_{t}-S_{t}=S_{t} r+W_{t}-C_{t}
$$

onde:

$F_{t}$ é o preço futuro do ativo no tempo $t$;

$S_{t}$ é o preço à vista do ativo no tempo $t$;

$r$ é a taxa de juros livre de risco;

$W_{t}$ é o custo marginal de armazenamento no tempo $t$;

$C_{t}$ é o ganho marginal de conveniência no tempo $t$.

O ganho marginal pela conveniência de se manter a posse física do ativo é um valor financeiro que representa o ganho com o aumento dos preços quando 
existe escassez. Para que o detentor tenha um retorno positivo é preciso que esse ganho supere a taxa livre de risco e o custo com estocagem.

Quando o preço da commodity no mercado à vista é maior que o preço no mercado futuro, ou seja, o ganho de conveniência é maior que os juros e o custo de armazenagem, $C_{t}>S_{t} r+W_{t}$, ocorre um fenômeno chamado de backwardation. Quando a situação é inversa, ou seja, o preço futuro é maior que o preços à vista e o ganho de conveniência é menor que os juros e custo de armazenamento, $C_{t}<$ $S_{t} r+W_{t}$, o fenômeno é chamado contango.

Pereira (2009) aponta quatro diferentes explicações, encontradas na literatura, para a existência de backwardation. A primeira teoria define o fenômeno como um prêmio pelo risco que o especulador merece por assumir o risco do hedger, que assume uma posição predominantemente vendida no mercado futuro, no caso o produtor que deseja garantir o preço de venda de sua commodity. A segunda teoria justifica existência de backwardation como resultante do retorno de conveniência. A terceira teoria explica o fenômeno de backwardation como resultante de erros de medida ou variável não observável. Por fim a quarta teoria procura defender o argumento de que o backwardation é causado pela distância dos estoques dos produtores em relação ao centro de consumo. Este autor ressalta que mais de uma teoria pode explicar o fenômeno e que não só as quatro teorias apontadas não contenham todos os fatores explicativos.

De acordo com a Teoria da Estocagem, a presença de backwardation é resultante de uma taxa de retorno de conveniência relativamente elevada, de modo a superar o custo marginal de armazenamento. Para entender melhor essa relação é necessário entender melhor o custo de carregamento.

O preço de estocagem, $S_{t} r+W_{t}-C_{t}$ representa a soma de todos os custos envolvidos na estocagem do produto. Esse custo é composto pelo custo de financiamento, representado pela taxa livre de risco, custo de armazenagem, custo de depreciação primária e retorno de conveniência.

A depreciação primária é a perda de parte do produto estocado em razão da degradação, contaminação ou qualquer outro fator que faça com que o produto perca as características mínimas de qualidade.

Em uma condição de não arbitragem a relação entre preço futuro e preço à vista pode ser representada pela equação 2.1.2 (Geman, 2005). 


$$
S_{t} e^{r(T-t)}=F_{t} e^{\delta_{t}(T-t)}
$$

onde:

$T$ é a data de vencimento do contrato futuro

$\delta_{t}$ é o custo de carregamento

Em diversos trabalhos presentes na literatura, o custo de carregamento $\delta_{t}$ é simplificado e tratado apenas como o retorno de conveniência, sendo os custos de armazenagem e depreciação primária suprimidos.

O retorno de conveniência é a taxa de remuneração, destinada ao detentor do produto em função da escassez de estoques. Backwardation e retorno de conveniência não são sinônimos, apesar de intimamente ligados. Segundo Pereira (2009) backwardation é uma variável observável, verificada pela diferença de preços entre o mercado à vista e o futuro, enquanto o retorno de conveniência é um conceito econômico não observável.

Utilizando a equação 2.1.2 e considerando apenas o retorno de conveniência, $c_{t}$, é possível determinar o preço futuro, como indica a equação 2.1.3.

$$
F_{t}=S_{t} e^{\left(r-c_{t}\right)(T-t)}
$$




\subsection{Mercado Sucroalcooleiro}

De acordo com Balat (2009) apesar de existirem outras fontes para a geração de etanol, somente a cana-de-açúcar e o milho são fontes viáveis comercialmente.

O Mercado Sucroalcooleiro vem ganhando complexidade com o avançar dos anos. O açúcar proveniente da cana-de-açúcar é negociado há quase 500 anos no Brasil e surgiu como uma das principais commodities agrícolas de exportação já no século XVI. Já a produção em larga escala de etanol a partir da cana-de-açúcar se deu a partir da década de 70 com o programa Proálcool que surgiu como alternativa a forte alta do petróleo da época (Moraes, 2007).

\subsubsection{Cenário Atual e Perspectivas para o Futuro}

Atualmente o etanol já se apresenta como um importante substituto a gasolina e sua produção segue crescendo desde a década de 70 . Seu rápido crescimento se dá em diferentes partes do mundo, o que faz do etanol um produto altamente competitivo no mercado de energia (Ajanovic, 2010).

Como a cana de açúcar é a matéria prima mais eficiente para a produção de etanol e também para a produção de açúcar, que é essencial para a alimentação, é esperado que os subprodutos da cana compitam economicamente pela preferência do produtor (Hira, 2010).

Em 2008 Brasil e Índia foram responsáveis por mais de 50\% da produção de açúcar como apresentado na tabela 2.2.1. Estados Unidos e Brasil lideram a produção mundial de etanol e sua produção somada chegou a $89 \%$ da produção mundial em 2008 (Mussato et al., 2010).

A despeito da polêmica em relação ao avanço em áreas de floresta nativa e a pressão nos preços dos alimentos, a verdade é que recentemente as pressões ambientais por biocombustíveis e a volatilidade dos preços do petróleo realimentaram as discussões no entorno dos biocombustíveis abrindo espaço para previsões agressivas no crescimento da demanda por etanol.

Associado a esse cenário, no Brasil, na última década, a disponibilidade de carros flex, ou seja, capazes de operar tanto com gasolina quanto com etanol em 
qualquer mistura desejada, também está ajudando a garantir uma demanda doméstica significativa e crescente.

Tabela 2.2.1 - Dez maiores produtores de cana de açúcar - 2008

\begin{tabular}{lc}
\hline País & Produção(Toneladas) \\
\hline Brasil & $648,921,280$ \\
Índia & $348,187,900$ \\
China & $124,917,502$ \\
Tailândia & $73,501,610$ \\
Paquistão & $63,920,000$ \\
México & $51,106,900$ \\
Colômbia & $38,500,000$ \\
Austrália & $33,973,000$ \\
Argentina & $29,950,600$ \\
EUA & $27,603,000$ \\
Mundo & $\mathbf{1 , 7 4 3 , 0 9 2 , 9 9 5}$
\end{tabular}

Fonte: Food And Agricultural Organization of United Nations: Economic And Social Department: The Statistical Division. Acesso em 17/06/2010

De acordo com Borges (2009) o Brasil hoje é responsável por 40\% das exportações mundiais de açúcar, e até 2017, será responsável por 60\% das exportações mundiais. A União Européia representará o maior importador global de açúcar, comprando mais de 5 milhões de toneladas. Em seguida, virão China, EUA e Rússia. Segundo este autor, no caso do etanol, a União Européia admite o domínio do Brasil como exportador e os EUA como o principal importador. O comércio internacional deve crescer rapidamente e as exportações brasileiras podem alcançar 13 bilhões de litros até 2017.

Apesar de a demanda externa por álcool crescer consistentemente, uma série de barreiras ao comércio, impostas pelos países do bloco Europeu, Japão e Estados Unidos, dificultam a exportação do álcool brasileiro. Contudo inúmeros esforços comerciais brasileiros associados a pressões ambientais por biocombustíveis, e econômicas, como a alta do petróleo e incertezas políticas nos maiores produtores de petróleo criaram um cenário onde a demanda mundial por álcool pode crescer repentinamente. Associado a isso também existe uma pressão na demanda mundial de açúcar, com o aumento do consumo de alimentos industrializados por populações de países em desenvolvimento, como China e Índia. 
Para Borges (2009) o Brasil estará moendo, em 2015, aproximadamente, 1 bilhão de toneladas de cana, em 14 milhões de hectares. Isto representa, no período 2008-2015, um crescimento anual da ordem de $8 \%$ ao ano, lembrando que no período 2004-2008, o crescimento anual foi de $10 \%$ ao ano.

A produção de açúcar irá crescer cerca de 3\% ao ano, no período 20082015 , enquanto a produção de álcool deve crescer entre $11 \%$ e $12 \%$ ao ano, atingindo algo próximo de 60 bilhões de litros em 2015. No período 2004-2008, as produções de açúcar e álcool cresceram cerca de $4 \%$ e $16 \%$ ao ano, respectivamente.

De acordo com Figueira (2005) Alemanha, França, Itália e Reino Unido terão papel importante no crescimento da demanda, devido aos compromissos de emissão de gases responsáveis pelo efeito estufa que atualmente promovem discussões sobre o aumento da proporção de etanol nesses países. Apesar do potencial dos países Europeus, o Japão foi apontado pelo autor como o país que isoladamente apresenta o maior potencial para importação do etanol devido as expansões da proporção de etanol na mistura com a gasolina.

As perspectivas de crescimento de demanda por álcool criaram um cenário onde novos e grandes produtores podem surgir em países da América Central e África. A presença de novos produtores pode facilitar a aprovação de medidas que viabilizem o comércio internacional de álcool, uma vez que na visão dos países consumidores esse fato reduz riscos de fornecimento ou alta nos preços. Os impactos da liberalização do comércio de etanol nos Estados Unidos são apresentados por Elobeid e Tokgoz (2008), que indicam que as barreiras comerciais norte americanas tem sido efetivas na proteção da indústria de etanol e que uma possível liberação comercial traria impactos não só na indústria de biocombustíveis e sim todo o mercado agrícola.

\subsubsection{Aspectos da Produção}

Para entender o valor da flexibilidade da cana-de-açúcar é importante entender também as fases da produção pelas quais se chega a diversos subprodutos.

Obviamente por ser um produto agrícola o ciclo de produção envolvido na indústria sucroalcooleira está sujeito a interferências do clima e da própria biologia 
da planta. O ciclo produtivo pode ser entendido em dois períodos distintos, a safra e a entressafra, o que confere um comportamento sazonal a produção de todos os subprodutos da cana.

Com o passar dos anos, novas técnicas permitem que hoje o período de colheita, ou safra, seja aumentado para oito meses consecutivos, de abril a novembro. Contudo ainda existe um período de produção baixa ou nula nos outros quatro meses do ano.

Uma medida de eficiência energética da cana-de-açúcar é o ATR (Açúcar Recuperável Total). O ATR mede a capacidade que a planta tem de produzir açúcar, em termos de sua massa e varia entre 100 e 200. Por exemplo, a cana-de-açúcar com um ATR de 105 é capaz de produzir uma massa de açúcar que corresponde a $5 \%$ da sua massa inicial. O ATR da cana-de-açúcar produzida no Brasil é, em média, 114, ou seja, $14 \%$ da massa da cana utilizada inicialmente pode ser transformado em açúcar.

A qualidade da cana-de-açúcar também costuma ser medida através do nível de polarização (POL) do açúcar que a planta é capaz de produzir. A POL define a porcentagem de sacarose do açúcar produzido e é expressa em ${ }^{\circ} Z$ (graus Zucker). O açúcar de maior grau de pureza costuma ser produzido entre os meses de julho e setembro.

É possível criar uma linha divisória no processo de produção da cana-deaçúcar e seus derivados, essa linha separa o ponto de decisão no qual o produtor define quais subprodutos irá gerar e em qual proporção. O processo produtivo da cana-de-açúcar é ilustrado na Figura 2.2.1.

É possível perceber diversos produtos intermediários no processamento da cana, que não os diversos tipos de açúcar e etanol. Entre esses produtos intermediários existe a palha que é gerada no processo de colheita mecanizada e serve tanto como cobertura vegetal para os campos quanto como combustível para geração de eletricidade. A geração de eletricidade recebe ainda o bagaço da cana, que é o resíduo fibroso oriundo da moagem da cana.

O processo de moagem da cana gera o caldo bruto que é filtrado e tratado gerando então caldo tratado e torta de filtro. A torta de filtro é um resíduo do processo de filtragem altamente rico em fósforo e reutilizado no plantio da cana.

É na fase em que o usineiro possui o caldo que a decisão de produzir mais açúcar ou mais etanol é colocada em prática. No caso da produção de açúcar, o 
caldo passa por um processo de cozimento e depois de cristalização e centrifugação. O processo de cristalização e centrifugação por sua vez gera açúcar e melaço. O melaço é utilizado para geração de etanol, de modo que nada se perde no processo.

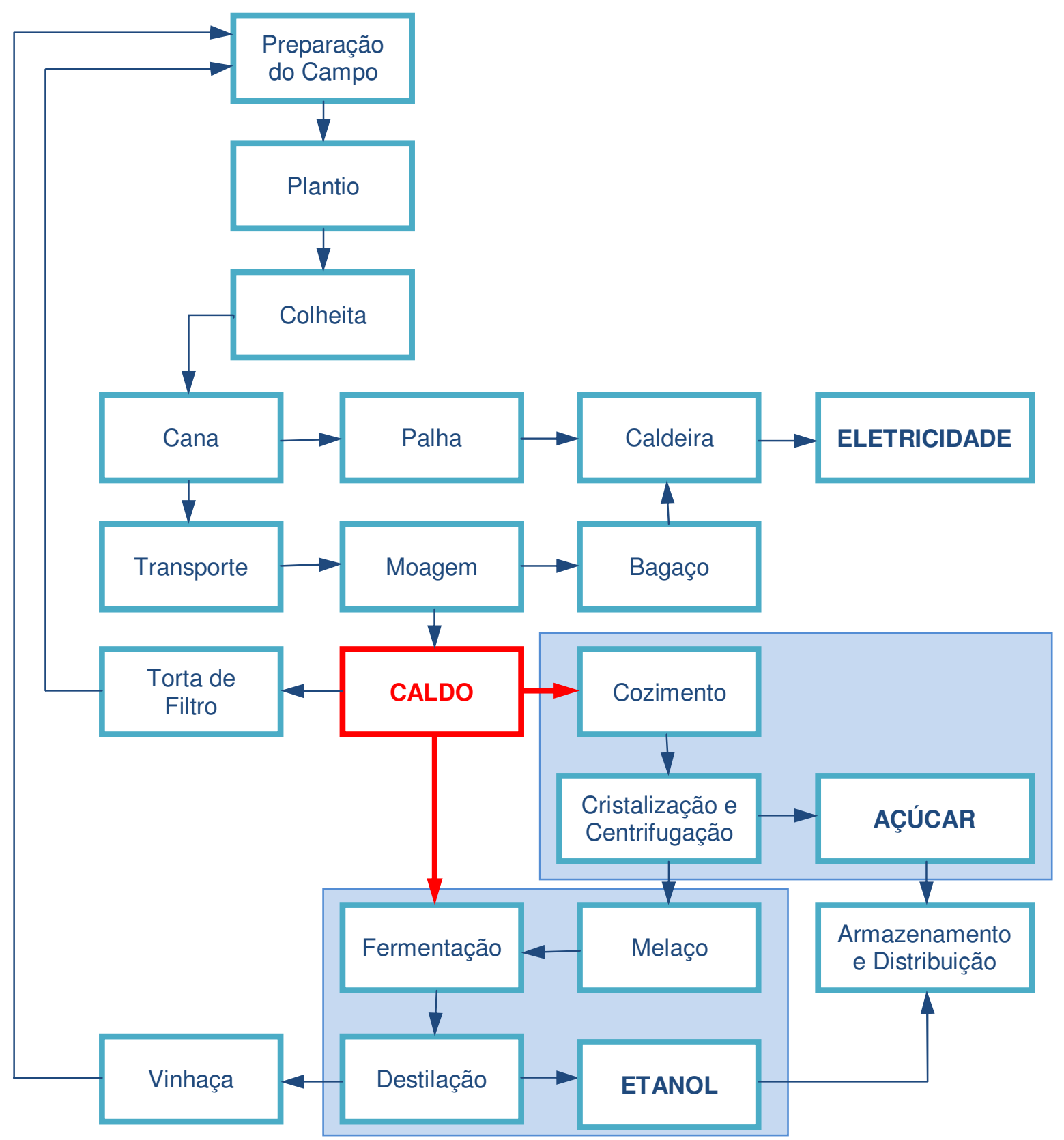

Figura 2.2.1 - Processo Produtivo da Cana-de-açúcar

Fonte: Adaptado de UNICA - União da Indústria de Cana de Açúcar, Acesso em 21/06/2011.

A parte do caldo destinada a produção de etanol se junta com o melaço oriundo do processo de fabricação do açúcar e segue então para a fase de 
fermentação e destilação. O processo de destilação gera álcool hidratado e vinhaça. A vinhaça, assim como a torta de filtro, é utilizada como fertilizante.

O álcool hidratado é costumeiramente utilizado como combustível para carros flex, todavia pode ser processado para geração de álcool anidro, utilizado na mistura de álcool com a gasolina, ou ainda diversos outros tipos de álcool, como o utilizado para a produção de plásticos biodegradáveis.

Cada tonelada de cana produz cerca de $280 \mathrm{~kg}$ de bagaço e $40 \mathrm{~kg}$ de torta de filtro e 680 litros de caldo bruto. Esses 680 litros de caldo bruto podem ser transformados em cerca de 85 litros de álcool hidratado ou cerca de $120 \mathrm{~kg}$ de açúcar.

Como apontado o processo para produção de açúcar e álcool é muito similar e difere apenas nos passos finais após a extração do caldo, quando o produtor determina a proporção de açúcar e etanol a ser produzida (Goldemberg e Moreira, 1999).

\subsubsection{Preços no Mercado Sucroalcooleiro}

Segundo Fontes, Castro e Azevedo (2005) o processo de comercialização de álcool e açúcar ainda é feito diretamente, na grande maioria das vezes, através de uma cooperativa onde produtores vendem diretamente aos compradores. $O$ comércio via derivativos, seja por Bolsa ou por Cédula do Produto Rural (CPR) ainda é pouco usado.

Diversas variáveis possuem relação com o preço do etanol e do açúcar. Entre elas, as variáveis típicas das commodities agrícolas, como níveis de estoque, retorno de conveniência, depreciação primária e taxa de juros. Schwartz (1997) utiliza os preços oriundos do mercado futuro como variável importante para previsão de preços. Os preços futuros de commodities negociados em bolsa são significativos, pois refletem as expectativas de oferta e demanda mundiais enquanto que preços à vista dependem, muitas vezes, de peculiaridades de mercados locais nos quais as negociações são realizadas (Dooley e Lenihan, 2005).

Costumeiramente parte da produção pode ser negociada até mesmo antes do plantio da cana, sendo que estratégias intermediárias, entre o plantio e a entrega do produto, precisam ser consideradas para proteção contra oscilações 
desfavoráveis nos preços, para reposicionamento em relação à divisão da produção, para reavaliação dos níveis de estoque, entre outras decisões.

Obviamente os preços do mercado futuro são importantes no processo de decisão do usineiro, uma vez que refletem expectativas do mercado em relação ao equilíbrio de oferta e demanda, enquanto os preços à vista costumam depender frequentemente de peculiaridades de mercados locais, onde as negociações tomam maior importância (Dooley e Lenihan, 2005). Podemos interpretar as cotações divulgadas pela Bolsa como sendo uma média das opiniões dos participantes do mercado em relação ao preço futuro de uma commodity.

No Brasil o mercado futuro de açúcar existe desde 1995 e o mercado de álcool desde 2000. Os preços dos contratos futuros de açúcar e álcool são negociados através da Bolsa de Mercadorias e Futuros (BM\&FBOVESPA). Os preços nos mercados futuro e à vista são fortemente relacionados, como já apontado por Geman (2005).

O mercado futuro brasileiro, que opera com o açúcar cristal, possuía liquidez, pelo menos nos contratos do primeiro vencimento, até o primeiro semestre de 2010, contudo o volume de negócios não acompanhou o crescimento do mercado físico e a liquidez deixou se ser representativa.

A liquidez no mercado futuro de etanol é ainda mais reduzida para qualquer vencimento e vem caindo para níveis menores nos últimos anos de modo que a validade e representatividade dos preços do etanol negociados no mercado futuro brasileiro é questionável. O desempenho dos mercados futuros de açúcar e etanol é discutido por Vian e Quintino (2007).

De acordo com Fileni (1999) a pequena participação de compradores e produtores nos mercados de futuros se deve à falta de conhecimento operacional e as incertezas em relação ao comportamento relativo dos preços a vista e futuros.

Entre empresas e setores da economia sujeitos aos riscos de oscilação de preços do álcool e do açúcar, de acordo com BM\&F (2006), temos as empresas de insumos agrícolas, produtores de cana, usineiros, indústria alimentícia e outras dependentes dos produtos, distribuidoras de combustíveis, negociadores do mercado financeiro e fundos de investimento. Por fim vale ressaltar que oscilações de preços afetam a população como um todo, seja na variação do preço do açúcar, como no preço do álcool. 
Para se estimar o preço futuro toma-se o preço a vista do ativo em questão e acrescenta-se os custos de manutenção de uma posição física do ativo, desse modo, soma-se o preço à vista da commodity ao seu custo de carregamento para uma data futura. Custos de armazenagem, transporte, financiamento e com seguros formam os principais custos que compõem o custo de carregamento. Além desses ainda existe um custo inerente à incerteza do preço da commodity no futuro. Assim é possível concluir que o preço futuro é formado pelo preço a vista da commodity, acrescido de um prêmio correspondente aos custos de manutenção da posição física mais um prêmio pela incerteza nos preços futuros.

De acordo com as regras da BM\&FBOVESPA, as posições em aberto sofrem um ajuste diário ao final de cada pregão. O ajuste diário é a diferença entre 0 preço na data $t$ menos o preço na data $t$-1. No caso em que o ajuste é positivo o titular da posição compradora é creditado e o titular da posição vendedora é debitado, no caso de ajuste negativo temos exatamente o contrário.

Apesar de o governo brasileiro ainda oferecer preços mínimos para o etanol como garantia aos produtores, o mercado de etanol é profundamente ligado ao mercado de gasolina, uma vez que a demanda doméstica é ditada em grande parte pelo consumo para alimentar os carros bicombustível, ou flex, que por sua vez podem ter a utilização de etanol ou gasolina modificada a qualquer instante. Por outro lado o mercado de açúcar, por ser mais globalizado pode ser atingido por quebras de safra de outros produtores mundiais o que leva a um aumento nos preços internacionais e consequentemente pode direcionar a produção brasileira para o açúcar reposicionando assim o preço do etanol.

Além das variáveis já citadas outras vêm sendo analisadas. Akram (2009) confirma a forte relação dos preços de commodities com a taxa de juros e a taxa do dólar. Thompson et al. (2009) trata da relação entre os preços do petróleo, do milho e da política de exigência de mistura de etanol na gasolina no valor do etanol. Farinelli et al. (2009) discute o impacto da demanda de países importadores do etanol brasileiro no preço do etanol para prever o comportamento dos preços com alterações de políticas a favor dos biocombústiveis nos países consumidores.

Justamente pela natureza exportadora da indústria brasileira de cana é esperado que a taxa de câmbio tenha influência sobre as decisões dos usineiros. Ribeiro e Oliveira (2011) mostram a capacidade da taxa de câmbio na previsão de preços do açúcar, utilizando redes neurais, para o mercado brasileiro e indiano. 


\subsection{Mercado de Milho, Etanol e Biodiesel nos Estados Unidos}

O milho foi descoberto por exploradores europeus em 05 de Novembro de 1942 (Smith et al., 2004), quando esses desembarcaram pela primeira vez na América central. Sua cultura foi rapidamente espalhada pelo mundo e hoje o milho é uma das principais sementes que compõem os gêneros alimentícios da sociedade moderna. O milho é um dos produtos agrícolas de maior diversificação, podendo gerar produtos como adoçantes, farinhas, espessantes, óleo, etanol, biodiesel, bebidas alcoólicas como o whisky, salgadinhos, pipoca, rações animais, produtos têxteis, entre muitas outras apresentações.

\subsubsection{Cenário Atual e Perspectivas para o Futuro}

Atualmente o maior produtor de milho são os Estados Unidos seguidos de longe da China, ver Tabela 2.3.1. Os Estados Unidos também são os maiores exportadores e consumidores do milho e seus derivados.

Tabela 2.3.1 - Dez maiores produtores de milho - 2009

\begin{tabular}{lc}
\hline País & Produção (Toneladas) \\
\hline EUA & $333,010,910$ \\
China & $163,118,097$ \\
Brasil & $51,232,447$ \\
México & $20,202,600$ \\
Indonésia & $17,629,740$ \\
Índia & $17,300,000$ \\
França & $15,299,900$ \\
Argentina & $13,121,380$ \\
África do Sul & $12,050,000$ \\
Ucrânia & $10,486,300$ \\
Mundo & $\mathbf{8 1 7 , 1 1 0 , 5 0 9}$
\end{tabular}

Fonte: Food And Agricultural Organization of United Nations: Economic And Social Department: The Statistical Division. Acesso em 20/10/2011

A Figura 2.3.1 apresenta a produção de milho dos Estados Unidos ao longo dos tempos, primeiramente a média anual para as décadas de 30 a 90 e na sequência para os anos 2000 a 2010. A Figura 2.3.1 evidencia que nos últimos 
quatro da série a produção se manteve na faixa entre 12 e 13 bilhões de bushels de milho.

Produção de Milho - EUA, 1930-2010

Milhões de Bushels

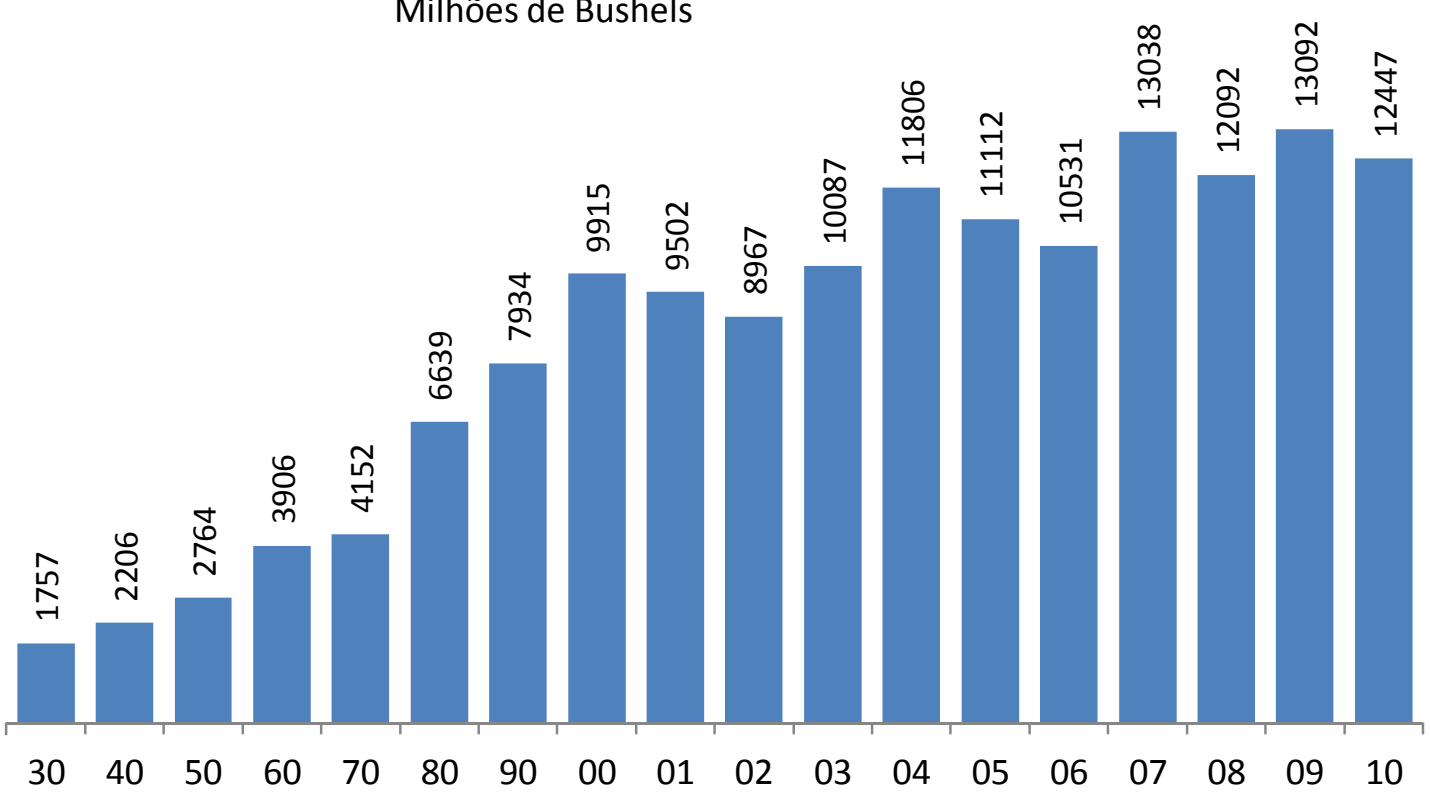

Figura 2.3.1 - Produção de Milho - EUA, 1930-2010

Fonte: USDA, NASS Crop Production 2010 Summary 12/Jan/2011

Já a produção de etanol de milho possui uma curva de crescimento mais acentuada, como apresentado pela Figura 2.3.2, onde é possível verificar que a produção de etanol representa cerca de 6\% da utilização do milho em 2000 e em apenas 10 anos a proporção do milho destinada a produção de etanol já chegava a quase $40 \%$.

De acordo com Crago et al. (2010) o aumento na produção do etanol de milho foi promovido pelo banimento do MTBE (Metil Tércio Butil Éter) em 2005, que era utilizado como aditivo obrigatório da gasolina, sendo que o etanol foi considerado seu melhor substituto. Contudo, o grande impulso na produção veio através de um programa do Governo Americano chamado de RFS (Renewable Fuel Standard) que depois foi estendido e aumentado pelo ato EISA (Energy Independence and Security Act) de 2007. Esse mesmo programa também tem efeitos sobre a produção de biodiesel, através da geração de incentivos fiscais e comerciais a produção. 


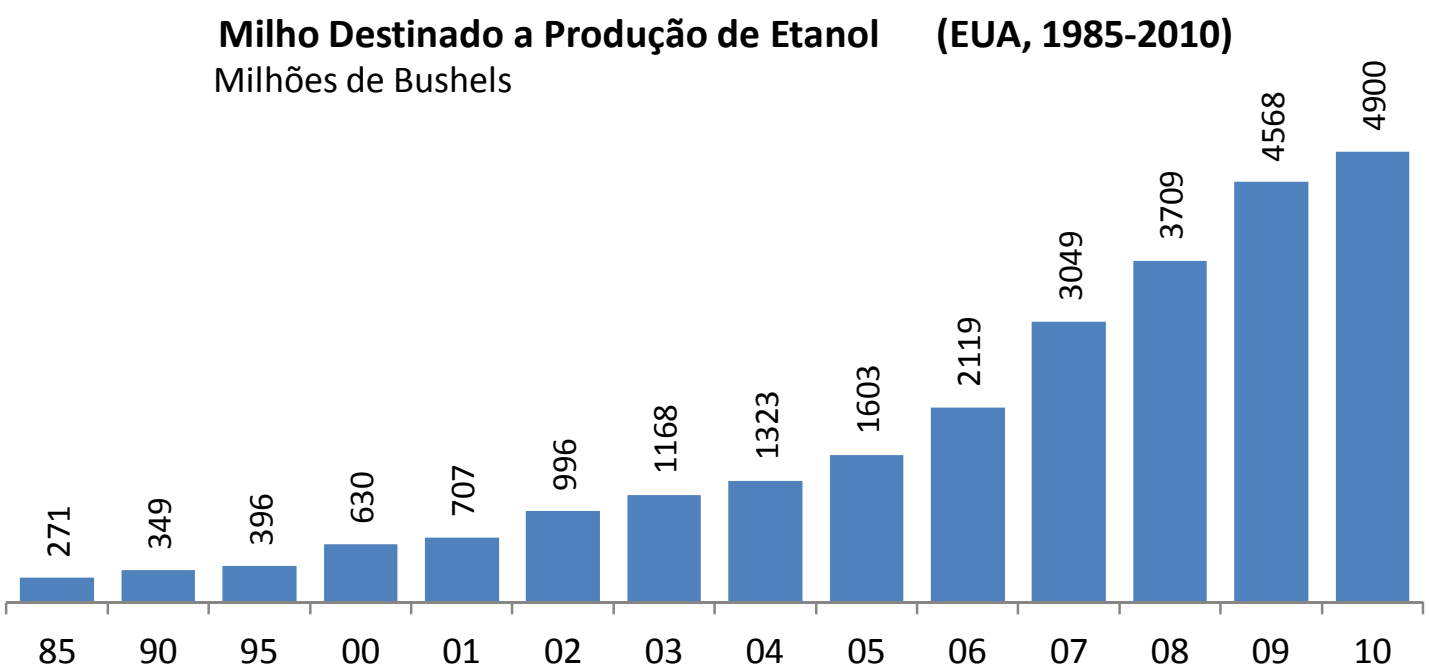

Figura 2.3.2 - Milho Destinado a Produção de Etanol - EUA, 1985-2010

Fonte: USDA, ERS Feed Outlook, Jan/2011

A Figura 2.3.3 apresenta a produção de biodiesel dos Estados Unidos de 2005 a 2010. Note que ocorreu um pico de produção em 2008 seguido de uma forte queda nos dois anos seguintes. Segundo a EPA (Environmental Protection Agency US) a produção de 2011 pode superar os 900 milhões de galões, o que promissor para o programa RFS do governo americano que espera que a produção ultrapasse 1 bilhão de galões em 2012.

Produção de Biodiesel - EUA, 2005-2011

Milhões de Galões

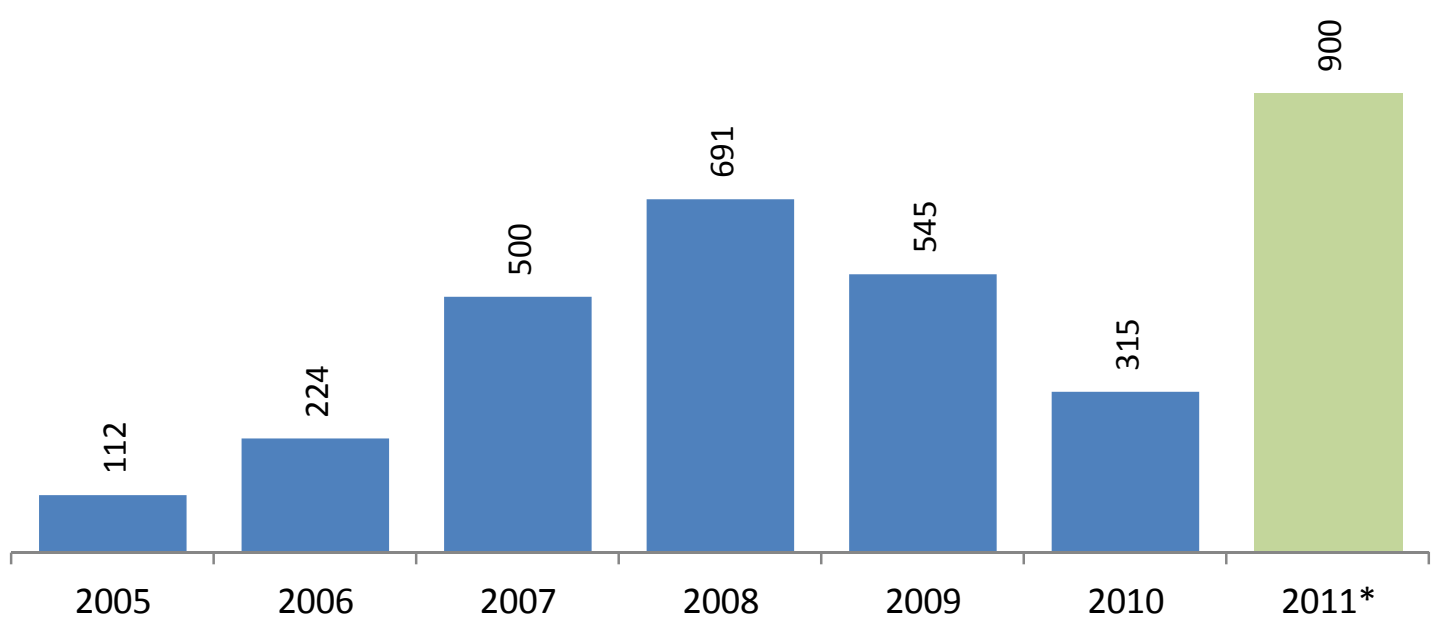

Figura 2.3.3 - Produção de Biodiesel - EUA, 2005-2010

Fonte: National Biodiesel Board, Production Estimates, 2011 


\subsubsection{Aspectos da Produção}

O processamento do milho se divide em dois processos auto-excludentes, a moagem úmida e a moagem seca. Segundo Souza et al. (1998) a moagem úmida é um processo hoje dominado por grandes industrias que buscam ganhos de custo pela larga escala. O processo de moagem úmida é detalhado na Figura 2.3.4 e nele o milho gera diversos subprodutos, como óleo de milho, que pode ser convertido em biodiesel, amido que pode ser convertido em diversos produtos, inclusive etanol, e a fibra e o glúten utilizados na preparação de rações animais.

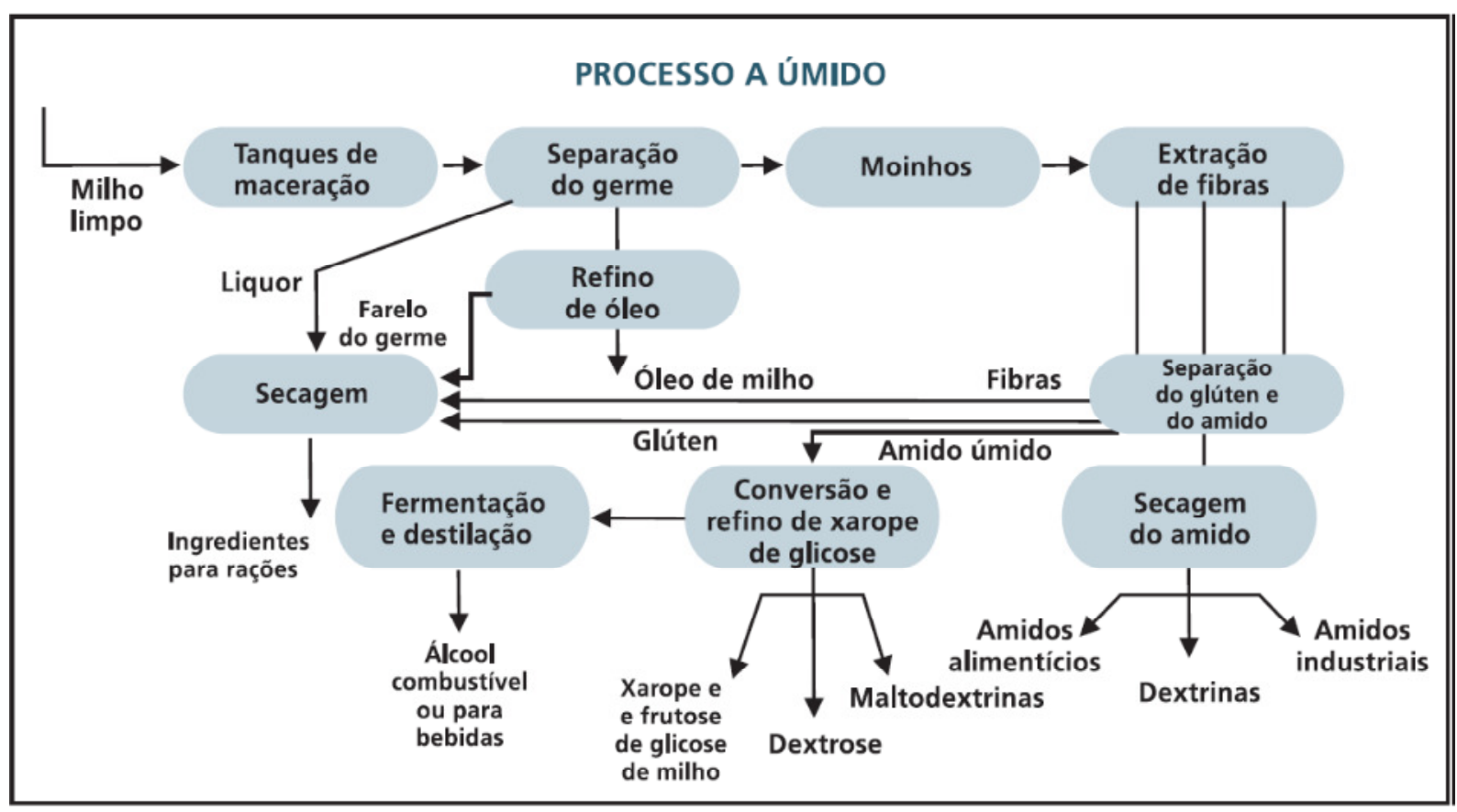

Figura 2.3.4 - Processo Produtivo do Milho - Moagem Úmida Fonte: Abimilho - Acesso em 02/11/2011.

O processo de moagem seca (Figura 2.3.5), mais difundido em pequenos e médios produtores, por exigir investimentos menores, não é capaz de gerar os mesmos produtos, especialmente os produtos relacionados ao setor de energia, biodiesel e etanol.

O biodiesel é produzido através da reação química de um óleo vegetal ou gordura animal com um tipo álcool. Dentre os óleos vegetais passíveis de serem transformados em biodiesel, existe a canola, o dendê, o girassol, a mamona, a soja, o milho entre outros. E dos alcoóis mais comuns para o processamento do biodiesel 
estão o metanol e o etanol. Dessa forma o milho, mesmo não sendo a semente oleaginosa mais produtiva para a geração de óleo, é capaz de gerar óleo e etanol, e assim gerar biodiesel de modo independente.

O biodiesel puro é conhecido como B100, mas é possível ainda encontrar o biodiesel misturado ao diesel convencional e misturas com $5 \%$ de biodiesel, por exemplo, conhecida como B5.

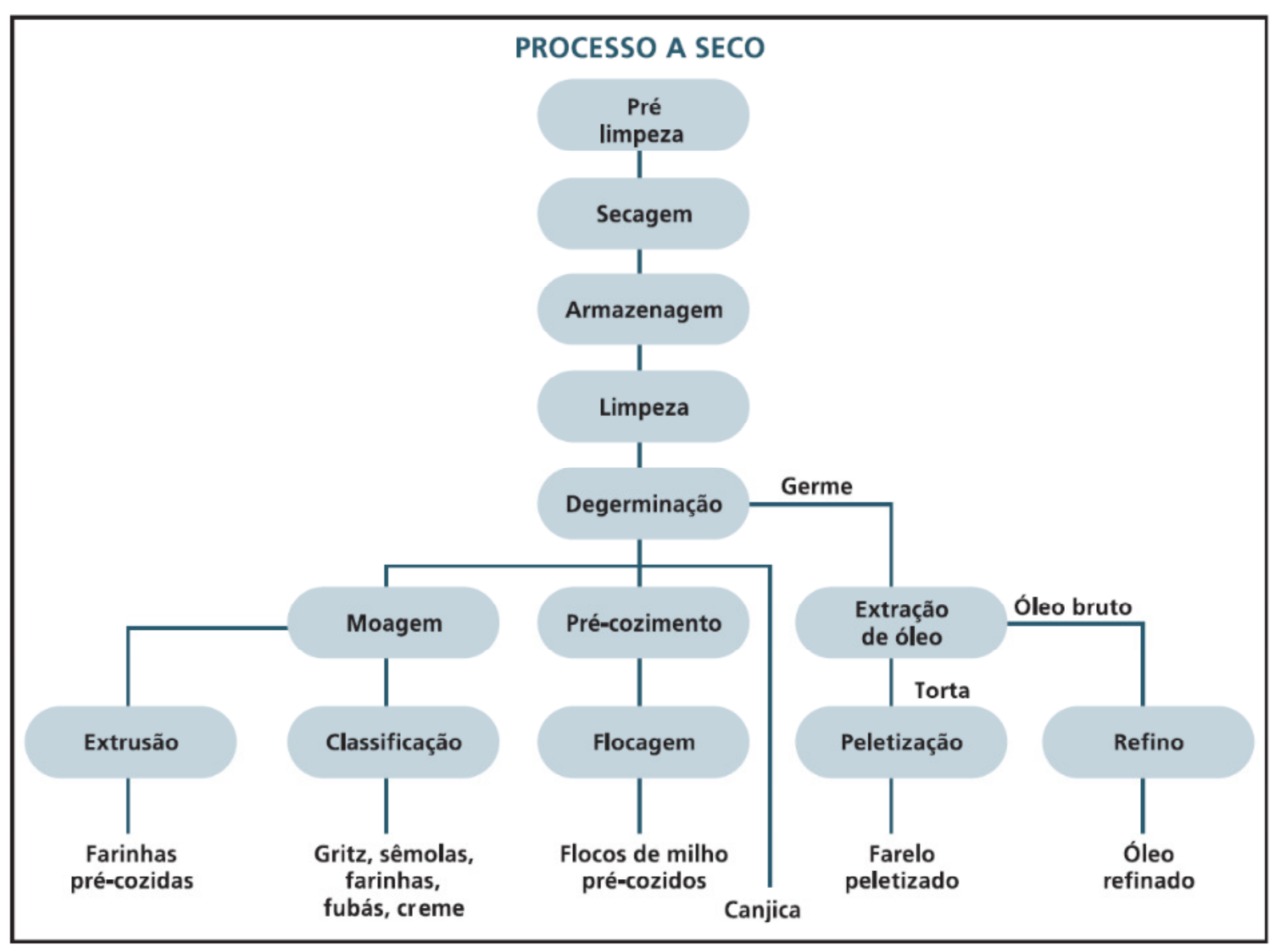

Figura 2.3.5 - Processo Produtivo do Milho - Moagem Seca

Fonte: Abimilho - Acesso em 02/11/2011.

\subsubsection{Preços no Mercado de Milho, Etanol e Biodiesel}

Nos Estados Unidos a comercialização do milho e de diversas commodities agrícolas se dá através de cooperativas que agrupam pequenos e médios produtores e principalmente grande produtores que negociam suas produções com grandes empresas dos diversos setores interessados, como alimentos, energia, 
têxtil, químico e outros. O porte das empresas relacionadas ao agronegócio no Estados Unidos cresceu na última década na busca de ganho de escala.

Dentre os fatores que afetam o preço do etanol nos Estados Unidos o principal é o preço do milho, de forma, que os formadores do custo da produção do milho terão impacto no preço do etanol. Diferentemente do Etanol do mercado sucroalcooleiro brasileiro, onde o petróleo tem relação de produto substituto com o etanol, uma vez que o consumidor pode optar por consumir gasolina ou etanol, nos Estados Unidos isso não é possível, sendo o consumo de etanol obrigatório, uma vez que a mistura de etanol com gasolina é obrigatória. Contudo o preço do petróleo tem influência direta nos custos do produtor de milho, uma vez que a produção e o processamento do milho nos Estados Unidos são altamente mecanizados.

Segundo Smith et al. (2004) o governo americano teve e tem papel preponderante na definição dos preços de commodities agrícolas e biocombustíveis nos Estados Unidos, seja por seus programas de financiamento agrícola, por benefícios fiscais, subsídios ou barreiras comerciais. Serra et al. (2010) mostra que quando a política de biocombustíveis é dependente da mistura com o combustível fóssil equivalente o preço do biocombustível varia de acordo com o preço desse combustível fóssil, em geral gasolina ou diesel.

A queda acentuada na produção de biodiesel para os anos de 2009 e 2010 nos Estados Unidos se deve a baixa rentabilidade para a maioria dos produtores nesses anos, com a queda nos preços do petróleo e a manutenção de altos preços do óleo de soja, que é a principal matéria prima para o biodiesel nos Estados Unidos. Contudo para o produtor de biodiesel a partir do óleo de milho, esse custo se reduz drasticamente pela característica do processamento do milho, o que fez com que as margens para produção de biodiesel a partir do milho se mantivessem elevadas mesmo nos anos de baixa do preço do petróleo, como será evidenciado pelo modelo proposto no capítulo 5. 


\section{Previsão de Preços de Commodities}

Uma abordagem comum para a previsão no mercado de commodities baseia-se na descrição de preços como processos estocásticos. Busca-se modelar o comportamento dos preços de commodities e sua volatilidade através de processos estocásticos que consideram os preços no mercado futuro, como apresentado por Gibson e Schwartz (1990), Schwartz (1997), Schwartz (1998), Schwartz e Smith (2000), e Manoliu e Tompaidis (2002). Como algumas variáveis associadas a commodities não são observáveis, estes autores empregam o filtro de Kalman em conjunto com dados sobre preços futuros.

Métodos de previsão alternativos que empregam redes neurais para previsão de preços ou da volatilidade de preços são também conhecidos, como tratado em Hu e Tsoukalas (1999), Chen et al. (2003), Hamid e lqbal (2004), e Zhang e Qi (2005). Em especial Ribeiro, Sosnoski e Widonsck (2005), Ribeiro, Miranda e Widonsck (2005) e Ribeiro et al. (2007) utilizam redes neurais para previsão de preços e volatilidade no mercado sucroalcooleiro.

Finalmente, existem os modelos híbridos ou combinados, onde dois ou mais modelos são agregados de forma a aumentar a capacidade preditiva. Os modelos híbridos permitem o uso de métodos com diferentes características estruturais, por exemplo, integrando métodos que consideram não linearidades para descrever a evolução dos preços, com métodos que empregam variáveis qualitativas para correção dos mesmos. Ainda que estes modelos, na maioria das vezes, não forneçam previsões ótimas, em decorrência da hierarquização, são modelos que apresentam bastante flexibilidade.

Os modelos híbridos vêm ganhando destaque na literatura recente. Zhang (2003) apresenta um modelo que agrega modelos ARIMA e redes neurais, aplicável a séries temporais univariadas. Tseng et al. (2008) combina o modelo ARIMA para séries temporais sazonais com Redes Neurais feedfoward para o índice de preços de opções. Bildiricia e Ersin (2009) utilizam um modelo APGARCH associado com Redes Neurais para prever o índice geral da bolsa de Istanbul. Wang (2009) refina os resultados de um modelo Grey-GJR-GARCH através de Redes Neurais para o apreçamento de opções. Aladag (2009) associa o modelo ARIMA com Redes 
Neurais Recorrentes, ao invés de redes Neurais feedfoward e verifica a maior acuracidade dessa abordagem em um caso específico.

Poucos trabalhos utilizam modelos híbridos para previsão de preços de commodities agrícolas. Zou et al. (2007) compara o desempenho do modelo ARIMA com o modelo por Redes Neurais, além da combinação dos modelos para a previsão dos preços do trigo no mercado Chinês e conclui que o modelo simples por Redes Neurais é o mais eficaz nesse caso. Co e Boosarawongse (2007) comparam o desempenho de técnicas de previsão clássicas com o das redes neurais em uma aplicação para o mercado de arroz da Tailândia.

Um modelo híbrido é proposto nesta tese para prever o preço à vista de commodities. Em abordagem similar à proposta por Schwartz (1997), Schwartz e Smith (2000) e Manoliu e Tompaidis (2002) o processo estocástico que descreve a evolução temporal dos preços é expresso na linguagem de modelos de espaço de estados. Emprega-se então o filtro de Kalman para realizar uma primeira previsão dos preços. O filtro de Kalman é mais abrangente em termos de resultados do que os modelos auto-regressivos mais difundidos, como os modelos usualmente empregados nos modelos híbridos. A seguir um segundo modelo corrige o resultado do primeiro através de Redes Neurais feedfoward. A entrada da rede considera a saída do primeiro modelo juntamente com outras variáveis exógenas, cuja escolha baseia-se nas especificidades do mercado analisado. 


\subsection{Modelo de Previsão Proposto}

A evolução do preço de um ativo pode ser descrita através de um processo estocástico. Pode se considerar ainda um tipo específico de processo estocástico onde apenas o valor atual de uma variável é relevante para prever o valor futuro, e os valores passados anteriormente ao valor atual são irrelevantes. Esse tipo de processo estocástico é conhecido como processo de Markov.

Os modelos por processos estocásticos para previsão de preços de commodities consideram, que o comportamento dos preços obedece a um processo de Markov.

Conforme Luenberger (1998) um tipo particular de processo estocástico de Markov é o Movimento Geométrico Browniano cuja equação é apresentada a seguir:

$$
d x(t)=a(x ; t) d t+b(x ; t) d B_{t}
$$

onde, $a(x ; t)$ representa uma componente da tendência representada pelo ganho médio, $b(x ; t)$ representa a parcela do erro estocástico do sistema e $B_{t}$ é a variável responsável pela variação aleatória.

Considerando que a componente $x(t)$ sejam os preços de uma commodity no mercado à vista no tempo $t, S_{t}, a(x ; t)$ o retorno médio esperado da commodity, $\mu$, e $b(x ; t)$ o desvio padrão dos preços, $\sigma$, tem-se:

$$
\frac{d S_{t}}{S_{t}}=\mu d t+\sigma d B_{t}
$$

onde, $\mu$ é a média de longo prazo dos retornos dos preços à vista.

Contudo, como já apresentado os mercados de commodities estocáveis partilham de uma singularidade, o retorno de conveniência. De acordo com Frechette e Fackler (1999), o retorno de conveniência pode ser comparado a taxa de dividendos (dividend yield) paga no mercado de ações. Segundo Geman (2005) o retorno de conveniência é a diferença entre o ganho positivo de possuir a commodity física menos o custo de carregamento, portanto o retorno de conveniência pode ser 
positivo ou negativo dependendo do período, do tipo de commodity e dos níveis de estoque físico.

Desse modo o retorno de conveniência é expresso como uma taxa e depende do custo de carregamento, que por sua vez envolve os custos de financiamento, seguros, transporte, custos de estocagem e a depreciação primária, que é a perda do valor da commodity pela mera passagem do tempo. Brennan e Schwartz (1985) apontam que o retorno de conveniência é o retorno médio, em termos de taxa, que o detentor da commodity física recebe pela possibilidade de queda nos estoques em uma data futura.

Adicionando o retorno de conveniência à equação 3.1.2, tem-se um caso particular do Movimento Geométrico Browniano:

$$
d S_{t}=(\mu-c) S_{t} d t+\sigma S_{t} d B_{t}
$$

onde $c$ é o retorno de conveniência.

Considerando $X_{t}=\ln \left(S_{t}\right)$, aplicando o Lema de Itô e considerando o tempo discreto chega-se a equação 3.1.4 que relaciona o preço à vista no tempo $t$ com o preço à vista no tempo $t-1$, (Elliott e Hyndman, 2007):

$$
X_{t}=\left(\mu-c-\frac{1}{2} \sigma^{2}\right) \Delta t+X_{t-1}+\sigma \sqrt{\Delta_{t}} \xi_{k}, \text { para } k=1 ; \ldots ; N
$$

onde $N$ é o número de períodos, $\Delta_{t}$ é o comprimento do intervalo usado na discretização, e $\xi_{k}$ é uma sequência de variáveis aleatórias com distribuição normal. Desse modo é obtido um modelo estocástico Markoviano para os preços à vista de commodities estocáveis.

É comum utilizar informações advindas dos mercados futuros para prever preços à vista. Segundo Geman (2005), a equação 3.1.5 relaciona preços futuros para um determinado vencimento com o preço à vista:

$$
F(S, t, T)=S_{t} e^{(r-c)(T-t)}
$$


onde $r$ é a taxa livre de risco, $t$ é o instante de tempo atual e $T$ é o tempo de vencimento do contrato futuro. Dado que $X_{t}=\ln \left(S_{t}\right)$ e $Y_{t}=\ln \left(F_{t}\right)$, e ainda adicionando um ruído que representa o desvio aleatório em relação a uma tendência do preço futuro (Elliott e Hyndman, 2007), tem-se:

$$
Y_{t}=X_{t}+(r-c)(T-t)+v \psi_{k}
$$

onde $v$ é uma medida de dispersão e $\psi_{k}$ é uma variável aleatória com distribuição normal e média igual a 0.

No caso de contratos futuros com $M+1$ vencimentos diferentes $\left\{T_{i}\right\}_{i=0}^{M}$, tem-se:

$$
Y_{t}^{i}=X_{t}+(r-c)\left(T_{i}-t\right)+v \psi_{k} \text {, para } t=1 ; \ldots ; N \text { e } i=0 ; \ldots ; M
$$

No modelo que considera a evolução dos preços à vista, a relação dos preços à vista com os preços futuros de contratos com diversos vencimentos existem variáveis aleatórias, ou ruídos, que para fins de simplificação são considerados ruídos brancos, com distribuição normal e variância unitária. Além disso, algumas variáveis podem ser consideradas não observáveis, como é o caso do preço à vista, onde em geral existe baixa liquidez e/ou incerteza em relação aos preços negociados.

\subsubsection{Filtro de Kalman}

Problemas com dados discretos e com uma ou mais variáveis não observáveis, de acordo com Harvey (1989), exigem métodos de filtragem, como o Filtro de Kalman. O filtro de Kalman é um algoritmo iterativo para estimativas computacionais de variáveis de estado $X$ (podendo estas serem observáveis ou não) baseadas em variáveis externas observáveis $Y$ e seus ruídos $\varepsilon$.

$O$ algoritmo do filtro de Kalman estima o estado $x \in \mathfrak{R}^{\mathrm{n}}$ de um processo em tempo discreto governado pelo seguinte modelo estocástico (Welch e Bishop, 2001), 


$$
x_{t}=A x_{t-1}+B+w_{t-1}
$$

com medida,

$$
y_{t}=C x_{t}+D+v_{t}
$$

onde, $x_{t}$ é uma matriz $N \times 1$, $y_{t}$ é uma matriz $M \times 1, A$ é uma matriz $N \times N, B$ é uma matriz $N \times 1, C$ é uma matriz $M \times N$, e $D$ é uma matriz $M \times 1$.

As variáveis aleatórias $w_{t}$ e $v_{t}$ representam os ruídos do processo e da medida respectivamente. É assumido que esses ruídos são independentes um do outro, obedecem a uma distribuição normal com média zero e matrizes com covariância $I_{N}$ e $I_{M}$ respectivamente - que é, $w \approx N\left(0, I_{N}\right)$ e $v \approx N\left(0, I_{M}\right)$. $I_{N}$ denota a matriz identidade $N \times N$ e $I_{M}$ denota a matriz identidade $M \times M$.

Na prática as matrizes $A, B, C, D, Q$ e $R$ podem variar no tempo, mas no presente estudo elas serão consideradas constantes.

Reescrevendo as equações 3.1.4 e 3.1.7 de acordo com as equações 3.1.8 e 3.1.9 teremos:

$$
\begin{gathered}
A=1 \\
B=\left(\mu-c-\frac{1}{2} \sigma^{2}\right) \Delta t \\
Q=\sigma \sqrt{\Delta t} \\
C=\left[\begin{array}{c}
1 \\
\vdots \\
1
\end{array}\right] \\
D=\left[\begin{array}{c}
(r-c)\left(T_{1}-k \Delta t\right) \\
\vdots \\
(r-c)\left(T_{M}-k \Delta t\right)
\end{array}\right],
\end{gathered}
$$




$$
R=v
$$

Para a execução do algoritmo do Filtro de Kalman é necessário estimar os parâmetros $\mu, \sigma, c$ e $R$, o que leva a um problema de otimização.

Existem diversos métodos para estimação de parâmetros, entre eles o método de estimação por minimização do erro quadrático médio, o método de maximização numérica da função de máxima verossimilhança e um método de maximização da esperança para calcular a máxima verossimilhança, como apresentado por Elliott e Hyndman (2007).

\subsubsection{Redes Neurais Artificiais}

Redes neurais têm sido utilizadas em numerosas aplicações dentro de diferentes áreas nas últimas duas décadas (Jain e Kumar, 2007). Em particular várias aplicações interessantes de redes neurais para previsão de séries temporais complexas e não lineares são relatadas na literatura.

Estes modelos não presumem uma específica distribuição de probabilidade para as variáveis de interesse. As redes neurais artificiais (ANN) são modelos não lineares que consistem de uma estrutura constituída de unidades denominadas neurônios. Os neurônios são conectados entre si e pesos $w_{j k}$ determinam a intensidade destas conexões. Estes pesos, os parâmetros do modelo, são obtidos através de técnicas de otimização que minimizam alguma medida de erro. Os pesos são modificados á medida que novos dados tornam se disponíveis, sendo por isto modelos dinâmicos com aprendizado.

Um modelo importante é a rede neural feedforward, onde os neurônios não possuem conexões com neurônios de camadas anteriores ou da mesma camada, e também não existe retroalimentação. Em especial temos as redes neurais Perceptron multicamada que possuem uma camada de entrada, camadas ocultas intermediárias e uma camada de saída. As entradas $s_{k}$ de um neurônio $k$ são ponderadas pelos pesos $w_{j k}$ e uma função de ativação $F_{k}$ gera o resultado $y_{k}$ que é a saída do neurônio. Este processo é repetido através de todas as camadas e a 
saída da última camada é comparada com os valores desejados (alvo), sendo os pesos ajustados de forma a minimizar alguma medida de erro.

Desse modo a saída de cada neurônio $k$, em uma instância $t$ do processo de aprendizado é dada por:

$$
y_{k}(t+1)=F_{k}\left(s_{k}(t)\right)=F_{k}\left(\sum_{j} w_{j k}(t) y_{j}(t)+\theta_{k}(t)\right),
$$

onde $\theta_{k}(t)$ é uma entrada externa ou "offset".

O erro quadrático é calculado com base na saída da rede $y_{0}^{P}$ e nos valores desejados ou de alvo $d_{0}^{P}$ :

$$
E^{P}=\frac{1}{2} \sum_{o=1}^{N o}\left(d_{0}^{P}-y_{0}^{P}\right)^{2}
$$

onde $O$ é o neurônio em análise.

A construção de uma rede neural consiste, primeiramente em selecionar sua arquitetura, ou seja, determinar o número de camadas, o número de neurônios em cada camada e as funções de ativação.

Funahashi (1989) e Hornik et. al. (1990) indicam que apenas uma camada oculta com função de ativação sigmóide é suficiente para que a rede seja uma função aproximadora universal.

Wang et. al. (1994) trata da determinação do número de neurônios em cada camada em redes neurais feedforward com duas camadas ocultas. Nesse caso o número de neurônios depende da complexidade e dimensões de entrada e saída da rede. Porém de acordo com Tu (1996) não existe consenso em relação a teoria para a predeterminação do número de neurônios em uma camada oculta, o que leva a abordagens por tentativa e erro para essa determinação.

Os pesos $w_{j k}$ são obtidos através de um método de treinamento que utiliza parte dos dados e reduz iterativamente a diferença entre o valor de saída da rede e o alvo até que algum critério de parada seja alcançado.

Como método de treinamento da Rede Neural foi utilizado o algoritmo apresentado inicialmente por Levenberg (1944) e aperfeiçoado por Marquardt 
(1963), que ficou conhecido como algoritmo LM. Hagan e Menhaj (1994), El-Bakry (2003), Kisi (2004) e Cigizoglu e Kisi (2005) consideram o algoritmo de LevenbergMarquardt o mais rápido para treinamento de redes neurais e mais poderoso que outras técnicas convencionais de redução do gradiente.

Outra definição importante está relacionada aos critérios de parada, que garantem paradas antecipadas em caso de overfitting. Overfitting é a deterioração do resultado, onde o erro cresce durante o processo de treinamento ao invés de reduzir (Geman et. al. 1992). Prechelt (1998) compara três critérios de parada por cross validation e indica o critério por perda de generalização para maximizar a probabilidade de se encontrar uma boa solução, apesar de aumentar o tempo de processamento. Este será o critério utilizado no modelo de aplicação a ser apresentado.

$$
G L(t)=100\left(\frac{E_{V A}(t)}{E_{O P T}(t)}-1\right),
$$

A equação 3.1.18 apresenta a fórmula de cálculo da perda por generalização na epoch $t, G L(t)$, onde $E_{V A}(t)$ é o erro correspondente ao conjunto de dados de validação que é utilizado pelo critério de parada e $E_{O P T}(t)$ é o menor erro do conjunto de dados de validação obtido até a epocht.

$$
E_{O P T}(t)=\min _{t \prime \leq t} E_{V A}\left(t^{\prime}\right)
$$

A perda de generalização é obviamente uma razão para parar o treinamento, uma vez que indica overfitting. Desse modo o treinamento é interrompido quando a perda de generalização atingir um patamar mínimo pré estabelecido.

\subsection{Resultados do Modelo de Previsão de Preços}

O modelo proposto foi testado com dados reais do mercado sucroalcooleiro Brasileiro e Indiano. Em ambos os casos foram encontradas dificuldades com a periodicidade dos dados, em especial para a utilização de variáveis exógenas no modelo de redes neurais, uma vez que muitos dados estavam disponíveis somente em bases anuais. Dados como taxas de juros podem utilizar o CDI futuro negociado na BM\&FBOVESPA como estimadores para o comportamento futuro, assim como o 
câmbio futuro. Existem previsões de produção de cana de açúcar e açúcar, porém em bases anuais, porém dados de estoque só são divulgados após os fatos terem ocorrido e nenhum instituto de pesquisa brasileiro ou indiano indicam seus níveis de estoque previstos, portanto essas variáveis não puderam ser utilizadas.

\subsubsection{Processos Estocásticos e Filtro de Kalman}

Para a aplicação do modelo são utilizadas séries históricas de preços de açúcar e álcool de contratos no mercado à vista e futuros.

Um dos problemas encontrado está relacionado com a rolagem da posição no mercado futuro, seja porque os produtores operam no mercado financeiro só para efeitos de hedge, não têm a intenção de realmente fazer a entrega do produto, seja por incompatibilidade de prazos no mercado físico com os vencimentos do mercado futuro. Dessa maneira, precisam liquidar a posição antes do vencimento e nessa operação de rolagem podem ocorrer perdas e custos de transação. Esse problema não é tratado explicitamente pelo modelo o que pode acarretar maior imprecisão.

No caso do Brasil, como entrada do modelo foram utilizadas 82 observações de dados mensais de preços à vista do açúcar e do etanol hidratado, de Março de 2002 a Dezembro de 2008, obtidos do Centro de Estudos Avançados em Economia Aplicada (CEPEA/ESALQ) e preços futuros do açúcar (sugar No.11) para o primeiro vencimento advindos da Bolsa de Mercadorias e Futuros BM\&FBOVESPA.

No caso da Índia, 64 observações de dados mensais de preços à vista do açúcar, de Setembro de 2004 a Dezembro de 2009, fornecidos pelo National Commodity \& Derivatives Ltd (CDEX). Preços futuros da bolsa New York Mercatile Exchange (NYMEX) foram considerados nesse caso.

A estimativa do retorno médio $\boldsymbol{\mu}$, da volatilidade do preço do ativo à vista $\boldsymbol{\sigma}$ e do retorno de conveniência $\boldsymbol{c}$ é realizada através da determinação dos parâmetros do filtro de Kalman durante a minimização do erro quadrático médio.

Diversas medidas de desempenho foram analisadas, entre elas, o erro médio absoluto (MAE), o erro quadrático médio (MSE), o erro percentual absoluto médio (MAPE) e, por fim, a variância do erro. As expressões de cada uma destas medidas são apresentadas a seguir. 


$$
\begin{aligned}
& M A E=\frac{1}{N} \sum_{i=1}^{n}\left|e_{i}\right| \\
& M S E=\frac{1}{N} \sum_{i=1}^{n} e_{i}^{2} \\
& M A P E=\frac{1}{N} \sum_{i=1}^{n}\left|\frac{e_{i}}{A_{i}}\right| \\
& \text { Variância }=\frac{1}{N} \sum_{i=1}^{n}\left(e_{i}-\bar{e}\right)^{2}
\end{aligned}
$$

Nas expressões acima, $e_{i}$ é o erro no tempo $i$, ou seja, a diferença entre o valor previsto e o valor real. O valor real é $A_{i}$ e $\bar{e}$ é o erro médio.

Tabela 3.2.1 - Resultado do modelo por processos estocásticos e Filtro de Kalman para a previsão do preço à vista do açúcar um mês a frente

\begin{tabular}{lccccc}
\hline \multirow{2}{*}{$\begin{array}{l}\text { Medidas } \\
\text { de Erro }\end{array}$} & \multicolumn{2}{c}{ Brasil } & & \multicolumn{2}{c}{ Índia } \\
\cline { 2 - 3 } \cline { 5 - 6 } & Base & $\begin{array}{l}\text { Filtro de } \\
\text { Kalman }\end{array}$ & & Base & $\begin{array}{c}\text { Filtro de } \\
\text { Kalman }\end{array}$ \\
\hline MAE & 0.0822 & 0.0778 & & 0.3495 & 0.0423 \\
MSE & 2.1362 & 0.7539 & & 1.4306 & 0.6661 \\
MAPE (\%) & 8.88 & 5.30 & & 3.53 & 3.51 \\
Variância & 2.1560 & 0.7572 & & 1.3293 & 0.6749 \\
\hline
\end{tabular}

Para fins comparativos foi definido um modelo base que considera o preço no próximo mês como sendo igual ao preço do mês corrente. A Tabela 3.2.1 apresenta diversas medidas de erro encontradas para o modelo de base e para o modelo do Filtro de Kalman, tanto para os dados do mercado Brasileiro quanto para o mercado Indiano.

Todas as medidas de erro são melhores utilizando o modelo proposto que 0 modelo de base, tanto para o açúcar quanto para o etanol. Os melhores resultados foram obtidos para a previsão de preços do açúcar, o que já era esperado uma vez que o contrato futuro é uma variável observável, é o contrato de açúcar. 


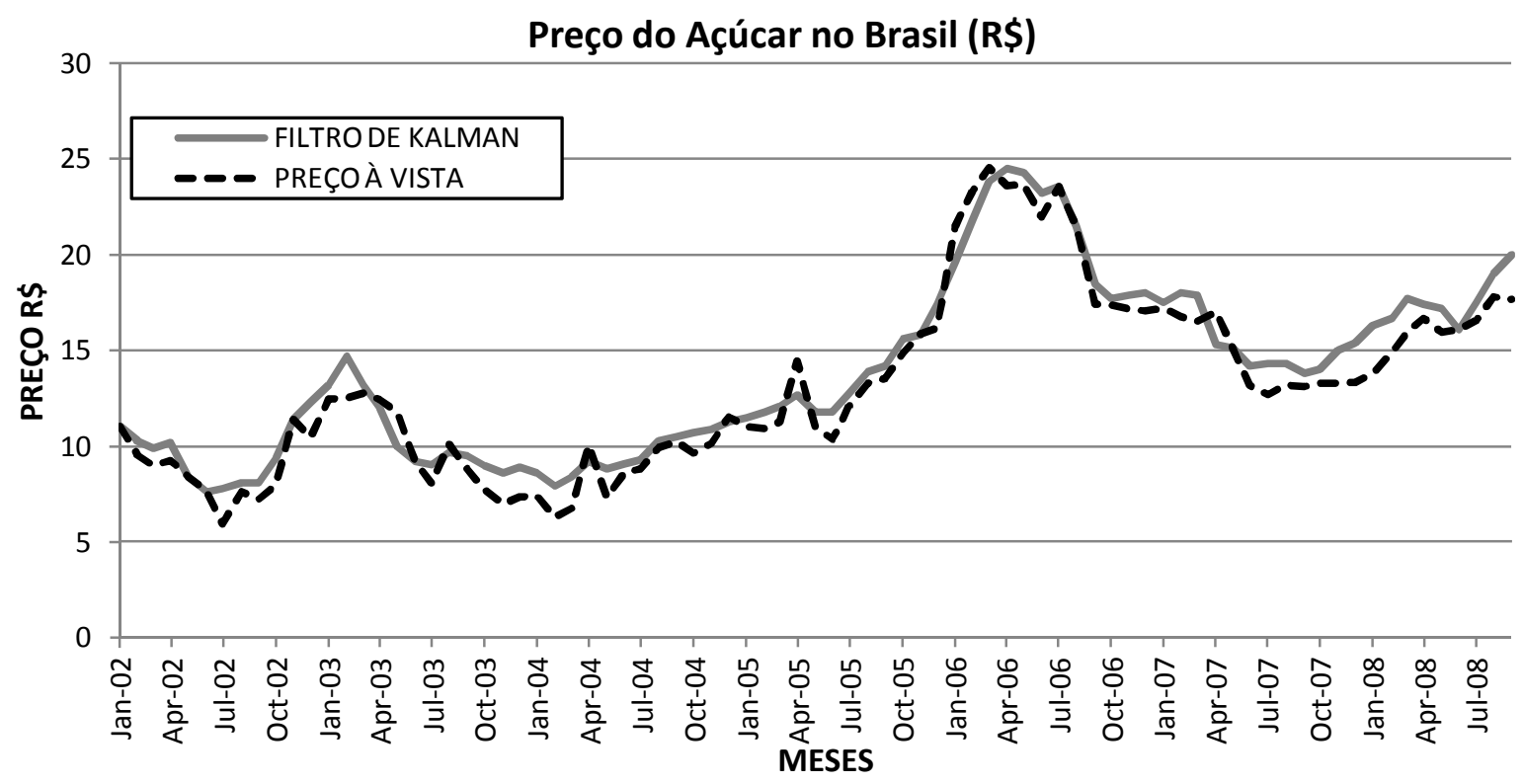

Figura 3.2.1 - Preço real do açúcar e preço estimado pelo Filtro de Kalman para o mercado sucroalcooleiro Brasileiro

Uma representação gráfica do resultado do modelo de previsão de preços utilizando processos estocásticos e filtro de Kalman, para o açúcar e o etanol é apresentada através das Figuras 3.2.1 e 3.2.2.

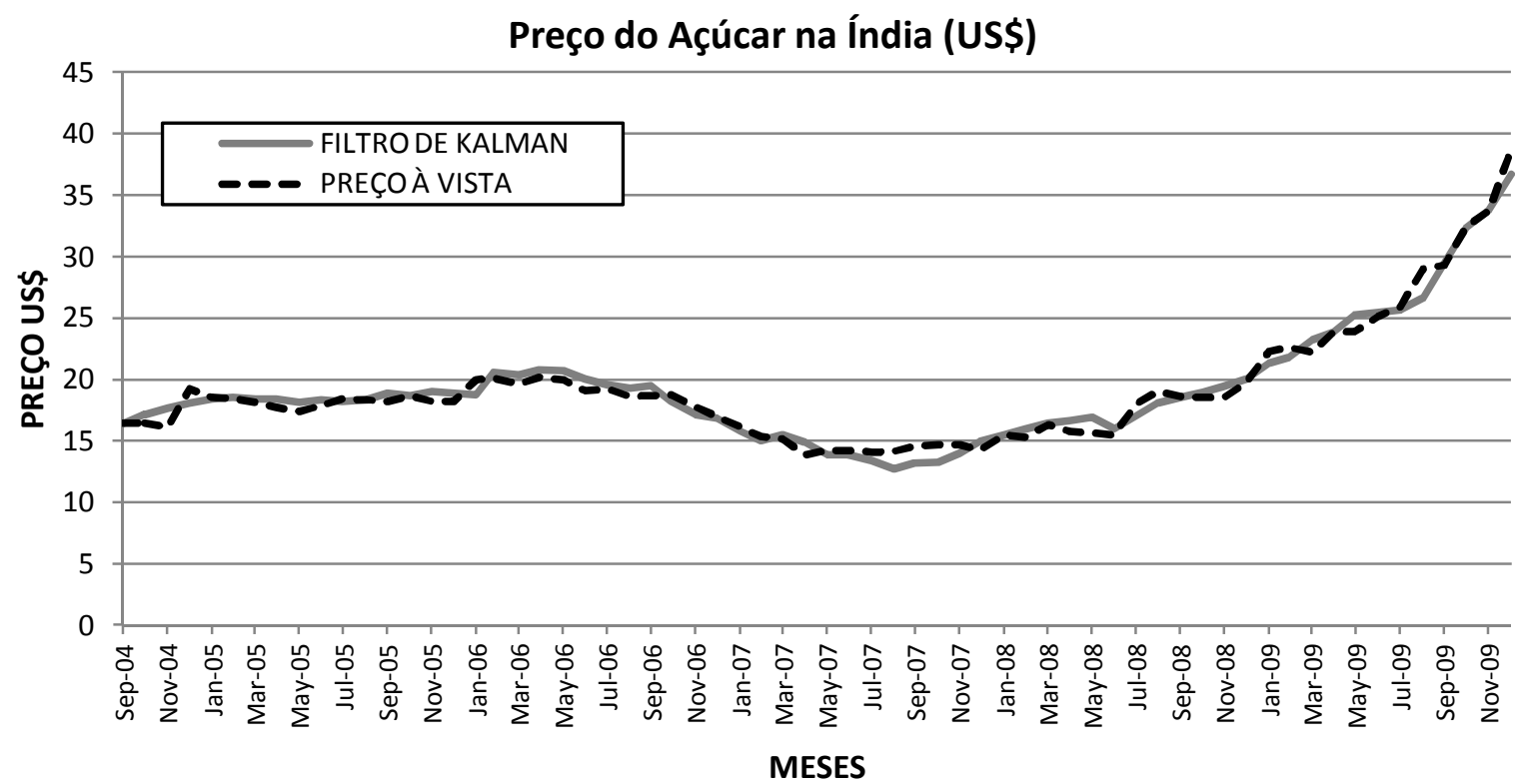

Figura 3.2.2 - Preço real do açúcar e preço estimado pelo Filtro de Kalman para o mercado sucroalcooleiro Indiano 


\subsubsection{Correção por Redes Neurais Artificiais}

É esperado que as redes neurais possam reduzir as medidas de erro, através da inclusão de novas variáveis. Para esse fim, adicionalmente aos valores encontrados pelo modelo pelo filtro de Kalman e aos preços futuros, novas variáveis foram testadas, uma a uma, para isolar seu impacto, simplificar o problema e reduzir dificuldades de convergência e overfitting. As Tabelas 3.2.2 e 3.2.3 apresentam as variáveis exógenas selecionadas para teste para o mercados Brasileiro e Indiano respectivamente.

O processo de análise da capacidade de cada variável reduzir o erro médio e sua variância seguiu os seguintes passos:

1. Escolha de uma das variáveis

2. Teste de diversos Modelos da Rede Neural, variando o número de neurônios da camada intermediária.

3. Treinamento e Simulação

Tabela 3.2.2 - Variáveis exógenas usadas no modelo de redes neurais (Dados Brasileiros)

\begin{tabular}{|c|c|c|}
\hline Dados & Sigla & Fonte \\
\hline Produção de Cana de Açúcar & PBC & $\begin{array}{c}\text { União da Indústria de Cana-de-açúcar } \\
\text { (UNICA) }\end{array}$ \\
\hline Produção de Açúcar & PBA & $\begin{array}{c}\text { União da Indústria de Cana-de-açúcar } \\
\text { (UNICA) }\end{array}$ \\
\hline PIB Agrícola & PIB & $\begin{array}{l}\text { Instituto de Pesquisa Econômica Aplicada } \\
\text { (IPEA) }\end{array}$ \\
\hline Taxa de Câmbio (Dólar/Real) & CDR & $\begin{array}{c}\text { Bolsa de Mercadorias e de Futuros } \\
\text { (BM\&FBOVESPA) }\end{array}$ \\
\hline Preços do Barril de Petróleo & PBP & New York Board of Trade (NYBOT) \\
\hline Venda de Veículos Bicombustível & VBB & $\begin{array}{l}\text { Associação Nacional dos Fabricantes de } \\
\text { Veículos Automotores (ANFAVEA) }\end{array}$ \\
\hline Taxa de Juros (Selic) & SLC & Banco Central do Brasil (BCB) \\
\hline
\end{tabular}

Geman e Ohana (2009) destacam a importância do volume dos estoques para descrever o comportamento dos preços, uma vez que esta variável é capaz de explicar diferenças entre preços à vista e futuros. 
Tabela 3.2.3 - Variáveis exógenas usadas no modelo de redes neurais (Dados Indianos)

\begin{tabular}{llc}
\hline Dados & Sigla & Fonte \\
\hline Taxa de Câmbio (Dólar/Rúpia) & CDR & Banco Central da Índia \\
Preços do Barril de Petróleo & PBP & New York Board of Trade (NYBOT) \\
\hline
\end{tabular}

Para Pereira (2009), em certas ocasiões o preço à vista de uma mercadoria pode ficar acima do preço no mercado futuro. Isso ocorre porque o detentor da mercadoria física possui o benefício de reter os estoques e, em busca de melhores preços, aguardar um melhor momento para realizar a venda. $O$ detentor do estoque, ao tomar essa decisão, deve levar em consideração algumas variáveis relevantes, tais como as taxas de juros, a sazonalidade nos preços, o custo de armazenagem e o benefício esperado com o aumento do preço de venda.

No Brasil a informação sobre os estoques de açúcar e álcool não é levantada com periodicidade e abrangência suficiente para que esses dados reflitam a realidade plena dos estoques nacionais e por esse motivo não foi possível utilizar essa variável.

A produção de cana-de-açúcar e de açúcar refletem diretamente a oferta dos produtos em um determinado ano que por sua vez afeta os estoques e o preço. O PIB agrícola que mede todas as riquezas geradas pela produção agrícola no Brasil, também mede indiretamente a oferta de cana-de-açúcar no mercado. No Brasil dados de PIB agrícola, produção de cana-de-açúcar e açúcar são levantados anualmente e para serem utilizados precisaram ser estimados mês a mês.

A exportação de etanol ainda tem pouca representatividade, com as novas metas para redução de emissões de dióxido de carbono e com o avanço dos programas de bicombustíveis em países europeus e asiáticos é esperado um crescimento substancial das exportações brasileiras.

A taxa de juros representada no Brasil pela taxa básica SELIC, definida pelo Banco Central como taxa de pagamentos de títulos do governo Brasileiro, também afeta a decisão sobre estoques, que por sua vez afeta a oferta e finalmente o preço. A taxa de juros aparece explicitamente no modelo de preços que relaciona preços do mercado futuro com o mercado à vista, através da Equação 3.1.6, já apresentada anteriormente. 
Como não há bases de dados sobre venda ou demanda mensais de álcool, pode-se utilizar venda mensal de veículos bicombustíveis como um indicador de demanda potencial. De acordo com projeções da União da indústria de cana-deaçúcar - ÚNICA (2009), 50\% da frota circulante será bicombustível em 2012 e subirá, em 2015, para 65\%. No Brasil também de acordo com a ÚNICA (2009), 50\% do consumo de gasolina já foi substituído pelo etanol, o que explicita a relação de substituição do petróleo pelo etanol.

A taxa de câmbio tem a capacidade de melhorar significativamente a previsão de preços de commodities como apontado por Chen et. al. (2010) e por Engel e West (2005).

Devido a ausência de informações oficiais, relativas ao mercado Indiano de açúcar, somente duas variáveis foram testadas. Como o estudo com dados do mercado Indiano foi conduzido após o estudo com dados do mercado Brasileiro foi possível selecionar as mesmas variáveis que haviam demonstrado eficiência para o mercado brasileiro. Nesse caso a taxa de câmbio entre a rúpia e o dólar e o preço do petróleo foram as variáveis escolhidas.

A determinação da arquitetura da rede seguiu a literatura da área. A rede neural utilizada possui três neurônios de entrada na primeira camada, sendo eles: 0 preço à vista previsto para um período à frente, obtido pelo modelo do Filtro de Kalman, o preço futuro e uma das sete variáveis exógenas apresentadas nas Tabelas 3.2.2 e 3.2.3. A escolha de analisar apenas uma variável exógena como entrada se deveu à presença de overfitting em análises com duas ou mais variáveis. Tentativas foram feitas com duas ou mais variáveis, e mesmo relaxando critérios de parada e efetuando diversas simulações a ocorrência de overfitting impediu a melhoria dos resultados. A rede utilizada possui apenas uma camada oculta, como indicado pela literatura (Funahashi 1989; Hornik et. al. 1990). Por não haver consenso em relação a determinação do número de neurônios da camada oculta, (Tu 1996), é necessário testar diversas configurações. Nesse estudo algumas configurações com três, dois e um neurônio na camada oculta foram testadas, porém os melhores resultados foram encontrados para dois neurônios na camada oculta. Existem diversas opções para funções ativação, entre elas temos a função linear, a sigmóide, a tangente hiperbólica e a gaussiana. A escolha adequada da função de ativação afeta a convergência da rede neural. A função sigmóide é a mais 
comumente encontrada em aplicações financeiras e é a escolhida para o presente caso, (Funahashi 1989; Hornik et. al. 1990).

A Figura 3.2.3 ilustra a arquitetura da rede neural utilizada.

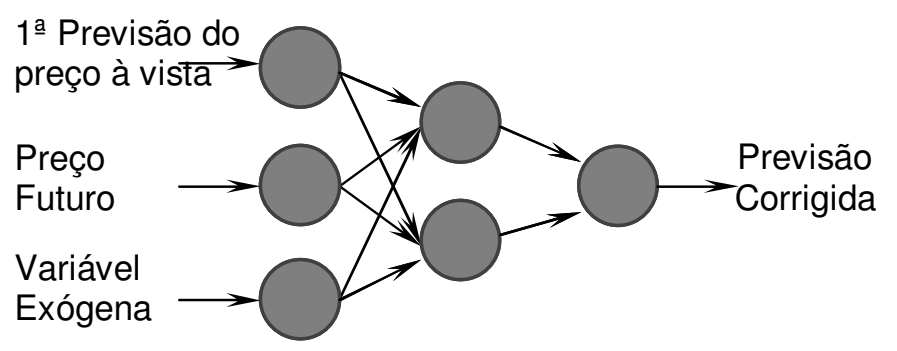

Figura 3.2.3 - Estrutura da rede neural

O treinamento da rede seguiu o seguinte procedimento. Dos 82 meses avaliados, um conjunto de preços dos 40 primeiros meses foi utilizado para o treinamento da rede. De acordo com Zhang (2003) o tamanho total da amostra tem forte influência na convergência do erro e grandes conjuntos de dados costumam ser necessários para garantir um bom comportamento do modelo. Apesar de existirem dados do mercado à vista além dos 82 meses considerados, não seria possível obter dados sobre o mercado futuro de açúcar que é relativamente recente no Brasil. Além disso, a participação relativa dos veículos bicombustíveis só passou a ser importante a partir de 2004, sendo o crescimento na demanda por etanol, por esse motivo, irrelevante em períodos anteriores. Desse modo, mesmo com uma maior possibilidade de ocorrência de overfitting somente 82 meses puderam ser utilizados. No estudo Indiano, o conjunto de dados foi ainda mais reduzido, devido ao fato de não existirem dados de preços à vista do açúcar anteriores a 2004.

Como critérios de parada do algoritmo de treinamento de LevenbergMarquardt foram utilizados a variância do erro, que deveria ser menor que a apresentada pelo modelo anterior ou então um número máximo de epochs, que consistem de uma varredura completa nos dados de teste e pode garantir uma parada antecipada e redução do tempo de processamento. O algoritmo utilizado já conta com o método de validação cruzada por perda de generalização para reduzir o efeito de overfitting garantindo uma parada antecipada nos casos em que o erro começa a crescer ao invés de reduzir. 
A Tabela 3.2.4 apresenta um resumo comparativo, com as medidas de erro de cada variável exógena, com a saída do modelo do Filtro de Kalman (FK) para o mercado Brasileiro.

Tabela 3.2.4 - Resultados do modelo por redes neurais para cada variável exógena (dados Brasileiros)

\begin{tabular}{lcccccccc}
\hline $\begin{array}{l}\text { Medidas } \\
\text { de Erro }\end{array}$ & $\begin{array}{c}\text { Filtro de Taxa de } \\
\text { Kalman Câmbio }\end{array}$ & $\begin{array}{c}\text { Venda de } \\
\text { Veículos } \\
\text { Bicombustível Petróleo }\end{array}$ & $\begin{array}{c}\text { Preço } \\
\text { Barril }\end{array}$ & $\begin{array}{c}\text { Taxa de } \\
\text { Juros }\end{array}$ & $\begin{array}{c}\text { PIB } \\
\text { Agrícola }\end{array}$ & $\begin{array}{c}\text { Produção Produção } \\
\text { de Cana }\end{array}$ & $\begin{array}{c}\text { Pe Açúcar } \\
\text { de }\end{array}$ \\
\hline MAE & 0.0778 & 0.0280 & 0.0363 & 0.0105 & 0.0562 & 0.0679 & 0.1227 & 0.4143 \\
MSE & 0.7539 & 0.6026 & 0.6562 & 0.6044 & 0.6835 & 0.6588 & 0.6813 & 0.9047 \\
MAPE (\%) & 5.30 & 5.07 & 5.19 & 5.03 & 5.30 & 5.00 & 5.17 & 6.41 \\
Variância & 0.7572 & 0.6093 & 0.6630 & 0.6119 & 0.6888 & 0.6624 & 0.6746 & 0.7422 \\
\hline
\end{tabular}

Com os resultados apresentados na Tabela 3.2.4 é possível verificar que as variáveis de Produção de Cana (PBC) e de Açúcar (PBA) não conseguiram melhorar sequer o erro absoluto médio (MAE) em relação aos resultados advindos do primeiro modelo, possivelmente por serem variáveis anuais que precisaram ser estimadas mês a mês.

O PIB (produto interno bruto) agrícola mensal que representa as riquezas originadas pelo setor agrícola brasileiro a cada mês também não conseguiu melhorar significativamente os resultados do primeiro modelo possivelmente por englobar mais variáveis desconectadas da produção de cana e açúcar.

A variável de taxa de juros (Selic) conseguiu reduzir o erro absoluto médio (MAE), mas não o erro percentual absoluto médio (MAPE) em relação a saída do modelo do Filtro de Kalman.

As variáveis Preço do Petróleo, Venda de Veículos Bicombustíveis e Taxa de Câmbio foram as mais significativas e conseguiram reduzir todos as medidas de erro analisadas, sendo a taxa de câmbio e o preço do petróleo os mais significativos.

A Figura 3.2.4 apresenta o resultado do modelo de redes neurais com a variável taxa de câmbio (CDR) em comparação com os preços reais e com a previsão advinda do primeiro modelo. 


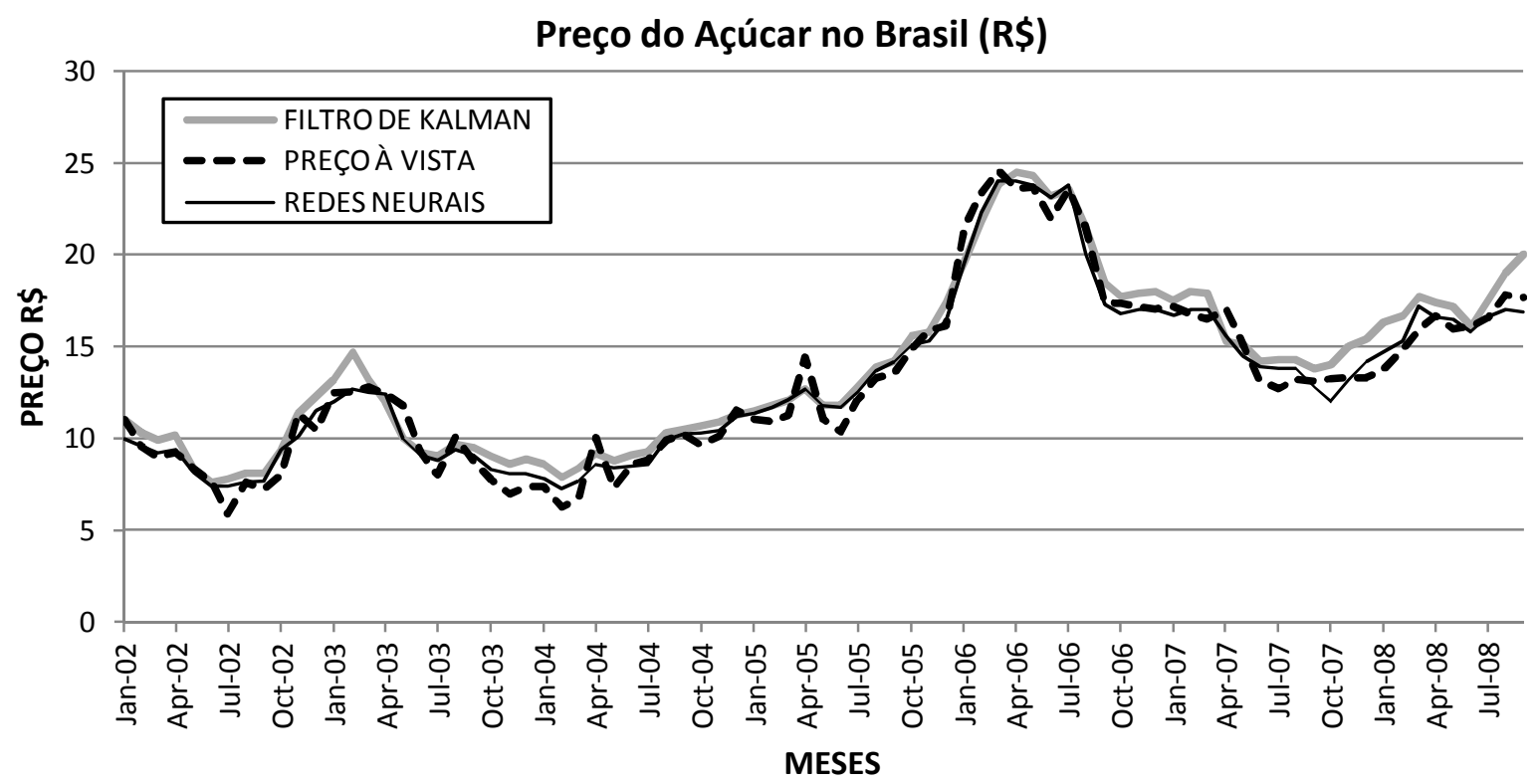

Figura 3.2.4 - Resultados do modelo por redes neurais com taxa de câmbio como entrada (dados Brasileiros)

A Tabela 3.2.5 apresenta o resultado do modelo de redes neurais para os dados Indianos comparando as medidas de erro geradas pelo modelo do Filtro de Kalman (FK) com as medidas de erro encontradas para cada variável exógena testada no modelo por redes neurais. A taxa de câmbio e o preço do petróleo apresentaram resultados similares, sendo que nenhum foi capaz de reduzir o erro absoluto médio (MAE), mas foram capazes de reduzir todas as outras medidas de erro. A pequena amostra usada para prever os preços, com apenas 64 meses, certamente contribuiu para esses resultados, como já previsto por Zhang (2003).

Tabela 3.2.5 - Resultados do modelo por redes neurais para cada variável exógena (dados Indianos)

\begin{tabular}{lccc}
\hline $\begin{array}{l}\text { Medidas } \\
\text { de Erro }\end{array}$ & $\begin{array}{c}\text { Filtro de } \\
\text { Kalman }\end{array}$ & $\begin{array}{c}\text { Taxa de } \\
\text { Câmbio }\end{array}$ & $\begin{array}{c}\text { Preço } \\
\text { Barril } \\
\text { Petróleo }\end{array}$ \\
\hline MAE & 0.0423 & 0.1378 & 0.1351 \\
MSE & 0.661 & 0.5941 & 0.6082 \\
MAPE (\%) & 3.51 & 3.21 & 3.23 \\
Variância & 0.76749 & 0.5842 & 0.5993 \\
\hline
\end{tabular}




\subsection{Conclusões do Modelo de Previsão de Preços}

O modelo híbrido de previsão de preços proposto foi capaz de reduzir as quatro medidas de erro, com dados Brasileiros e três medidas de erro com dados Indianos, em comparação com um modelo de previsão, chamado de base, em que o preço um período a frente é igual ao preço no período atual.

Para os dados Brasileiros, as variáveis exógenas que tiveram um impacto significante na previsão dos preços do açúcar, através das redes neurais, foram o preço do petróleo, venda de veículos bicombustível no Brasil e taxa de câmbio. Essas variáveis foram bem sucedidas na difícil tarefa de reduzir ainda mais as já reduzidas medidas de erro geradas pelo modelo do Filtro de Kalman. No caso dos dados Indianos as variáveis taxa de câmbio e preço do petróleo só não conseguiram reduzir o erro absoluto médio (MAE).

É possível apontar como pontos fortes do modelo híbrido sua flexibilidade e boa qualidade de resultados, sendo que quase toda a redução nas medidas de erro é gerada pelo modelo por processos estocásticos e Filtro de Kalman, sendo a melhoria gerada pelas redes neurais menos relevante.

Contudo o modelo proposto é exigente no que tange a qualidade das variáveis, seja pela periodicidade, ou pelo momento em que o dado é gerado, principalmente em se tratando das variáveis exógenas. Esse fator associado a um ambiente altamente carente de dados faz com que o modelo seja de difícil aplicação e que seus resultados não sejam os melhores. É importante notar o potencial do modelo, pois para grandes produtores o levantamento de dados pode ser viável e desse modo o modelo híbrido terá todo seu potencial utilizado.

Os estudos para a proposição do modelo híbrido de previsão de preços dessa tese originou três publicações: Ribeiro et al. (2009), Ribeiro et al. (2010) e Ribeiro et al. (2011). 


\section{Modelo de Decisão de Mix de Produção, Comercialização, Hedge e Estocagem}

Nesse capítulo apresenta-se o modelo de decisão, que é analisado com base em dados reais.

A incerteza do modelo de previsão é incorporada ao modelo de decisão através de técnicas de otimização robusta. Com isso objetiva-se melhorar a qualidade do modelo de decisão do ponto de vista de sua efetiva aplicação a problemas reais.

\subsection{Fundamentação Teórica}

O modelo para decisões relativas a produção e comercialização de commodities agrícolas diversificáveis é construído com base em conceitos como gestão da produção, teoria de estocagem, teoria de carteiras, decisões sob incerteza, entre outros. O presente tópico é dedicado a apresentar os fundamentos que permitiram a proposição do modelo.

\subsubsection{Estratégias de Hedging}

A palavra hedge pode ser entendida como proteção. No mercado financeiro o hedge permite que se minimize a exposição ao risco de oscilação indesejada dos preços. Estratégias de hedging podem ser feitas através da utilização de uma grande variedade de instrumentos no mercado de derivativos, em especial o mercado futuro e de opções.

No caso em estudo somente dois agentes são considerados para o hedge, o produtor e o consumidor da commodity que pode ser, por exemplo, uma empresa do setor alimentício ou de energia no caso do setor sucroalcooleiro. Ambas as partes tem interesse em fixar o preço em um determinado patamar. O produtor deseja garantir um retorno mínimo enquanto a indústria que necessita da commodity quer assegurar um limite máximo para o custo. Tanto produtor quanto consumidor são chamados de hedgers, pois buscam reduzir sua exposição ao risco de oscilação nos preços.

Uma maneira de realizar hedge é através do mercado a termo. Em um contrato a termo bastam as duas partes citadas, porém existe a dificuldade de encontrar duas partes com a mesma necessidade em termos de volume, preços e 
prazos. Para resolver esse problema que o mercado futuro pode ser utilizado. $O$ mercado futuro possui padronização em seus contratos de modo a facilitar o encontro das partes interessadas. Contudo o mercado futuro também atrai um outro agente chamado de especulador, que entende sobre formação de preços e está disposto a correr riscos. Seu interesse é obter lucro, porém acaba por ter um papel importante, aumentando a liquidez do mercado de derivativos.

Adicionalmente os arbitradores atuam no mercado buscando situações de lucro sem correr riscos. Normalmente isso é feito atuando em mercados diferentes do mesmo ativo, como o mercado a vista e futuro ou ainda operando com diferentes vencimentos.

Os mecanismos de hedge para cada um dos mercados, futuro e de opções, são discutidos nos próximos tópicos.

\subsubsection{Hedging com Futuros}

Em geral na construção de uma estratégia de proteção financeira no mercado futuro, o agente irá construir duas posições, uma no mercado à vista e outra no mercado futuro, com o intuito de reduzir ou até eliminar o risco de movimentos desfavoráveis dos preços. Segundo Chen, Lee e Shresta (2003) essa proteção ou hedging pode ser interpretada como uma carteira de investimento, uma vez que se constrói um portfólio com posições no mercado a vista e futuro para reduzir o risco e maximizar a utilidade do investidor.

O produtor, detentor da commodity, se posiciona vendido no mercado futuro, ou seja, ele vende contratos futuros. É possível que o preço do contrato futuro seja diferente do preço da commodity no mercado à vista, evidenciando a existência do fenômeno de backwardation ou contango. Luenberger (1998) indica que teoricamente é esperado que os preços à vista e futuro sejam correlacionados e que os preços à vista e futuro convirjam na data de vencimento dos contratos futuros. Desse modo quando o produtor sofre uma perda no mercado à vista ele é compensado por um ganho no mercado futuro, e vice-versa. Devido ao fato de a posição no mercado futuro gerar resultado oposto ao do mercado à vista, o hedge pode tanto compensar uma perda como reduzir o lucro, dependendo do movimento dos preços. 
Uma estratégia de hedge é considerada perfeita quando os resultados nos mercados à vista e futuro são opostos e de igual magnitude. Teoricamente é esperado que essa condição ocorra quando os contratos futuros se equiparam a natureza da commodity em termos de data de entrega e igualdade de produtos negociados.

Contudo, de acordo com Hull (2006) hedges perfeitos são raros devido à existência dos riscos de base. O risco de base pode ocorrer por descasamento de prazos, pela inexistência de um contrato plenamente compatível com a commodity que se deseja hedgear ou ainda por outras imperfeições dos mercados. A base é a diferença entre o preço à vista do ativo que se deseja hedgear e os preços do contrato futuro disponível.

Construir uma posição no mercado futuro pode implicar em descasamento de prazos. Contratos futuros com prazos superiores ao prazo desejado podem aumentar o risco de base e contratos futuros com prazos inferiores ao desejado podem obrigar o hedger a "rolar" sua posição, ou seja, fechar sua posição nos contratos com vencimento em prazo menor e se reposicionar com contratos de prazo maior, enfrentando os riscos dessa operação.

A utilização de contratos futuros que não correspondem ao mesmo ativo que se deseja hedgear, pode obrigar o hedger a construir uma posição maior ou menor no mercado futuro que a posição no mercado à vista. Essa operação é chamada de hedge cruzado ou crosshedging.

A proporção da posição no mercado futuro relativa a exposição no mercado à vista é chamada de razão de hedge. Para entender essa relação, considere um portfólio composto de $C_{S}$ unidades do produto no mercado à vista e $C_{F}$ unidades de contratos no mercado futuro e sejam $S_{t}$ e $F_{t}$ os preços à vista e futuro no instante $t$, respectivamente. Quando uma estratégia de hedging é adotada, no mercado futuro, o retorno do portfólio será dado por:

$$
R_{h}=\frac{\left(C_{S} S_{t} R_{S}-C_{f} S_{t} R_{f}\right)}{C_{S} S_{t}}=R_{S}-h R_{f}
$$

onde:

$$
R_{S}=\frac{\left(S_{t+1}-S_{t}\right)}{S_{t}}
$$


e

$$
R_{f}=\frac{\left(F_{t+1}-F_{t}\right)}{F_{t}}
$$

O valor $h=\frac{C_{f} F_{t}}{C_{S} S_{t}}$ é denominado razão de hedge. A razão de hedge, pode assumir qualquer valor entre 0 e 1, e indica a porcentagem da produção que está hedgeada com instrumentos derivativos. Isso é, quanto mais próximo de 1 a razão de hedge estiver, menor o risco de preço do produtor, pois todo o prejuízo em um mercado será compensado em outro. Contudo no mercado futuro o hedge também limita o ganho de modo que existe um equilíbrio entre risco e retorno que precisa ser encontrado de acordo a tolerância a risco do produtor.

Algumas vezes a razão de hedge é abordada como sendo derivada da variação de preços ao invés de retornos. Neste caso o valor do portfólio protegido, e a razão de hedge, são respectivamente dados pelas equações 4.1.4 e 4.1.5.

$$
\begin{gathered}
\Delta V H=C_{S} \Delta S_{t}-C_{f} \Delta F_{t} \\
H=\frac{C_{f}}{C_{S}}
\end{gathered}
$$

Onde $\Delta V H$ é variação de valor do portfólio protegido, $H$ é a razão de hedge, $\Delta S_{t}=S_{t+1}-S_{t}$ e $\Delta F_{t}=F_{t+1}-F_{t}$. É importante notar que tanto o ganho quanto a perda com contratos futuros não tem limites, ou seja, o lucro ou prejuízo depende apenas da diferença entre os preços à vista e futuro ao final da operação.

Para se obter uma estratégia de proteção ótima é preciso escolher a razão de hedge ótima, cujo valor depende da medida de utilidade utilizada.

A razão de hedge pode ser estática ou dinâmica. A razão de hedge é estática se ela permanecer a mesma durante todo o período de análise. Chen, Lee e Shresta (2003) dividem a razão de hedge estática em oito categorias. A razão de hedge é dinâmica se ela se alterar durante o período de análise. Essa abordagem envolve o cálculo da razão de hedge baseado em informações condicionais. 


\subsubsection{Seleção de Portfólio}

Em geral os modelos de seleção de portfólio buscam minimizar alguma medida de risco, obedecendo uma série de restrições. De acordo com a medida de risco empregada e com a estrutura do conjunto de pontos viáveis, $X$, o modelo resultante pode ser mais ou menos complexo. Em linhas gerais objetiva-se:

$$
\begin{aligned}
& \min _{x \in X} \operatorname{Risco}(x) \\
& X=\left\{x \in \mathbb{R}^{n} \mid A x \leq b\right\}
\end{aligned}
$$

Esta seção apresenta dois modelos clássicos de seleção de portfólio, o primeiro, criado em 1952 por Markowitz, utiliza como medida de risco a variância, enquanto o segundo modelo, proposto por Rockafellar e Uryasev (2002) e aperfeiçoado por Di Clemente (2002), utiliza o CVaR (Conditional Value at Risk), como medida de risco. Também é discutido o VaR (Value at Risk) como medida de risco.

4.1.2.1 Modelo de Markowitz e a minimização do valor em risco

O modelo de seleção de portfólio mais disseminado é o modelo apresentado por Markowitz (1952). De uma maneira resumida, o modelo de Markowitz, utilizando estimativas dos retornos e variâncias dos ativos, determina um portfólio com o mínimo risco possível para um dado retorno esperado.

O portfólio de mínimo risco, ou mínima variância para um dado retorno $G$, é dado por:

$\min _{w} w^{\prime} \Sigma w$

com restrições:

$$
\sum_{i=1}^{n} w_{i} r_{i} \geq G
$$


$\sum_{i=1}^{n} w_{i}=1$

$w_{i} \geq 0, i=1, \ldots, n$

onde $w$ é o vetor com a proporção de cada ativo da carteira e $\sum$ é a matriz de covariâncias entre os retornos dos ativos da carteira, sendo o produto vetorial $w^{\prime} \sum w$ a variância da carteira. As restrições 4.1 .8 e 4.1 .9 obrigam que a carteira gere um retorno mínimo $G$ e que todos os recursos sejam distribuídos entre os ativos.

É possível construir carteiras em que o risco da carteira é inferior ao do ativo de menor risco da carteira graças a formação de uma carteira com ativos de retorno negativamente correlacionados (Costa e Assunção, 2005).

Apesar de amplamente utilizada a variância possui deficiências. O primeiro problema está relacionado ao tratamento igualitário a desvios negativos ou positivos. Dessa forma ativos que possuem retornos acima da média ou abaixo da média são considerados como tendo risco semelhante. O segundo problema é que a variância não expressa as características das caudas das distribuição de probabilidade dos retornos. Assim sendo duas carteiras podem ter a mesma variância e gerarem perdas diferentes. Por fim, Duxbury e Summers (2004) evidenciam que os investidores não possuem aversão a variância e sim a possibilidade de perda.

Para medir o risco de perda é necessário analisar as caudas das distribuições de retorno (Ribeiro e Ferreira, 2005). Para You e Daigler (2009) a medida de risco mais popular e mais utilizada pelos agentes do setor financeiro é o Valor em Risco (VaR). O VaR representa a perda máxima do valor de um ativo ou carteira, em determinado período de tempo, com um determinado nível de confiança.

Considera-se o retorno $X$ como uma variável aleatória e $F$ a função de probabilidade acumulada da distribuição de perdas, em que (Quaranta e Zaffaroni, 2008):

$$
F(a)=P\{X \leq a\} \text { e } F^{-1}(b)=\min \{a: F(a) \geq b\}
$$

onde $\boldsymbol{b}$ é o percentil considerado e $\boldsymbol{a}$ é a perda máxima tolerada.

Dessa forma, o VaR poder ser definido como: 


$$
\operatorname{VaR}_{\beta}(X)=F^{-1}(\beta)
$$

onde $\boldsymbol{\beta}$ é o nível de confiança.

Apesar de suas qualidades o VaR também possui deficiências. Uma delas é que o VaR não analisa a cauda da distribuição (ou perda) após o valor máximo definido pelo nível de confiança. Ou seja, é possível encontrar dois ativos com o mesmo VaR porém um deles permite uma perda muito mais dispersa que o outro. Uma segunda deficiência do VaR, apresentada por Artzner et al. (1999), é que essa não é uma medida coerente de risco. Segundo os autores, o VaR não obedece o axioma da subaditividade, ou seja, que não é possível garantir que o risco resultante da soma de dois portfólios de risco $\operatorname{VaR}\left(X_{1}\right)$ e $\operatorname{VaR}\left(X_{2}\right)$ seja igual ou menor que a soma dos riscos individuais, $\operatorname{VaR}\left(X_{1}\right)+\operatorname{VaR}\left(X_{2}\right)$. Além disso, o VaR não é uma função convexa em relação à composição da carteira, o que dificulta a otimização na seleção de ativos (Ribeiro e Ferreira, 2005). Um modelo que utilize o VaR como medida de risco não seria capaz de considerar a dispersão da cauda da distribuição, ou seja, não seria sensível a caudas pesadas (fat tail).

\subsubsection{Modelo de Minimização de CVaR}

Uma terceira medida de risco, que não apresenta os problemas da variância e do VaR é chamada de CVaR (Conditional Value-at-Risk) ou ES (Expected Shortfall). O CVaR representa o valor médio da cauda da distribuição de retornos, para um dado período e nível de confiança. Desse modo o CVaR é a média das perdas da carteira superiores ao VaR. Além de ser uma medida coerente de risco (Artzner et al., 1999) o CVaR, quando utilizado em problemas de seleção de portfólios, possibilita o uso de técnicas de programação linear, o que simplifica expressivamente a resolução do modelo. De acordo com Fabozzi et al. (2007) o CVaR é definido pela expressão a seguir:

$$
\operatorname{CVaR}_{1-\beta}(x)=E\left(f(x, S) \mid f(x, S)>\operatorname{VaR}_{1-\beta}(x)\right)
$$


em que $f(x, S)$ representa a função de perda de um portfólio com variável de decisão $x \in \mathbb{R}^{n}$ e variável aleatória $S \in \mathbb{R}^{d}$. Do mesmo modo que definido no VaR, o nível de confiança é definido por $1-\beta$, comumente sendo adotado uma valor igual a $90 \%, 95 \%$ ou $99 \%$.

Supondo que todas as variáveis aleatórias sejam contínuas, a probabilidade que a função de perda não exceda um certo valor VaR, é dada pela equação 4.1.14.

$$
\mathrm{CVaR}_{1-\beta}(x)=(1-\beta)^{-1} \int_{f(x, S) \geq \operatorname{VaR}_{1-\beta}(x)} f(x, S) p(S) d S
$$

Rockafellar e Uryasev (2002) desenvolveram uma abordagem para determinar simultaneamente o $\mathrm{CVaR}$ e o VaR de um portfólio, resolvendo um problema de otimização, como segue:

$$
\min _{(x, \alpha)} F_{\beta}(x, \alpha)=\min _{(x, \alpha)}\left(\alpha+\frac{1}{(1-\beta)} \int_{f(x, S) \geq \operatorname{VaR}_{1-\beta}(x)}(f(x, S)-\alpha) p(S) d S\right)
$$

Rockafellar e Uryasev (2002) definem $m$ diferentes cenários que são obtidos como uma amostra da função de densidade de probabilidade $S=\left\{S_{1}, \ldots, S_{m}\right\}$, ou através de simulação computacional. Reescrevendo a equação 4.1 .15 considerando cenários, tem-se:

$$
\min _{(x, \alpha)}\left(\alpha+\frac{1}{m(1-\beta)} \sum_{i=1}^{m} \max \left(f\left(x, S_{i}\right)-\alpha, 0\right)\right)
$$

Substituindo $\max \left(f\left(x, S_{i}\right)-\alpha, 0\right)$ por variáveis auxiliares $Y_{i}$, juntamente com as restrições adequadas, se obtém o problema de otimização, dado por:

$$
\min _{(X, \alpha)} \alpha+\frac{1}{m(1-\beta)} \sum_{i=1}^{m} Y_{i}
$$


com restrições:

$Y_{i} \geq 0, \quad \forall i \in\{1, \ldots, m\}$;

$Y_{i} \geq f\left(x, S_{i}\right)-\alpha, \forall i \in\{1, \ldots, m\}$

que pode ainda estar sujeito a outras restrições.

Desse modo se chega a um problema linear que pode ser resolvido de modo eficiente com técnicas de programação linear.

\subsubsection{Otimização Robusta}

Ainda que os algoritmos de otimização permitam que se resolva uma grande variedade de problemas, as soluções ótimas produzidas podem ser muito sensíveis a pequenas flutuações nas entradas (parâmetros) do modelo, uma vez que parâmetros obtidos a partir de dados reais são raramente certos ou precisos. Para Ben-Tal e Nemirovski (2000) pequenos erros nos dados podem fazer com que a resposta seja altamente não factível.

O método de tratamento de incertezas em parâmetros mais antigo é a análise de sensibilidade. Essa análise permite ao usuário determinar as faixas de variação dos parâmetros que mantém a solução ótima encontrada. Contudo a técnica testa apenas um parâmetro por vez, enquanto mantém os demais fixos.

Outros métodos incorporam a incerteza diretamente durante o cálculo da solução ótima. Métodos de programação estocástica, por exemplo, representam os dados incertos através da geração antecipada de cenários: a programação estocástica linear tradicional encontra uma solução ótima que produz o melhor valor médio da função objetivo considerando todos os cenários.

Para Fabozzi et al. (2007) um grande problema com as formulações de programação estocástica é que, na prática muitas vezes é difícil obter informações detalhadas sobre as distribuições de probabilidade das incertezas no modelo. Ao mesmo tempo, dependendo do número de cenários envolvidos, os métodos de programação estocástica podem ser proibitivamente caros computacionalmente.

Ainda de acordo com Fabozzi et al. (2007) métodos de otimização robusta surgiram como uma alternativa computacional atraente aos métodos de programação estocástica. Eles tratam a incerteza como deterministica, mas não 
limitam os valores dos parâmetros a estimativas pontuais. A otimização robusta trata problemas determinados para os quais a solução permanece viável para quaisquer valores dos parâmetros incertos em conjuntos de incerteza pré-especificados. Quando os conjuntos de incerteza têm formas especiais, o problema de otimização robusta resultante pode ser resolvido de forma eficiente. A otimização robusta faz suposições relativamente gerais sobre as distribuições de probabilidade dos parâmetros incertos, a fim de trabalhar com formulações que são mais tratáveis computacionalmente.

No problema clássico de otimização parte-se de uma função objetivo e restrições, todas exatamente conhecidas e cuja otimização levará a um valor exato. A otimização robusta constrói uma contrapartida ao problema, considerando o pior dos casos, através da definição de conjuntos para os parâmetros incertos, porém definindo esse cenário de modo inteligente para evitar o excesso de conservadorismo.

O problema clássico de otimização consiste em minimizar (ou maximizar) uma função objetivo, obedecendo a um conjunto de restrições, ou seja,

$$
\begin{array}{cl} 
& \min f(x) \\
\text { s.t. } & g(x) \leq 0 \\
& h(x)=0
\end{array}
$$

Quando escrito em função dos parâmetros tem-se que as funções $f(),. g($. e $h($.$) podem ser escritas em função dos parâmetros que as definem, ou seja,$ $\min f(x, \alpha)$.

As incertezas podem estar presentes nas restrições de desigualdade $g(x, \alpha)$, de igualdade $h(x, \alpha)$ ou ainda na função objetivo $f(x, \alpha)$, sendo que $\alpha$ representa a incerteza nos parâmetros e $x$ a variável de decisão.

Para Rustem e Howe (2002) a definição da contraparte robusta parte do conceito minimax, ou seja, a minimização da perda máxima possível. Sendo assim, para definir a contraparte robusta a função $f(x, \alpha)$ com incertezas $\alpha$ que podem oscilar num conjunto $\Omega$, chega-se ao problema: $\min _{\mathrm{x}} F(x, \alpha)$ em que $F(x, \alpha)=$ $\max _{\alpha}\{f(x, \alpha)\}$. 
No caso em que $\Omega$ é um conjunto discreto, onde existe um número finito, $m$, de cenários, considera-se $F(x, \alpha)=\max _{\alpha}\left\{f(x, \alpha) \mid \alpha \in\left\{\alpha_{1}, \ldots, \alpha_{m}\right\}\right\}$. Já para um conjunto $\Omega$ contínuo, por exemplo, em intervalo do tipo $\left[\alpha^{\prime}-\varepsilon, \alpha^{\prime}+\varepsilon\right]$, tem-se que $F(x, \alpha)=\max _{\alpha}\left\{f(x, \alpha) \mid \alpha^{\prime}-\varepsilon \leq \alpha \leq \alpha^{\prime}+\varepsilon\right\}$.

Esta seção é dedicada a apresentar o desenvolvimento de um modelo de otimização robusta para a solução do problema de seleção de portfólio. O foco é direcionado para a solução de Soyster (1973) e sua aplicação a seleção de portfólio considerando o CVaR como medida de risco, como já definido por Quaranta e Zaffaroni (2008) .

\subsubsection{O Modelo de Soyster}

Soyster (1973) propôs um modelo de otimização robusta que considera que os parâmetros incertos nas restrições podem ser definidos através de um intervalo fechado e simétrico, chamado de "caixa de incertezas", com centro no valor esperado. Soyster parte de um problema clássico de otimização linear,

$$
\max _{x} c^{\prime} x
$$

$$
\begin{array}{ll}
\text { s.t. } & A x \leq b \\
& x \geq 0
\end{array}
$$

onde $c \in \mathbb{R}^{n}, x \in \mathbb{R}^{n}, b \in \mathbb{R}^{n}, A=\left(a_{1}, \ldots, a_{N}\right) \operatorname{com} a_{j} \in \mathbb{R}^{n}$.

Assume-se que a matriz de restrições possua parâmetros com incertezas. Além disso considera-se que a única informação certa em relação ao valor real $a_{i j}$ do parâmetro relativo à linha $i$, coluna $j$, é que $a_{i j} \in\left[a_{i j}^{\prime}-s_{i}, a^{\prime}{ }_{i j}+s_{i}\right]$, sendo $a_{i j}^{\prime}$ o valor esperado para o parâmetro e $2 s_{i}$ a amplitude do intervalo, que mede a inexatidão do mesmo.

Soyster demonstrou que nestas condições a contraparte robusta é dada pelo seguinte:

$$
\max _{x} c^{\prime} x
$$


s.t. $\quad \sum_{j} a_{i j}^{\prime} x_{j}+\sum_{j} s_{i j} y_{j} \leq b_{i}, \quad \forall i$

$$
\begin{gathered}
-y_{j} \leq x_{j} \leq y_{j}, \quad \forall j \\
y \geq 0
\end{gathered}
$$

onde $x \in \mathbb{R}^{n}$ e é o vetor das variáveis de decisão do problema de otimização, $y \in \mathbb{R}^{n}$ e é o vetor das variáveis auxiliares utilizadas na resolução do problema, $a_{i j}^{\prime}$ é a estimativa para os parâmetros pertencentes à linha $i$, e coluna $j$ da matriz $A$ e $s_{i j}$ é a amplitude do intervalo definido de acordo com a inexatidão relativa ao parâmetro $a_{i j}$.

Quaranta e Zaffaroni (2008) empregaram a abordagem proposta por Soyster para modelar o problema de seleção de portfólio que considera o CVaR como medida de risco:

$$
\min _{(\alpha, w, Y, p)} \alpha+\frac{1}{(1-\beta)} \sum_{t=1}^{m-1} \frac{1}{m-1} Y_{t}
$$

com restrições:

$Y_{t} \geq \sum_{i=1}^{N}\left(S_{t-1, i}-S_{t, i}\right) w_{i}-\alpha$,

$\sum_{i=1}^{N} S_{i} w_{i}=\sum_{i=1}^{N} S_{i} q_{i}$

$\sum_{i=1}^{N} r_{i}^{\prime} w_{i}-\sum_{i=1}^{N} s_{i} p_{i} \geq G$,

$p_{i} \geq w_{i}$

$p_{i} \geq-w_{i}$

$Y_{t} \geq 0$

onde:

$i=1, \ldots, N$ : são os ativos que compõem o portfólio,

$t=1, \ldots, m$ : são os cenários considerados,

$\beta$ é o nível de confiança,

$G$ é o retorno mínimo exigido para o portfólio, 
$S_{t, i}$ é o preço corrente para o i-ésimo ativo no tempo $t$,

$q_{i}$ é a quantidade corrente para o i-ésimo ativo,

$r_{i}$ é o retorno esperado para o i-ésimo ativo e é um valor incerto,

$\alpha$ é a variável que aproxima o valor em risco do portfólio ao nível de significância $\beta$, $Y_{t}$ são as variáveis que representam as perdas do portfólio maiores que $\alpha$ nos diversos cenários,

$w_{i}$ é a proporção do i-ésimo ativo no portfólio,

Note que a função objetivo a ser minimizada é o CVaR do portfólio, onde:

$$
C V a R=\alpha+\frac{1}{(1-\beta)} \sum_{t=1}^{m-1} \frac{1}{m-1} Y_{t}
$$




\subsection{Modelo de Decisão Proposto}

Como já apresentado no capítulo 1, o objetivo central do presente trabalho é propor um modelo para suporte a tomada de decisão dos produtores de produtos agrícolas que possuem a capacidade de diversificação.

O modelo deve determinar:

1. Proporção da matéria prima a ser destinada para a produção de cada um dos diversos subprodutos

2. Proporção da quantidade de cada subproduto disponível, a ser comercializada no instante $t$, ou estocada e vendida no instante $t+1$

3. Proporção da quantidade de cada subproduto disponível a ser protegida através de hedge no mercado futuro

O modelo também considera parâmetros incertos, restrições de produção, de capacidade de armazenamento e de nível de risco aceitável, adotando o CVaR como medida de risco.

Desse modo, o presente trabalho propõe um modelo de minimização do risco do produtor, em um único período. Primeiramente apresenta-se um modelo que não considera a incerteza nos parâmetros e em seguida sua contrapartida robusta. Por fim é apresentada uma aplicação da utilização do modelo no setor sucroalcooleiro Brasileiro e no setor de milho, etanol e biodiesel dos Estados Unidos.

\subsubsection{Modelo de Otimização Não Robusto}

O modelo proposto considera três tipos de decisão simultaneamente a partir da definição de um portfólio, que contém ativos negociados no mercado à vista, no mercado futuro e ativos estocados.

A primeira decisão refere-se a definição do mix de produção, ou seja, a divisão do produto de base nos diversos subprodutos. Se pressupõe que em um determinado instante $t$, o produtor possui a sua disposição certa quantidade de matéria prima, como cana-de-açúcar, soja ou milho, e deve determinar como essa quantidade deve ser dividida para produção de cada subproduto, considerando para isso os preços previstos, os custos de produção e o risco (CVaR) de cada 
subproduto no instante de tempo $t+1$, de modo a definir uma fronteira eficiente que permita ao produtor selecionar o par risco/retorno que lhe seja mais adequado.

A segunda decisão busca definir, para cada subproduto disponível em estoque ou no fim do processo produtivo, que proporção desse subproduto deve ser vendida no instante $t$ e que proporção deve estocada para ser vendida no instante $t+1$. A decisão considera o preço e os custos de produção de cada subproduto no instante $t$ e no instante $t+1$, assim como os custos de carregamento de cada subproduto no instante $t+1$. É importante notar que a venda do subproduto no instante $t$ não possui risco, uma vez que o preço e o custo são conhecidos. Já a estocagem do subproduto e venda no instante $t+1$ possui incerteza no preço de modo que esse risco precisa ser remunerado por um retorno em $t+1$ superior ao retorno em $t$ para que compense estocar.

O terceiro ponto a decidir refere-se a posição no mercado futuro de cada subproduto a fim de reduzir o risco de toda a operação. Para tanto é necessário considerar o preço futuro no instante $t$ para o próximo vencimento e o preço futuro no instante $t+1$, que de acordo com Geman (2005) é calculado através da seguinte equação:

$$
\widehat{F}_{j, t+1}=\hat{S}_{j, t+1} e^{(r-\hat{c}) T},
$$

onde $\widehat{F}_{j, t+1}$ é o preço futuro estimado do subproduto $j$ para o período $t+1, \hat{S}_{j, t+1}$ é o preço à vista previsto para o subproduto $j$ no período $t+1, r$ é a taxa livre de risco, $\hat{c}$ é o retorno de conveniência estimado do subproduto $j$ e $T$ é o tempo até o vencimento do contrato futuro. Vale lembrar que o retorno de conveniência $c$ é determinado pelo modelo de previsão de preços proposto no capítulo 4, assim como o próprio preço à vista $\hat{S}_{j, t+1}$, de modo que a estimativa do preço futuro é facilmente determinada.

É esperado que os preços do mercado futuro sejam correlacionados com o preços do mercado à vista, de modo que o produtor possa se posicionar vendido no mercado futuro e com isso reduzir seu risco de perda e consequentemente o retorno esperado para o portfólio. 
A qualidade do modelo de previsão de preços afeta diretamente o resultado de cada uma das três decisões tomadas pelo modelo de produção, comercialização, estocagem e hedge.

O modelo proposto é definido pelas equações de 4.2.3 a 4.2.16. O modelo considera um portfólio que como o modelo de Rockafellar e Uryasev (2002) e Di Clemente (2002), minimiza o CVaR (equação 4.2.3), tendo como restrição um retorno mínimo $R$ (equação 4.2.5). O modelo também define a razão de hedge considerando os contratos futuros na composição do portfólio.

O modelo obrigatoriamente utiliza as quantidades em uma mesma unidade, tanto para a matéria prima, como para os subprodutos, e geralmente essa unidade é ligada a matéria prima. Por exemplo, no caso do milho, os subprodutos, como o etanol, o milho, a farinha de milho e outros subprodutos podem ter suas quantidades medidas em quilogramas de milho. No caso da cana-de-açúcar, o açúcar, o etanol hidratado, o etanol anidro, o polietileno, e os outros possíveis subprodutos podem ter suas quantidades medidas em toneladas de cana-de-açúcar.

O modelo calcula o risco e o retorno através de proporções, que são as variáveis de decisão, como:

- proporção $v_{j}$ de uma quantidade de subproduto $j$, a ser vendida imediatamente. A quantidade disponível de cada de subproduto jé dada pela quantidade $Q_{j}$, recém processada, mais o estoque $S T_{j}$;

- proporção $w_{j}$ a ser transformada em cada subproduto $j$ a partir de uma certa quantidade de matéria prima $Q_{M P}$. Os subprodutos transformados só estarão disponíveis para venda no inicio do próximo período;

- proporção $s t_{j}$ de uma quantidade de subproduto $j$, a ser estocada e vendida no próximo período. A quantidade disponível de cada de subproduto jé dada pela quantidade $Q_{j}$, recém processada, mais 0 estoque $S T_{j}$, e

- proporção $h_{j}$ de uma quantidade de subproduto $j$ a ser protegida através de contratos futuros até o próximo período.

As proporções citadas fazem parte de uma quantidade total de matéria prima disponível $\left(Q_{\text {Total }}\right)$, não importando se essa quantidade advém da própria matéria prima $\left(Q_{M P}\right)$, ou de subprodutos disponíveis no fim do processo produtivo $\left(Q_{j}\right)$ ou nos 
estoques $\left(S T_{j}\right)$. A quantidade total de matéria prima $\left(Q_{\text {Total }}\right)$ em determinado instante $t$ é dada pela equação a seguir:

$$
Q_{\text {Total }}=Q_{M P}+\sum_{j=1}^{n}\left(Q_{j}+S T_{j}\right)
$$

onde $Q_{\text {Total }}$ é a quantidade total, em uma mesma unidade, $Q_{M P}$ é a quantidade de matéria prima, $Q_{j}$ é a quantidade do subproduto $j$, e $S T_{j}$ é a quantidade do subproduto $j$, disponível em estoque.

O hedge através de contratos futuros pode não ser possível pela inexistência de um mercado futuro para cada subproduto, nesse caso sugere-se utilizar crosshedge, ou seja, utilizar outro derivativo que tenha correlação suficientemente alta para permitir, mesmo que parcialmente, a proteção a variações indesejadas nos preços.

O modelo proposto é dado por:

$\min _{\alpha, w, Y} \alpha+\frac{1}{m(1-\beta)} \sum_{i=1}^{m} Y_{i}$

sujeito a

$$
\begin{aligned}
& Y_{i} \geq \sum_{i=1}^{m}\left(\sum_{j=1}^{n} \delta S_{j, i} w_{j, t+1}^{*}+\delta S_{j, i} s t_{j, t+1}+\delta F_{j, i} h_{j}\right)-\alpha \\
& r^{T} w \geq R \\
& v_{j, t}+s t_{j, t+1}=\frac{Q_{j, t}+S T_{j, t}}{Q_{\text {Total }, t}}, \forall j \in\{1, \ldots, n\} \\
& s t_{j, t+1} \leq \frac{C s t_{j}}{Q_{T o t a l, t}}, \forall j \in\{1, \ldots, n\} \\
& \sum_{j=1}^{n} w_{j, t+1}^{*}=\frac{Q_{M P, t}}{Q_{T o t a l, t}}, \forall j \in\{1, \ldots, n\} \\
& h_{j, t+1} \leq w_{j, t+1}^{*}+s t_{j, t+1}, \forall j \in\{1, \ldots, n\} \\
& Y_{i} \geq 0, \forall i \in\{1, \ldots, m\}
\end{aligned}
$$




$$
\begin{aligned}
& v_{j, t} \geq 0, \forall j \in\{1, \ldots, n\} \\
& w_{j, t+1}^{*} \geq 0, \forall j \in\{1, \ldots, n\} \\
& s t_{j, t+1} \geq 0, \forall j \in\{1, \ldots, n\} \\
& h_{j, t+1} \geq 0, \forall j \in\{1, \ldots, n\}
\end{aligned}
$$

O vetor de retornos médios esperados para cada ativo $r$ é da forma $r=$ $\left[\begin{array}{lllllll}r^{*} & \mid & \hat{r} & \widehat{r c} & \mid & \hat{f}\end{array}\right]$ em que $r \in \mathbb{R}^{4 n}$. O primeiro vetor $r^{*}$ representa as margens de lucro dos subprodutos no tempo $t$, o segundo vetor $\hat{r}$ representa as margens de lucro dos subprodutos vendidos no tempo $t+1$, o terceiro vetor $\widehat{r c}$ representa as margens de lucro dos subprodutos estocados e vendidos no tempo $t+1$, e o quarto e último vetor $\hat{f}$ representa os retornos dos preços do mercado futuro, entre $t$ e $t+$ 1. O vetor $r$, é apresentado pela equação 4.2.15.

$$
r=\left[\begin{array}{c}
r_{1, t}^{*} \\
\vdots \\
r_{n, t}^{*} \\
\hat{r}_{1, t+1} \\
\vdots \\
\hat{r}_{n, t+1} \\
\widehat{r c}_{1, t+1} \\
\vdots \\
\widehat{r c}_{n, t+1} \\
\hat{f}_{1, t+1} \\
\vdots \\
\hat{f}_{n, t+1}
\end{array}\right]=\left[\begin{array}{c}
\left(S_{1, t}-C_{1, t}\right) / S_{1, t} \\
\vdots \\
\left(S_{n, t}-C_{n, t}\right) / S_{n, t} \\
\left(\hat{S}_{1, t+1}-C_{1, t+1}\right) / \hat{S}_{1, t+1} \\
\vdots \\
\left(\hat{S}_{n, t+1}-C_{n, t+1}\right) / \hat{S}_{n, t+1} \\
\left(\hat{S}_{1, t+1}-C_{1, t+1}-C C_{1, t}\right) / \hat{S}_{1, t+1} \\
\vdots \\
\left(\hat{S}_{n, t+1}-C_{n, t+1}-C C_{n, t}\right) / \hat{S}_{n, t+1} \\
\left(\hat{F}_{1, t+1}-F_{1, t}\right) / F_{1, t} \\
\vdots \\
\left(\hat{F}_{n, t+1}-F_{n, t}\right) / F_{n, t}
\end{array}\right]
$$

Parâmetros do modelo:

$\beta$ é o nível de confiança;

$m$ é o número de cenários;

$n$ é o número de subprodutos;

$C s t_{j}$ é a capacidade de estocagem do subproduto $j$;

$\delta S_{j, i}$ é o retorno do preço à vista do subproduto $j$ para o cenário $i$;

$\delta F_{j, i}$ é o retorno do contrato futuro do subproduto $j$ para o cenário $i$;

$r_{j, t}^{*}$ é a margem de lucro do subproduto $j$ para o período $t$; 
$\hat{r}_{j, t+1}$ é a margem de lucro prevista para o subproduto $j$ no período $t+1$;

$\widehat{r c}_{j, t+1}$ é a margem de lucro prevista, com custo de carregamento, para o subproduto $j$ no período $t+1$;

$\hat{f}_{j, t+1}$ é o retorno futuro previsto do subproduto $j$ para o período $t+1$;

$S_{j, t}$ é o preço à vista do subproduto $j$ para o período $t$;

$\hat{S}_{j, t+1}$ é o preço à vista previsto para o subproduto $j$ no período $t+1$;

$C_{j, t+1}$ é o custo de produção do subproduto $j$, por um período;

$C C_{j, t}$ é o custo de carregamento do subproduto $j$ para o período $t$;

$F_{j, t}$ é o preço futuro do subproduto $j$ para o período $t, \mathrm{e}$

$\widehat{F}_{j, t+1}$ é o preço futuro estimado do subproduto $j$ para o período $t+1$.

As variáveis de decisão do modelo são:

$s t_{j, t+1}$ é a proporção do subproduto $j$, a ser estocado por um período;

$h_{j, t+1}$ é a proporção do subproduto $j$, a ser protegida no mercado futuro por um período;

$\alpha$ é o VaR ou valor em risco;

$Y_{i}$ é a variável auxiliar para o cenário $i$;

$w$ é uma matriz com variáveis de decisão, ou proporções;

$w_{j, t+1}^{*}$ é a proporção do subproduto $j$, a ser produzido no período $t+1$.

O vetor de proporções, ou variáveis de decisão $w$ também é composto de 4 vetores, sendo da forma $w=\left[\begin{array}{lllllll}v & \mid & w^{*} & \mid & s t & \mid\end{array}\right]$ em que $w \in \mathbb{R}^{4 n}$. O primeiro vetor $v$ representa as proporções de cada subproduto a ser vendida no tempo $t, 0$ segundo vetor $w^{*}$ representa as proporções de matéria prima a ser transformada em cada subproduto no tempo $t+1$, o terceiro vetor st representa as proporções de cada subproduto a ser estocada e vendida no tempo $t+1$, e o quarto vetor $h$ representa as proporções a serem protegidas no mercado futuro. O vetor $w$, é apresentado pela equação 4.2.16:

$w^{T}=\left[\begin{array}{llllllllllll}v_{1, t} & \cdots & v_{n, t} & w_{1, t+1} & \cdots & w_{n, t+1} & s t_{1, t+1} & \cdots & s t_{n, t+1} & h_{1} & \cdots & h_{n}\end{array}\right]$

onde $v_{j, t}$ é a proporção do subproduto $j$ a ser vendida no período $t$. 
A restrição que indica o limite máximo de estocagem é dada pela equação 4.2.7, onde a capacidade de estocagem $\left(C s t_{j}\right)$ é definida para cada subproduto $j . \mathrm{O}$ modelo, para garantir simplicidade, considera que a capacidade de estocagem constante.

Três restrições para as proporções são dadas pelas equações 4.2.6, 4.2 .8 e 4.2.9. A primeira restringe a proporção vendida $\left(v_{j, t}\right)$ e estocada $\left(s t_{j, t+1}\right)$ de cada subproduto $j$, de modo que essa represente exatamente a proporção de subproduto disponível, garantindo não se venda e estoque abaixo ou acima da quantidade disponível.

A segunda restrição de proporção garante que a soma das proporções de subprodutos a serem produzidos $\left(\sum_{j=1}^{n} w_{j, t+1}\right)$ não ultrapasse a proporção de matéria prima disponível $\left(Q_{M P, t} / Q_{\text {Total,t }}\right)$.

A terceira restrição garante que a posição a ser construída no mercado futuro $\left(h_{j, t+1}\right)$ não seja superior a proporção disponível de cada subproduto $\left(w_{j, t+1}+\right.$ $\left.s t_{j, t+1}\right)$. Essa restrição pode ser relaxada desde que existam evidências de um comportamento menos eficiente do mercado futuro, onde uma posição maior que a proporção disponível de cada subproduto possa compensar essa ineficiência. Esse tipo de situação pode ser mais comum no caso de crosshedge, e ela implica em avaliações de liquidez pela necessidade de reserva de margem.

A restrição dada pela equação 4.2 .14 ainda define que não é possível especular no mercado futuro, contudo novamente essa restrição pode ser revista pelo produtor dependendo das condições de mercado.

\subsubsection{Modelo de Otimização Robusta}

A contrapartida robusta para o modelo apresentado no item 1.2 impõe pequenas alterações nas restrições, a fim de considerar a incerteza inerente do modelo de previsão de preços. Essa incerteza é representada pelo desvio padrão do erro de previsão $(s)$, considerando uma janela temporal específica.

A incerteza é considerada sobre o retorno esperado do portfólio, na restrição dada pela equação 4.2.19, seguindo o modelo proposto por Soyster (1973), o que garante a linearidade e a simplicidade do problema. 
Para tal é necessário introduzir variáveis auxiliares $p \in \mathbb{R}$, a serem estimadas durante o processo de otimização, e mais duas restrições dadas pelas equações 4.2.20 e 4.2.21, que garantem a linearidade da contrapartida robusta.

$\min _{p, \alpha, w, Y} \alpha+\frac{1}{m(1-\beta)} \sum_{i=1}^{m} Y_{i}$

sujeito a

$Y_{i} \geq \sum_{i=1}^{m}\left(\sum_{j=1}^{n} \delta S_{j, i} w_{j, t+1}^{*}+\delta S_{j, i} s t_{j, t+1}+\delta F_{j, i} h_{j}\right)-\alpha$

$r^{T} w-s^{T} p \geq R$

$\boldsymbol{p}-\boldsymbol{w} \geq \mathbf{0}$

$\boldsymbol{p}+\boldsymbol{w} \geq \mathbf{0}$

$v_{j, t}+s t_{j, t+1}=\frac{Q_{j, t}+S T_{j, t}}{Q_{\text {Total }, t}}, \forall j \in\{1, \ldots, n\}$

$s t_{j, t+1} \leq \frac{C s t_{j}}{Q_{\text {Total }, t}}, \forall j \in\{1, \ldots, n\}$

$\sum_{j=1}^{n} w_{j, t+1}^{*}=\frac{Q_{M P, t}}{Q_{\text {Total }, t}}, \forall j \in\{1, \ldots, n\}$

$h_{j, t+1} \leq w_{j, t+1}^{*}+s t_{j, t+1}, \forall j \in\{1, \ldots, n\}$

$Y_{i} \geq 0, \forall i \in\{1, \ldots, m\}$

$v_{j, t} \geq 0, \forall j \in\{1, \ldots, n\}$

$w_{j, t+1}^{*} \geq 0, \forall j \in\{1, \ldots, n\}$

$s t_{j, t+1} \geq 0, \forall j \in\{1, \ldots, n\}$

$h_{j, t+1} \geq 0, \forall j \in\{1, \ldots, n\}$ 
Em que $s$ é um vetor de $\mathbb{R}^{4 n}$ com medidas de incerteza relativas a cada retorno da matriz r. Essa incerteza, no modelo proposto, é representada pelo desvio padrão da previsão dos preços um período a frente, e $p$ também é um vetor de $\mathbb{R}^{4 n}$ com as variáveis auxiliares advindas do modelo de Soyster (1973).

O vetor $s$ é da forma $s=\left[\begin{array}{lllllll}0 & \mid & s^{*} & \mid & s^{*} & \mid & s^{*}\end{array}\right]$ com $s \in \mathbb{R}^{4 n}$. O primeiro vetor é formado por $n$ zeros, pois não existe incerteza associada ao preço à vista no tempo $t$, uma vez que esses preços são conhecidos. Já os outros três vetores possuem a mesma incerteza oriunda do modelo de previsão. As incertezas são as mesmas nos três vetores, pois a formação das margens de lucro, como indicado pela equação 4.2.15, utilizam os mesmos preços previstos pelo modelo de previsão, seja na determinação da margem de lucro no tempo $t+1$, seja na determinação da margem de lucro diminuída do custo de carregamento ou ainda na determinação do retorno no mercado futuro, uma vez que o preço futuro em $t+1$ é definido a partir da previsão do preço em $t+1$, como indicado pela equação 4.2.1. 


\subsection{Aplicação do Modelo}

Foram realizadas duas simulações. Uma utilizando dados do mercado de milho, etanol e biodiesel norte-americano e outra com base em dados do mercado sucroalcooleiro brasileiro.

Dois momentos econômicos reais foram escolhidos para evidenciar características do modelo de decisão proposto, sendo sempre os resultados comparados com os resultados de um modelo não robusto.

Os melhores resultados encontrados foram obtidos no mercado norteamericano, onde existe forte correlação entre os mercados à vista e futuros, o que gera boas previsões de preços assim como boa eficácia das estratégias de hedge. $\mathrm{O}$ mercado de milho, etanol e biodiesel dos Estados Unidos conta ainda com possibilidade de gerar estratégias de hedge com contratos futuros de milho, etanol e petróleo.

Para o mercado sucroalcooleiro brasileiro os resultados foram menos promissores por motivos que serão discutidos adiante, mas entre eles está o fato de se utilizar contratos futuros de açúcar de outro país para hedgear tanto o açúcar quanto o etanol.

Entre os momentos econômicos escolhidos foram priorizados aqueles em que a incerteza pudesse modificar a decisão do modelo não robusto, por exemplo, onde as margens e níveis de risco fossem de magnitudes próximas seria esperado que a incerteza alterasse as decisões que envolvessem o uso do preço previsto calculado pelo Filtro de Kalman, reduzindo as posições que considerassem essa informação.

Momentos econômicos em que as incertezas de previsão afetam a decisão foram facilmente encontrados para o mercado de milho, etanol e biodiesel norteamericano, o mesmo não ocorrendo para o mercado sucroalcooleiro brasileiro. Em grande parte do período considerado para o caso brasileiro, as margens do açúcar superam em muito as margens do etanol e essa grande diferença de magnitude reduz o efeito da incerteza na decisão original. Além disso as decisões originais, geraram posições pouco dependentes dos preços previstos pelo Filtro de Kalman, o que também gera pouco de espaço de mudança para o modelo robusto.

Nos dois momentos econômicos escolhidos para o mercado norteamericano foram encontrados resultados muito diferentes entre a solução robusta e 
não robusta. Além da modificação das decisões de mix de produção foi possível verificar modificações no perfil de estocagem e hedge, sendo que o modelo robusto se mostrou capaz de controlar o risco através do mix de produção e dos estoques, enquanto o modelo não robusto o faz principalmente através de hedge.

No primeiro momento econômico para o mercado sucroalcooleiro brasileiro o modelo robusto encontrou uma solução que controlava o risco principalmente através dos estoques de etanol, ao invés do hedge, enquanto o modelo não robusto controlava o risco fundamentalmente através do hedge. Já para o segundo momento econômico não houve alteração nas decisões, pois a incerteza não alterava o binômio risco e retorno.

Em suma o modelo proposto pode se mostrar mais ou menos útil dependendo do mercado em que é aplicado e do momento econômico que esse mercado passa. Para o mercado norte-americano ficam evidentes os benefícios, do modelo proposto, de gerar decisões não triviais ou pouco intuitivas que minimizam o risco e a exposição à incertezas de previsão de preços. No caso do mercado sucroalcooleiro esses benefícios foram menos verificáveis, uma vez que o período analisado e o mercado apresentavam peculiaridades desfavoráveis.

4.3.1 Resultados com dados reais do mercado de milho, etanol e biodiesel dos Estados Unidos

No caso do mercado de milho, etanol de milho e biodiesel os preços e quantidades foram convertidos de forma a serem expressos na base bushel de milho. O bushel é uma medida inglesa de volume equivalente a 35,24 litros. Os preços foram convertidos para US $\$$ /bushel de milho utilizando os fatores de conversão do National Biodiesel Board, como indicado na Tabela A.1 do Anexo 1.

O modelo proposto utiliza as margens de lucro, calculadas utilizando os preços de mercado e os custos de produção. Os custos de produção do milho foram obtidos através dos relatórios Purdue Crop Cost \& Return Guide, emitido anualmente pela Purdue University do estado de Indiana nos Estados Unidos. Os custos de produção para o etanol de milho e o biodiesel foram fornecidos pelo Centro de Agricultura e Desenvolvimento Rural da Universidade do Estado de lowa (CARD Center for Agricultural and Rural Development / lowa State University), esses custos 
são separados em custos com matérias primas e outros custos operacionais, o que permite avaliar o ganho de margem com a produção de etanol e biodiesel.

Os preços previstos foram obtidos a partir de um modelo de previsão simplificado, contendo somente o Filtro de Kalman e sem as redes neurais. Como entrada do modelo foram utilizadas 30 observações de dados mensais de preços à vista do milho, do etanol anidro e do biodiesel B100 FOB Midwest, e preços futuros do milho, do etanol anidro e do petróleo (WTI) para o primeiro vencimento, de Março de 2009 a Agosto de 2011, obtidos da bolsa de mercadorias Chicago Board of Trade (CBOT). Todos os preços foram obtidos e mantidos em dólares americanos.

O modelo do Filtro de Kalman utilizou o preço futuro do milho como variável observável para a previsão do preço do milho à vista um período a frente, da mesma forma o preço do etanol anidro futuro foi utilizado na previsão do preço à vista do etanol anidro e o preço do petróleo futuro foi utilizado como variável observável para a previsão do preço do biodiesel B100, uma vez que ainda não existe mercado futuro com liquidez para o biodiesel.

A Tabela A.2 do Anexo 1 apresenta as diversas medidas de erro para 0 modelo do filtro de Kalman e para o modelo de Base que considera o preço em $t+1$ igual ao preço no período $t$. Todas as medidas de erro foram consideravelmente reduzidas pelo modelo do filtro de Kalman, em comparação com o modelo de base, para a previsão de preços à vista de todos os produtos.

Devido a dificuldade de encontrar informações confiáveis a respeito dos custos de estocagem, pelo período de um mês, do milho, do etanol de milho e do biodiesel, esses foram estimados em cerca de $2,6 \%, 4.7 \%$ e $4,1 \%$ do preço à vista de cada um dos produtos.

Também no caso Americano as quantidades disponíveis dos produtos, nesse caso, milho, etanol e biodiesel em estoque, e recém transformados foram definidas de modo a simplificar a interpretação dos resultados.

Dois momentos históricos foram escolhidos para representar comportamentos distintos de acordo com alterações nas relações de retorno e incerteza de previsão. A figura 4.3.1 apresenta algumas das margens de lucro líquidas utilizadas no modelo, assim como os momentos históricos selecionados para teste do modelo. 
Margens Líquidas

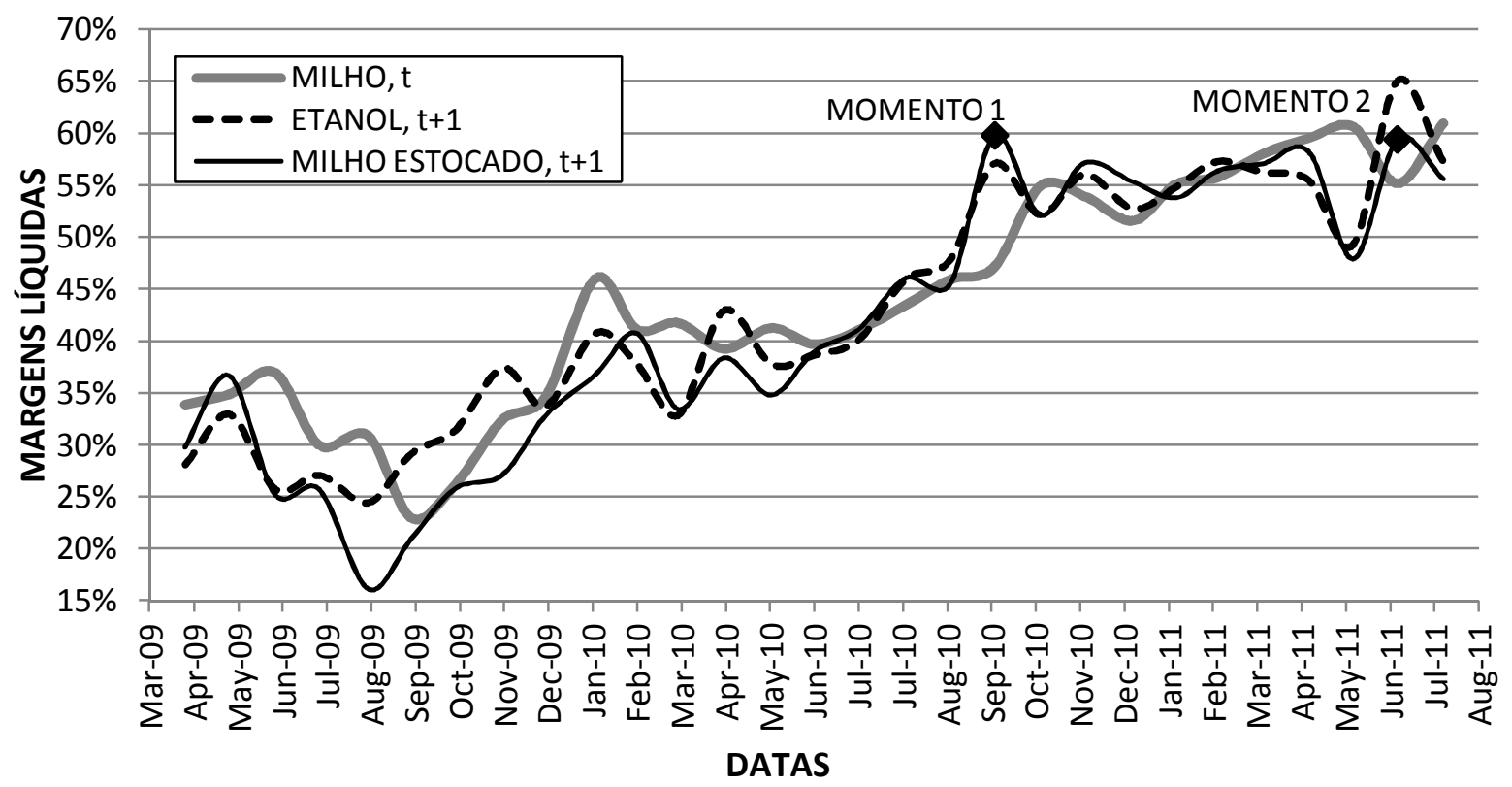

Figura 4.3.1 - Margens de lucro previstas e momentos escolhidos

O momento histórico 1, ocorrido em Outubro de 2010, apresenta uma situação onde a margem prevista obtida com a venda do milho estocado até Novembro supera a margem prevista para o etanol produzido em Outubro e vendido e Novembro, que por sua vez supera a margem obtida com a venda do milho disponível no mercado à vista em Outubro. É esperado que o modelo não robusto decida por estocar milho, e produzir etanol para venda do milho estocado e do etanol produzido no mês seguinte.

O momento histórico 2, ocorrido em Julho de 2011, apresenta uma situação onde a margem prevista para a produção do etanol no mês corrente e venda no mês seguinte supera a margem prevista para a estocagem do milho disponível e venda no mês seguinte e novamente a opção de vender o milho disponível no mercado à vista no mês corrente é a opção menos rentável, apesar de menos arriscada.

Uma peculiaridade da produção de biodiesel a partir do etanol de milho é que a produção de óleo de milho é praticamente inerente ao processo de produção de etanol, de modo que os custos adicionais para a produção de biodiesel são muito baixos, fazendo com que o ganho marginal seja sempre positivo e a margem com a produção de biodiesel a partir do etanol de milho seja sempre elevada. Um detalhe importante do processo é que não faz sentido para o produtor desse setor produzir apenas biodiesel, pois nesse sentido os custos seriam muito elevados e a produção 
relativamente pequena, uma vez que o milho não é a semente oleaginosa de primeira escolha para a produção de biodiesel. Sendo assim, na prática, quando o produtor possui instalações preparadas para tanto, sempre que houver a decisão de produzir etanol o biodiesel será produzido também como um subproduto, afetando positivamente a margem, o que obviamente afetará a decisão do produtor em manter o milho em natura ou transformá-lo em biocombustíveis.

Durante a simulação a determinação do CVaR é feita de forma discreta através da escolha de cenários históricos, e portanto a sua magnitude pode variar bastante dependendo dos cenários históricos escolhidos. No caso dos dados do mercado dos Estados Unidos 30 meses passados foram selecionados para os $\mathrm{m}$ cenários da equação 4.1.16. A seleção desses 30 meses foi especialmente complexa, devido ao cenário econômico peculiar precedente aos cenários de Outubro de 2010 e Julho de 2011, pois o efeito da crise de crédito de 2008 ainda estariam presentes no processo de decisão e portanto não seria conveniente considerar data anteriores a Julho de 2008.

No caso do mercado americano o comportamento do mercado futuro, seja de milho, de etanol ou de petróleo, tem forte correlação com seus respectivos mercados à vista, o que simplifica a construção de estratégias de hedge para esses produtos.

Os retornos e incertezas que formam os vetores $\boldsymbol{r}$ e $\boldsymbol{S}$, da equação 4.2.19, são apresentados nas tabelas A.3 e A.4 do Anexo 1 respectivamente. As incertezas foram obtidas a partir da previsão feita pelo Filtro de Kalman, e calculadas considerando os desvios padrões de uma janela de 5 meses.

As quantidades disponíveis, para cada subproduto, no final do processo e em estoque, a quantidade disponível de matéria prima, a capacidade de estoque para cada subproduto e quantidade total de produto disponível em uma mesma unidade, são apresentadas na Tabela A.5 do Anexo 1. Esses valores foram escolhidos arbitrariamente, pois não é foco tratar uma situação específica de um produtor real, e sim avaliar o modelo para uma situação genérica. 


\section{MOMENTO 1: Dados dos EUA}

Para o momento histórico 1, foi possível traçar a fronteira eficiente, na qual é possível determinar o retorno máximo para um determinado nível de risco (CVaR), e é esperado que quanto maior for o risco tolerado maior seja o retorno possível.

A fronteira eficiente para o momento histórico 1 está representada pela Figura 4.3.2, e possui forma adequada, apresentando maiores retornos para maiores exposições ao risco. A solução robusta apresentou retornos relativamente menores para os mesmos níveis de riscos, se comparados aos retornos da solução não robusta.

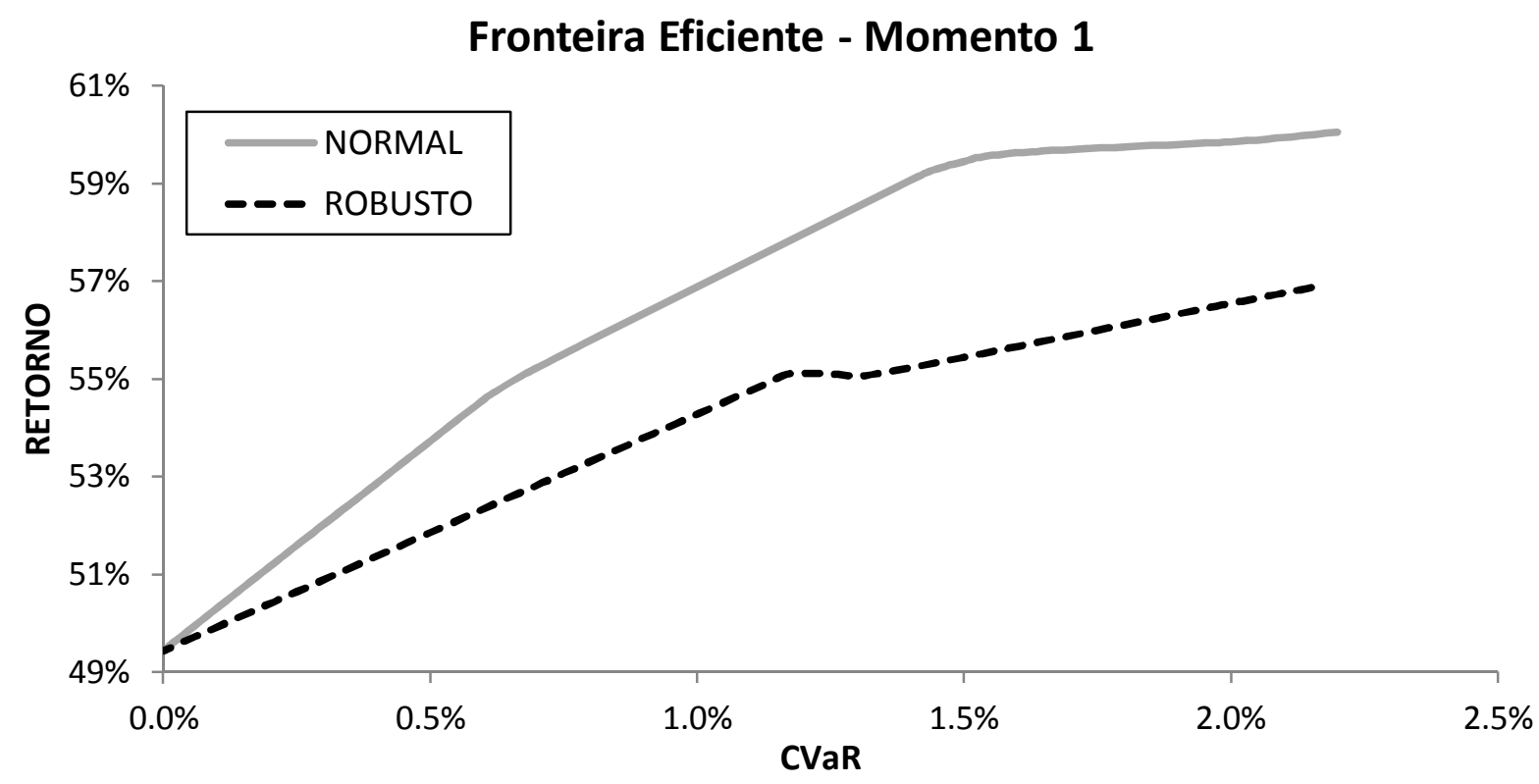

Figura 4.3.2 - Fronteira eficiente no momento 1 - dados reais EUA

Os gráficos de produção, estocagem e hedge de subprodutos, apresentados a seguir, variam de zero a 100\%, indicando, por exemplo, que a decisão de mix de produção direcionou $100 \%$ da matéria prima disponível para a produção de um determinado subproduto, ou então que a decisão de estocagem direcionou $0 \%$ aos estoques, ou seja, $100 \%$ do subproduto disponível foi vendido no mercado à vista.

\section{Decisão 1: Mix de Produção (Momento 1 - EUA)}

O mix de produção no caso do mercado de milho, etanol e biodiesel, define qual destino dar ao milho disponível na data corrente. Esse milho pode ser 
convertido em etanol mais biodiesel, ser vendido no mercado à vista, ou ainda estocado e vendido no mercado à vista um mês a frente.

As figuras 4.3.3 e 4.3.4 mostram as relações risco e incerteza pelo retorno, evidenciando que para o momento 1 , as incertezas mantém as mesmas relações de ordem que o risco. Chamamos de incerteza o desvio padrão do erro de previsão resultante do filtro de Kalman. Nas figuras $r_{C, t}^{*}$ representa a margem de lucro com a venda do milho no mercado à vista na data corrente, e obviamente essa estratégia não apresenta risco de mercado nem incerteza oriunda do modelo de previsão de preços. A sigla $\hat{r}_{E+B, t+1}$ representa a margem de lucro com a transformação do milho disponível em Etanol e Biodiesel e venda no período seguinte, e como essa margem está sujeita a variação de preços no próximo mês foi estimada pelo modelo de previsão de preços ela possui risco e incerteza. Da mesma forma a sigla $\widehat{r c}_{C, t+1}$ representa a margem de lucro com a estocagem do milho e venda um mês a frente, o que novamente apresenta risco de mercado e incerteza, pois depende da estimativa de preço do milho no futuro advinda do modelo de previsão por Filtro de Kalman.

Relação Risco e Retorno

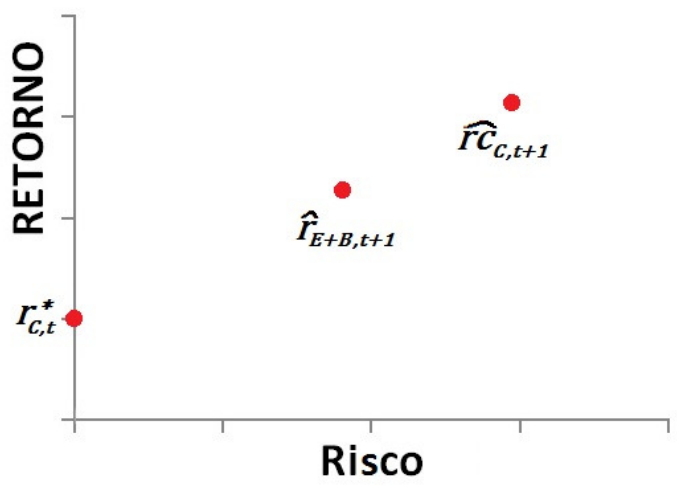

Figura 4.3.3 - Relação risco e retorno no momento 1 - dados EUA
Relação Incerteza e Retorno

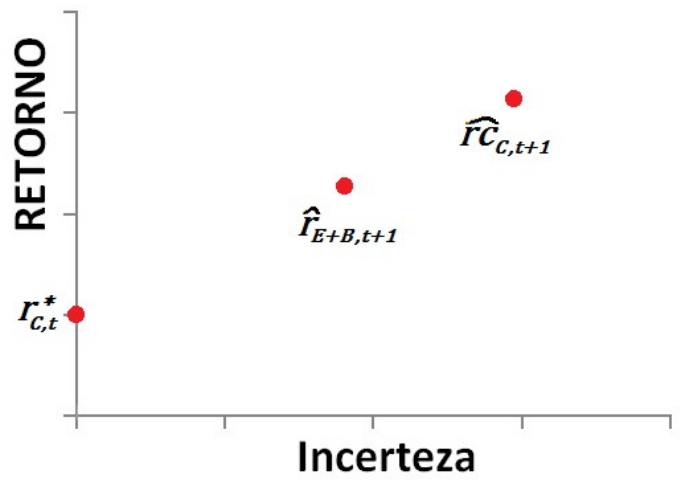

Figura 4.3.4 - Relação incerteza e retorno no momento 1 - dados EUA

Dada essas condições, onde a incerteza não afeta a relação risco retorno é esperado apenas que o modelo robusto busque reduzir as posições que dependam das estimativas do modelo de previsão de preços. É esperado que essa modificação reduza o retorno do portfólio, mas que reduza também a incerteza. A redução no retorno médio do portfólio, para o modelo robusto pode ser verificada através da fronteira eficiente da Figura 4.3.2. 
Também é esperado que a produção de etanol e biodiesel no caso robusto seja menos interessante, como pode ser constatado nas figuras 4.3.5 e 4.3.6.

Como no caso do mercado americano a produção de biodiesel depende da produção de etanol, e as margens de produção de biodiesel são relativamente elevadas, os modelos não robusto e robusto, decidem sempre produzir o máximo possível de biodiesel sempre que houver produção de etanol, ver Figura 4.3.6.

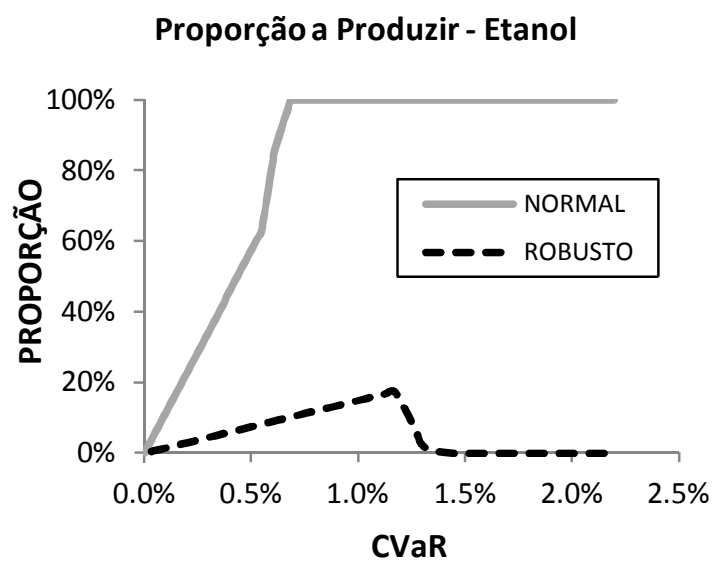

Figura 4.3.5 - Proporção a produzir de Etanol no momento 1 - dados EUA
Proporção a Produzir - Biodiesel

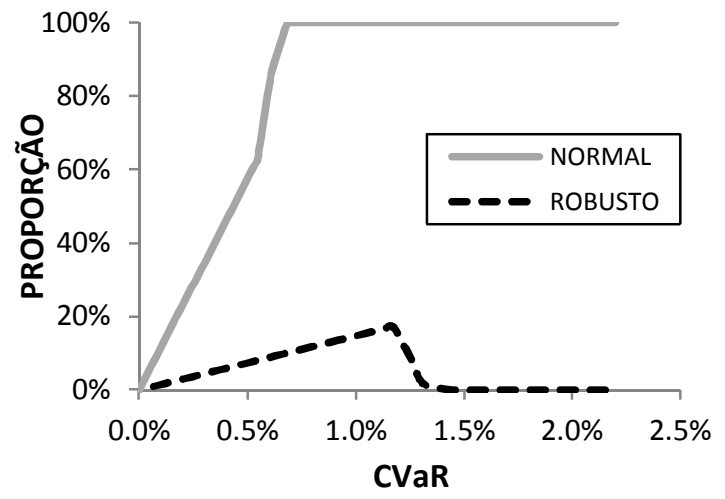

Figura 4.3.6 - Proporção a produzir de Biodiesel no momento 1 - dados EUA

É importante notar que quando a proporção de produção de etanol e biodiesel não atinge 100\%, isso indica que a quantidade que falta para atingir $100 \%$ é de milho a ser destinado a venda no mercado à vista ou destinado aos estoques para venda um mês a frente. Essa decisão é detalhada no próximo tópico.

\section{Decisão 2: Estocagem e Comercialização (Momento 1 - EUA)}

A decisão de estocagem e comercialização para o momento tem a finalidade de determinar o nível de estoque de cada produto, milho, etanol e biodiesel, dado que existe risco de mercado em se estocar os produtos. Por outro lado a decisão de estocagem também está sujeita a incerteza, uma vez que depende dos preços estimados pelo modelo de previsão de preços.

Como é possível notar pela tabela A.3 (em anexo) o retorno com a estocagem supera o retorno com a venda imediata dos produtos no período corrente. Desse modo a situação de menor risco e menor retorno será a de venda de 
$100 \%$ de todos os produtos disponíveis no período corrente. Dessa forma os estoques são a opção para estratégias mais arriscadas. O modelo robusto por sua vez buscará evitar os estoques para não expor o produtor à incerteza.

Nesse sentido é possível perceber que o modelo não robusto e robusto comportam-se como esperado.

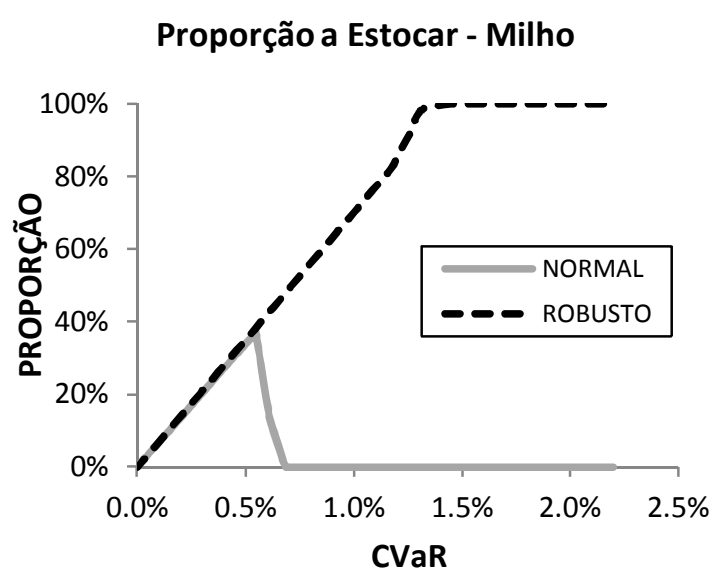

Figura 4.3.7 - Proporção a estocar de Milho no momento 1 - dados EUA Proporção a Estocar - Etanol

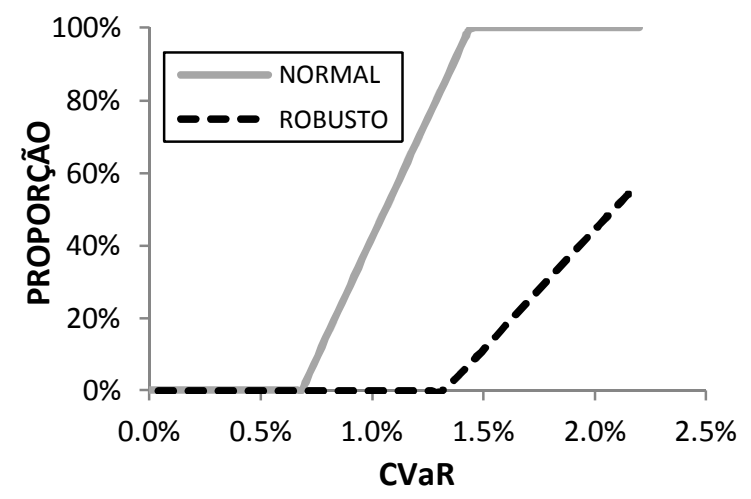

Figura 4.3.9 - Proporção a estocar de Etanol no momento 1 - dados EUA

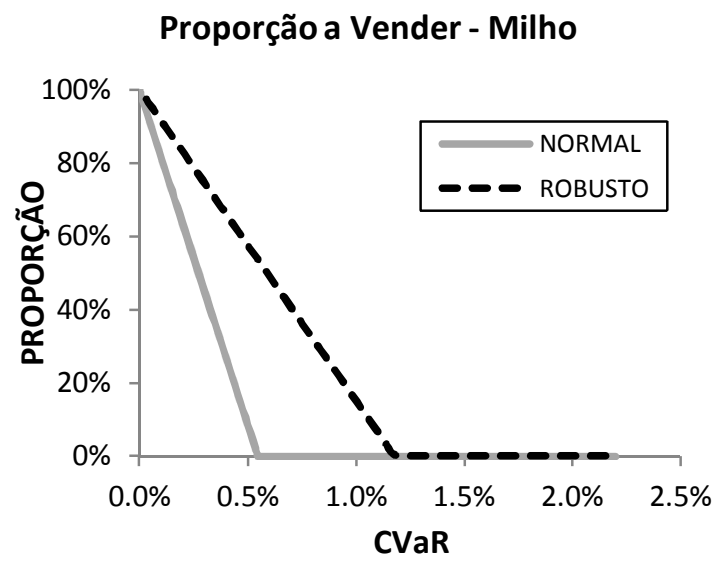

Figura 4.3.8 - Proporção a vender de Milho no momento 1 - dados EUA

$$
\text { Proporção a Estocar - Biodiesel }
$$

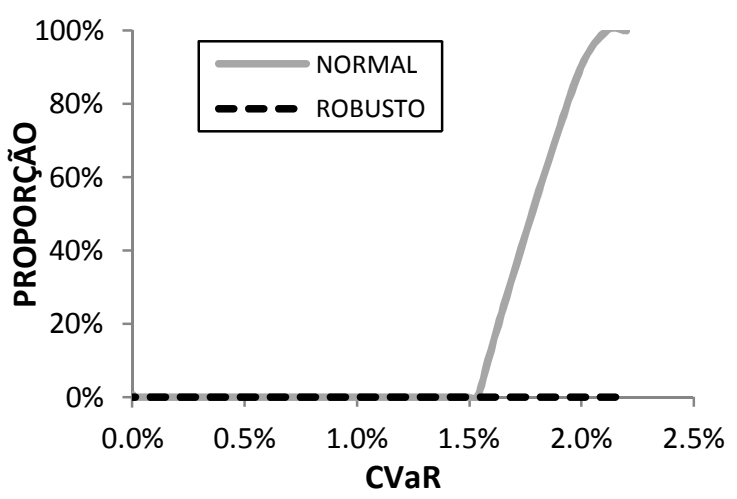

Figura 4.3.10 - Proporção a estocar de Biodiesel no momento 1 - dados EUA

A venda de milho no tempo atual t, é a decisão de menor risco possível e portanto, a decisão de se vender todo o milho possível quando se é intolerante a riscos pode ser vista na Figura 4.3.7.

Conforme a tolerância ao risco aumenta, os modelos robusto e não robusto, aumentam os estoques de milho, etanol e biodiesel para venda futura. É possível notar uma significativa diferença entre as decisões robusta e não robusta, uma vez 
que a incerteza de previsão afeta diretamente a decisão de estocagem, dessa forma, o modelo robusto costuma apresentar estoques menores que o modelo não robusto.

Uma exceção para esse fenômeno ocorre para o milho, pois para o milho disponível, existem três caminhos possíveis, venda no período corrente, estocagem ou transformação em etanol e biodiesel. Conforme a tolerância ao risco aumenta a contrapartida robusta indica que é melhor estocar milho que produzir etanol, o que é uma solução não intuitiva muito diferente da solução não robusta.

\section{Decisão 3: Hedge (Momento 1 - EUA)}

Por ainda não existir um mercado futuro com liquidez suficiente para o biodiesel, é possível utilizar o mercado futuro de petróleo, por sua alta correlação com o mercado de biodiesel.

O modelo proposto consegue utilizar os diferentes instrumentos de hedge disponíveis para cada produto, podendo até efetuar hedge cruzado, ou seja, utilizar derivativos de um produto para hedgear outro de modo não intuitivo, aproveitando situações de mercado que a primeira vista seriam difíceis de identificar.

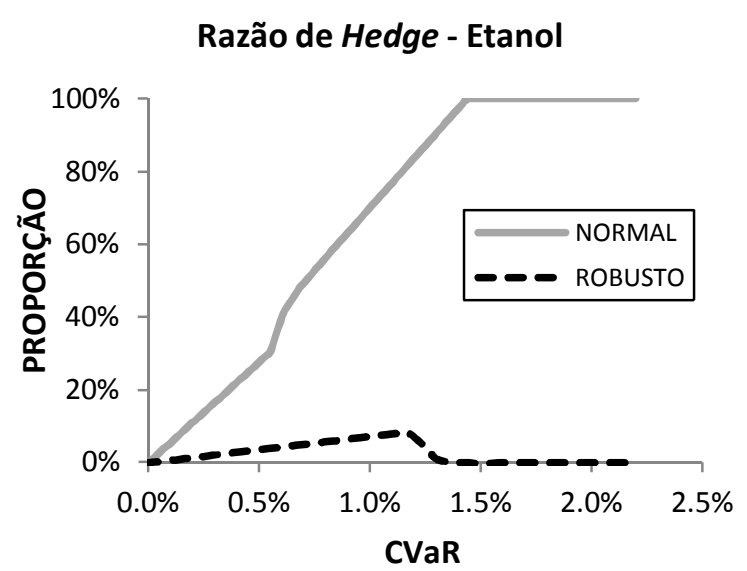

Figura 4.3.11 - Razão de hedge para o Etanol no momento 1 - dados EUA

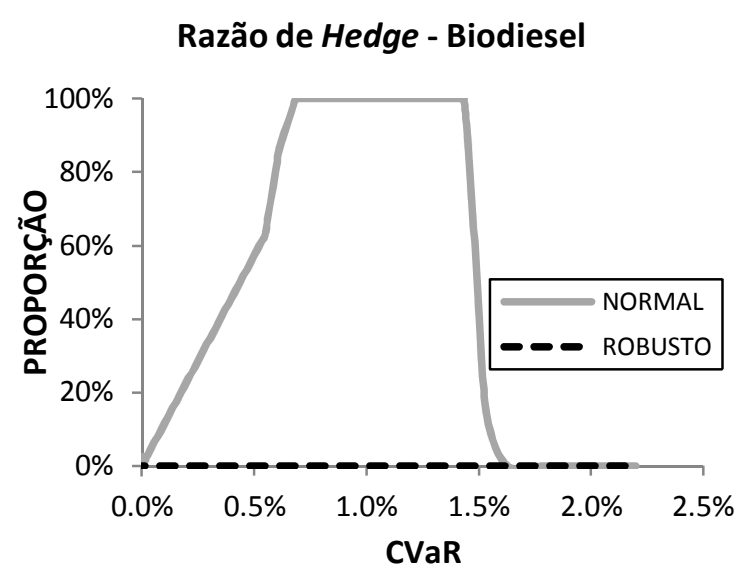

Figura 4.3.12 - Razão de hedge para o Biodiesel no momento 1 - dados EUA 


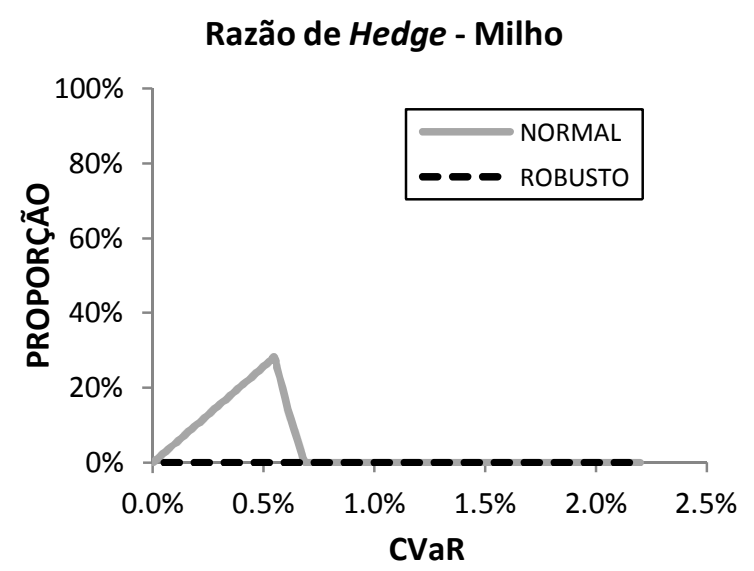

Figura 4.3.13 - Razão de hedge para o

Milho no momento 1 - dados EUA

Como esperado o modelo robusto apontou soluções onde os contratos futuros são evitados, pois os parâmetros de retorno dos contratos futuros estão sujeitos ao modelo de previsão de preços, ou seja, carregam incerteza. Desse modo o modelo robusto gerou uma solução sem a utilização de contratos futuros de milho e petróleo e somente manteve uma pequena porção de contratos futuros para o etanol, ver figuras 4.3.11, 4.3.12 e 4.3.13.

A quase não utilização de contratos futuros para mitigação do risco, tem implicações importantes, a primeira é a menor exposição à incerteza, a segunda uma redução no potencial de retorno de toda a operação e a terceira uma simplificação das operações financeiras.

\section{MOMENTO 2: Dados dos EUA}

A fronteira eficiente para o momento histórico 2 está representada pela Figura 4.3.14, e novamente apresenta maiores retornos para maiores exposições ao risco. Novamente a solução robusta gerou retornos relativamente menores para os mesmos níveis de riscos, se comparados aos retornos da solução não robusta. 


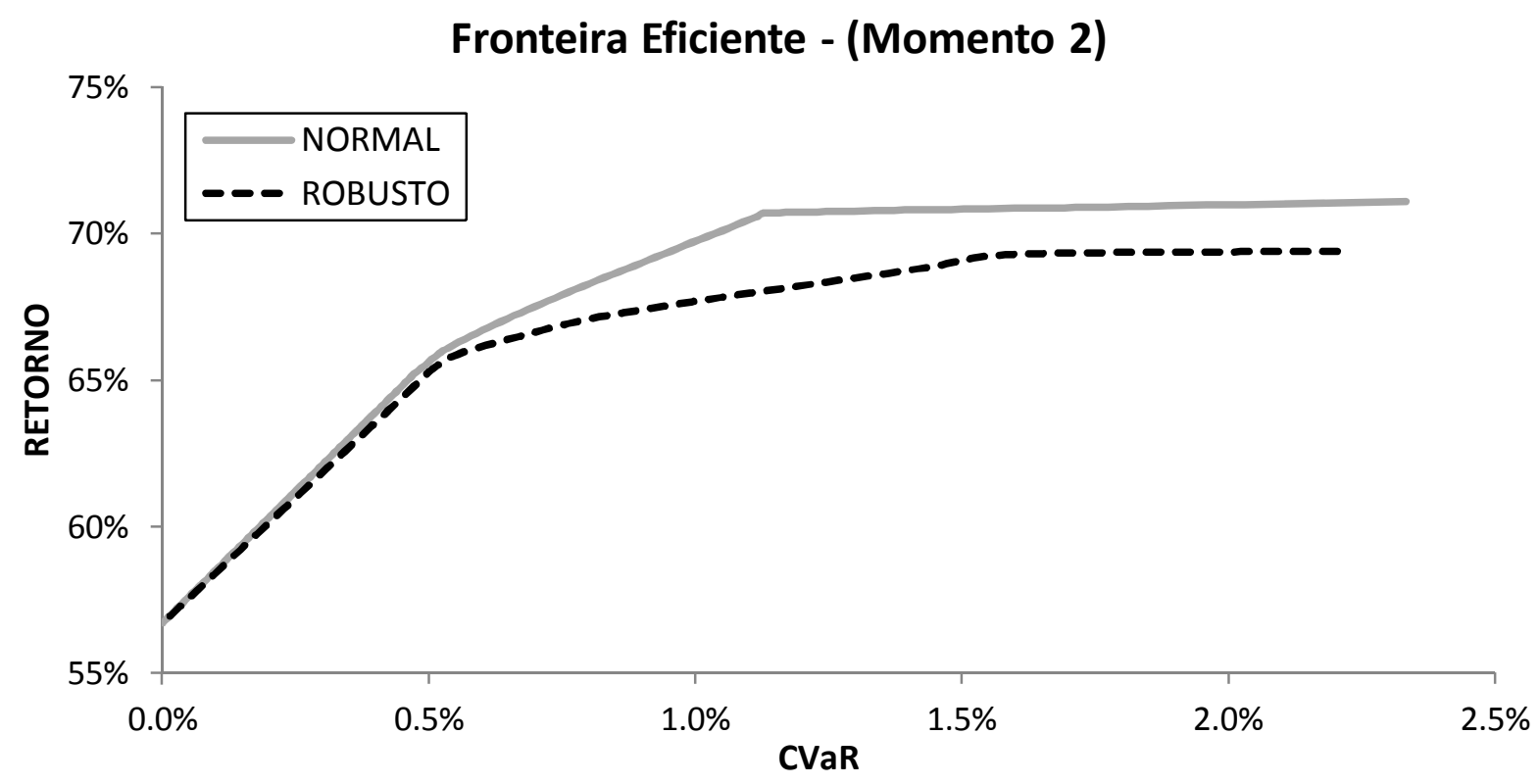

Figura 4.3.14 - Fronteira eficiente no momento 2 - dados reais EUA

\section{Decisão 1: Mix de Produção (Momento 2 - EUA)}

A decisão para divisão de produção para o momento 2 deveria ser aceita somente em situações de alta tolerância ao risco e à incerteza, pois apesar de o retorno com a produção de etanol e biodiesel serem elevados o risco e a incerteza associados a essa decisão também são muito elevados, como pode ser visto nas figuras 4.3.15 e 4.3.16.

Relação Risco e Retorno

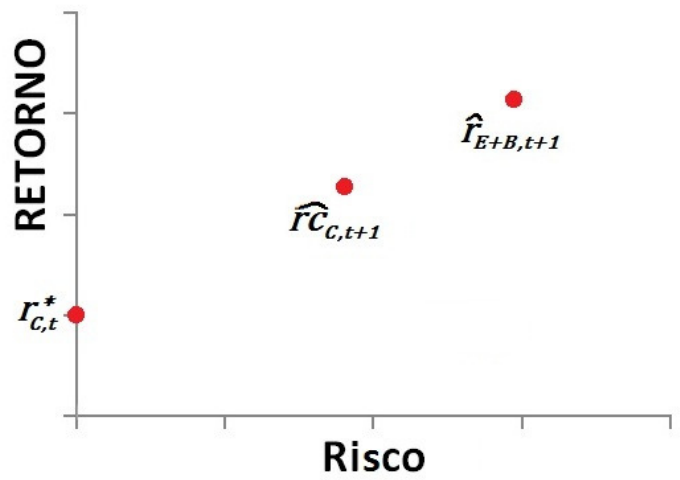

Figura 4.3.15 - Relação risco e retorno no momento 2 - dados EUA
Relação Incerteza e Retorno

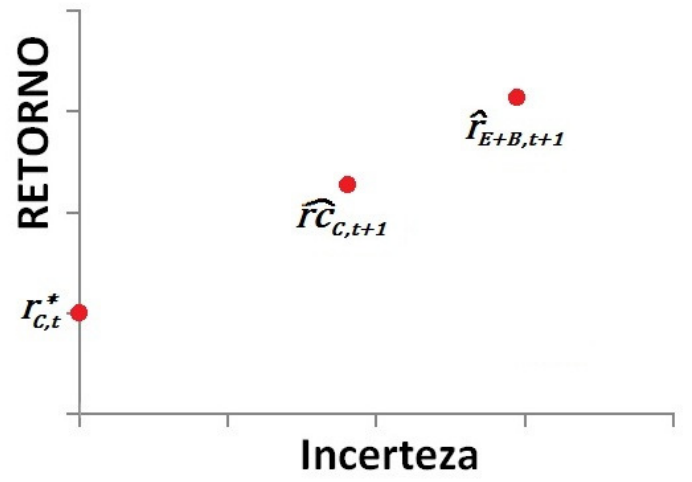

Figura 4.3.16 - Relação incerteza e retorno no momento 2 - dados EUA

Dessa forma a produção de etanol e biodiesel praticamente não é apontada como solução, como é possível ver nas figuras 4.3.17 e 4.3.18. É possível ainda 
notar que como existe incerteza associada a produção de etanol e biodiesel a solução robusta evitar ainda mais esse caminho.

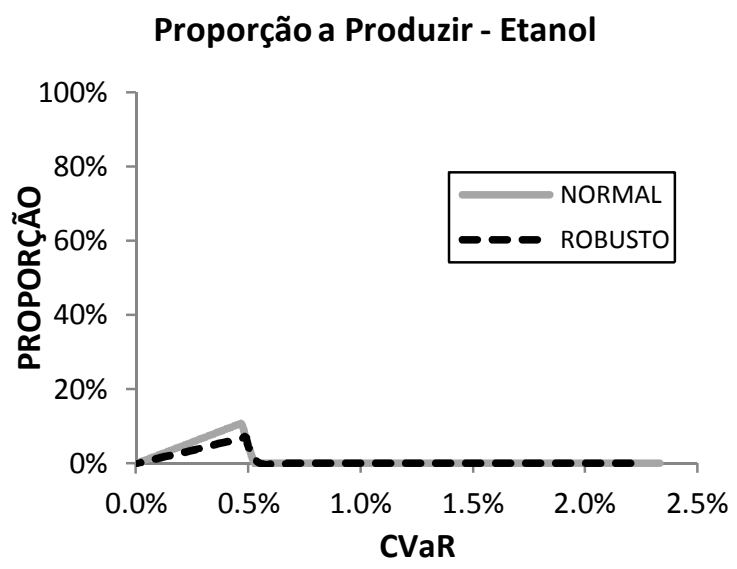

Figura 4.3.17 - Proporção a produzir de Etanol no momento 2 - dados EUA
Proporção a Produzir - Biodiesel

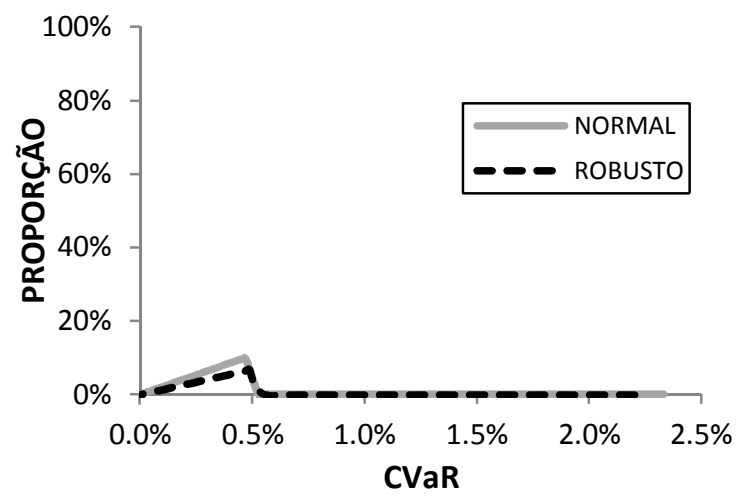

Figura 4.3.18 - Proporção a produzir de Biodiesel no momento 2 - dados EUA

\section{Decisão 2: Estocagem e Comercialização (Momento 2 - EUA)}

Como o risco e a incerteza associados a produção de etanol e biodielsel, as decisões relativas ao milho disponível se restringiram a estocagem e venda do milho como mostram as figuras 4.3.19 e 4.3.20. Para essa decisão em específico a existência de incerteza não afetou a estocagem de milho quando comparamos a decisão de estocagem do modelo não robusto e do modelo robusto.

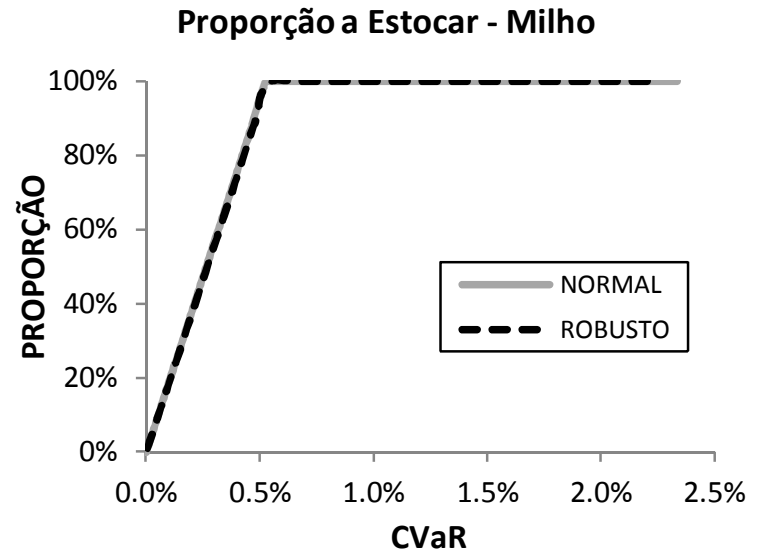

Figura 4.3.19 - Proporção a estocar de Milho no momento 2 - dados EUA

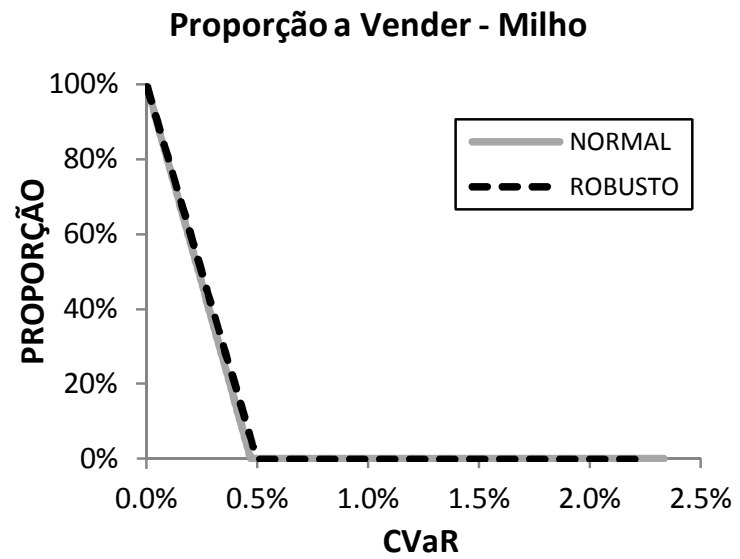

Figura 4.3.20 - Proporção a vender de Milho no momento 2 - dados EUA 


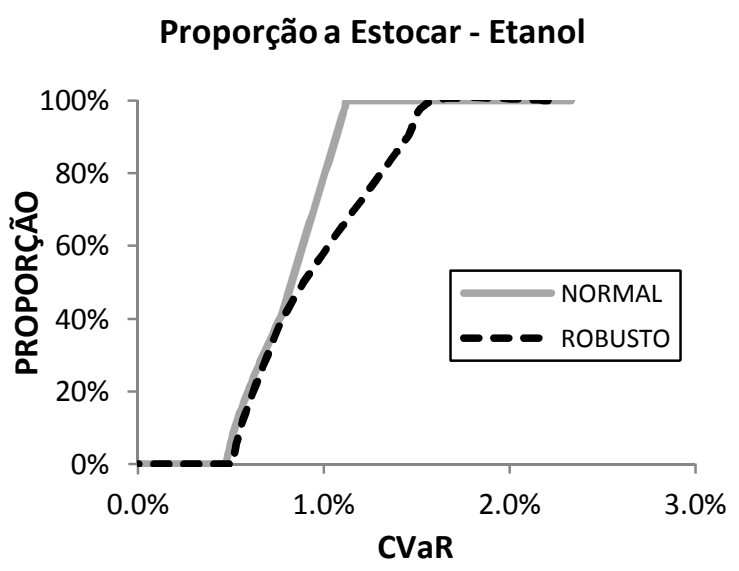

Figura 4.3.21 - Proporção a estocar de

Etanol no momento 2 - dados EUA

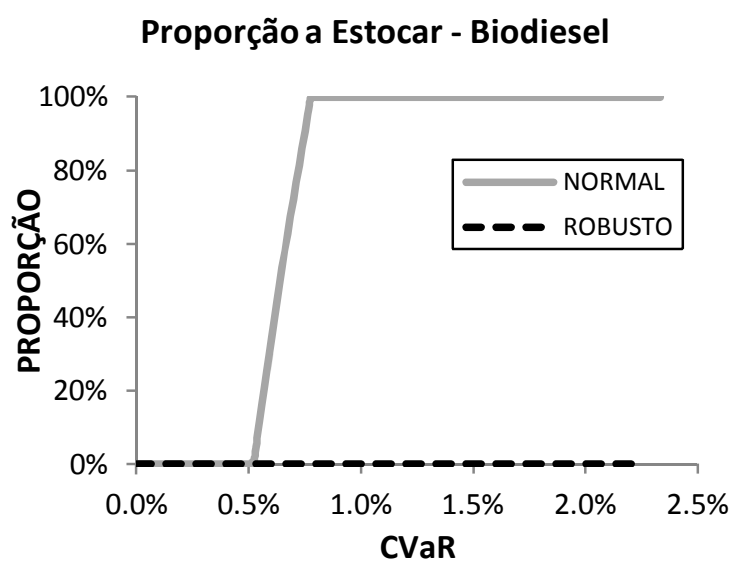

Figura 4.3.22 - Proporção a estocar de Biodiesel no momento 2 - dados EUA

A decisão entre venda e estocagem para o etanol e biodiesel disponíveis, ocorreram dentro do previsto, dado que os retornos previsto com a estocagem e venda futura superavam o retorno com a venda no período corrente. Diferentemente do que ocorreu com o milho a decisão do modelo robusto não se manteve, e evitou os estoques, uma vez que existe incerteza atrelada a decisão de estocar, pois os retornos de estocagem decorrem da estimativa de preços do modelo de previsão.

É possível notar que a diferença entre a estratégia robusta e não robusta para a estocagem de etanol foi relativamente pequena, enquanto para o biodiesel as decisões foram completamente diferentes, como pode ser verificado através das figuras 4.3.21 e 4.3.22.

\section{Decisão 3: Hedge (Momento 2 - EUA)}

Da mesma forma que no momento 1, é possível notar que o modelo robusto evita a utilização de contratos futuros para fins de hedge, diferenciando-se assim da sua contrapartida não robusta, ver figuras 4.3 .23 e 4.3.24. Contudo a solução não é tão trivial, a ponto de ser simplificada, uma vez que para o milho a estratégia de hedge através de contratos futuros se manteve inalterada, ver figura 4.3.25. 


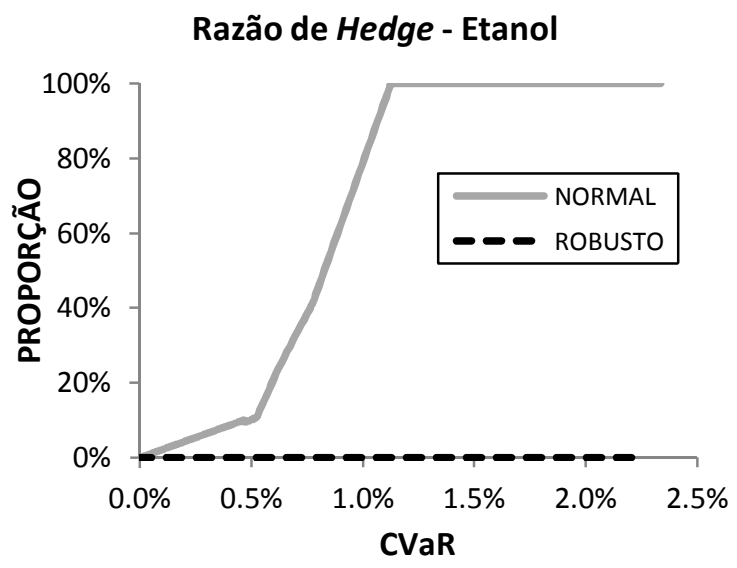

Figura 4.3.23 - Razão de hedge para o Etanol no momento 2 - dados EUA

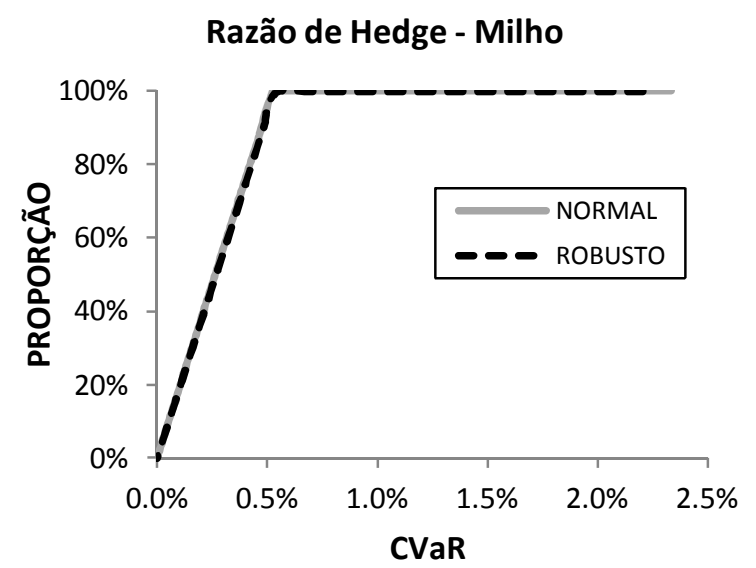

Figura 4.3.25 - Razão de hedge para o Milho no momento 2 - dados EUA

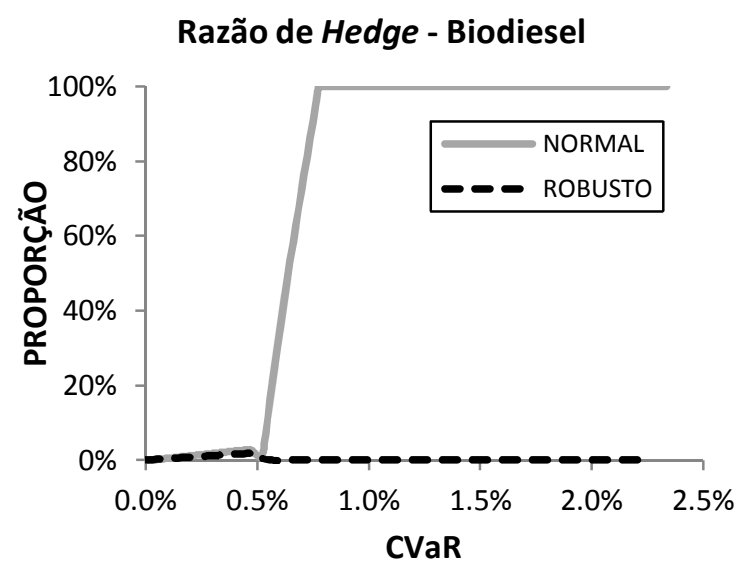

Figura 4.3.24 - Razão de hedge para o Biodiesel no momento 2 - dados EUA

\subsubsection{Resultados com dados reais do mercado sucroalcooleiro Brasileiro}

Para o mercado sucroalcooleiro todos os preços e quantidades estão na base ATR, ou Açúcar Total Recuperado. Os preços foram convertidos para US\$/ATR utilizando os fatores de conversão do Conselho de Produtores de Cana-de-açúcar (CONSECANA), como indicado na Tabela A.6 do Anexo 1.

O modelo proposto utiliza as margens de lucro, calculadas utilizando os preços de mercado e os custos de produção fornecidos pela Pecege/ESALQ, em bases anuais como indicado na Tabela A.7 do Anexo 1.

Os preços previstos foram obtidos a partir de um modelo de previsão simplificado, contendo somente o Filtro de Kalman e sem as redes neurais. Como entrada do modelo foram utilizadas 88 observações de dados mensais de preços à 
vista do açúcar e do etanol hidratado, de Janeiro de 2004 a Abril de 2011, obtidos do Centro de Estudos Avançados em Economia Aplicada (CEPEA/ESALQ) e preços futuros do açúcar (sugar No.11) para o primeiro vencimento advindos da Bolsa ICE de Nova lorque (Intercontinental Exchange).

Os preços futuros do açúcar foram utilizados como variáveis observáveis para a previsão dos preços à vista do açúcar e do etanol, uma vez que o mercado futuro de etanol no Brasil possui pouca liquidez e que o mercado futuro de etanol nos Estados Unidos está atrelado ao milho e não à cana-de-açúcar.

A Tabela A.8 do Anexo 1 apresenta diversas medidas de erro encontradas para o modelo de base ou de comparação e para o modelo do Filtro de Kalman. $O$ modelo de base usado para comparação considera os preços um período a frente exatamente iguais ao do período corrente.

Todas as medidas de erro geradas pelo Filtro de Kalman foram menores que as medidas de erro do modelo de base, tanto para o açúcar quanto para o etanol. Os melhores resultados foram obtidos para a previsão de preços do açúcar, o que já era esperado uma vez que os contratos futuros utilizados para a previsão dos preços do açúcar eram de açúcar, enquanto foram utilizados contratos futuros de açúcar para a previsão dos preços do etanol.

Os custos de estocagem do açúcar foram obtidos através do estudo apresentado por Gil et al. (2005), sendo $\mathrm{R} \$ 0,17$ para estocar um saco de $50 \mathrm{~kg}$ de açúcar por 1 mês, durante o ano de 2007. O custo de estocagem de etanol por falta de informações na literatura é considerado como sendo, $\mathrm{R} \$ 0,34$ para estocar 50 litros de etanol hidratado por 1 mês, durante o ano de 2007.

Pela dificuldade em se definir uma situação específica de uma usina real, diversos valores referentes as quantidades disponíveis de açúcar, etanol, açúcar em estoque, etanol em estoque, cana de açúcar a ser transformado, foram definidas de modo a simplificar a interpretação dos resultados.

Dois momentos históricos foram escolhidos para apresentar comportamentos distintos de acordo com alterações nas relações de retorno e incerteza de previsão. A Figura 4.3.22 apresenta as margens de lucro líquidas previstas para cada data do intervalo de dados utilizado, assim como os momentos selecionados para teste do modelo. 
Margens Líquidas Previstas

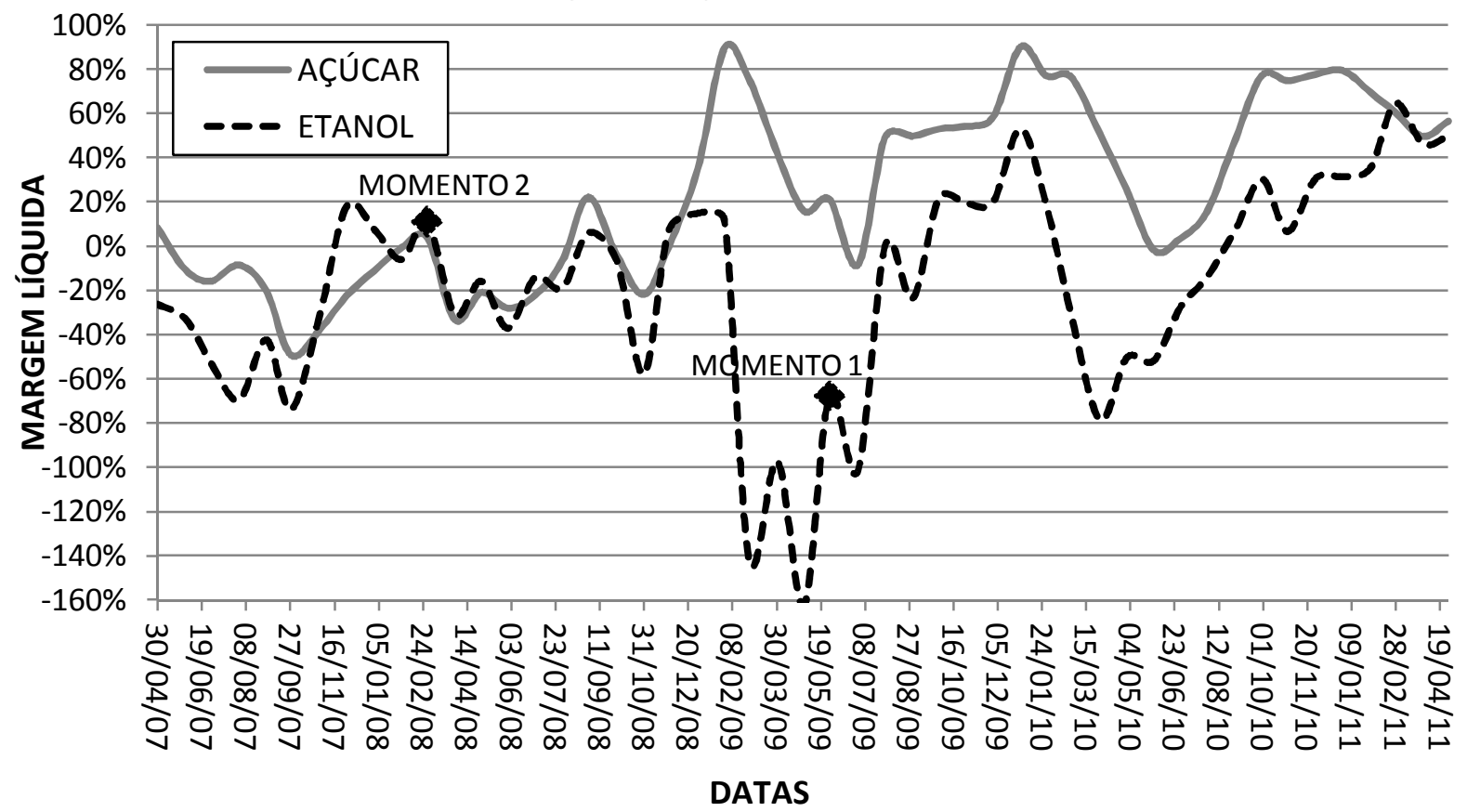

Figura 4.3.26 - Margens de lucro previstas e momentos históricos escolhidos

É interessante notar que por um período de quase 3 anos, de Fevereiro de 2008 a Abril de 2011, as margens de lucro do etanol não superaram significativamente e com persistência suficiente as margens do açúcar, o que o obviamente simplificou bastante o processo de decisão do produtor. O desinteresse do produtor pela produção de etanol gerou um série de medidas governamentais de incentivo a produção etanol durante o ano de 2011, porém até a finalização desse trabalho essas medidas não haviam surtido efeito e a produção de etanol não foi capaz de se restabelecer e garantir que o etanol tivesse preços menores que os da gasolina na maioria dos postos das capitais estaduais Brasileiras.

O momento histórico 1, ocorrido em Maio de 2009, apresenta uma das situações citadas acima, que persistiu por anos, onde a margem prevista obtida com o etanol é fortemente negativa (-68\%), enquanto a margem prevista do açúcar é positiva (21\%). É esperado que o modelo não robusto decida por produzir açúcar em todo o intervalo de risco e se utilize dos contratos futuros como ferramenta para reduzir o risco. O momento histórico 1 foi escolhido por representar o comportamento relativo das margens de lucro entre etanol e açúcar mais comumente encontrado pelo produtor nos últimos anos. 
O momento histórico 2, ocorrido em Fevereiro de 2008, apresenta uma situação onde a margem prevista do etanol (11\%) supera a margem prevista do açúcar (4\%). Nesse caso a decisão de mix de produção não é tão óbvia, pois depende do risco de cada subproduto e é possível que a versão robusta modifique as decisões caso à incerteza associada a previsão de preços do etanol seja suficientemente superior à incerteza de previsão do açúcar. O momento histórico 2 foi escolhido na tentativa de evidenciar o impacto da incerteza na decisão do produtor, uma vez que as margens de lucro dos subprodutos da cana estão muito próximas e pequenas incertezas podem afetar a decisão do produtor.

Uma peculiaridade do mercado sucroalcooleiro é o fato de o mercado futuro brasileiro, representado pela BM\&FBOVESPA deixou lentamente de ter liquidez e não pôde ser usado como parâmetro para o estudo. Esse mercado apresentava forte correlação com o mercado à vista, em especial com a série de preços divulgadas pela ESALQ. Já o mercado futuro internacional, no presente caso representado pela ICE, apresentava baixa correlação, e negativa, o que dificulta o processo de decisão a respeito de como o produtor deve se posicionar nesse mercado a fim de reduzir o risco.

Os vetores de retorno e incerteza são formados com os dados das Tabelas A.9 e A.10 do Anexo 1, respectivamente. A partir dos resultados da previsão do modelo do Filtro de Kalman as incertezas foram calculadas, considerando os desvios padrão dos retornos de uma janela de 5 meses.

As quantidades disponíveis, para cada subproduto, no final do processo e em estoque, a quantidade disponível de matéria prima, a capacidade de estoque para cada subproduto e quantidade total de produto disponível em uma mesma base, são apresentadas na Tabela A.11 do Anexo 1. Esses valores foram escolhidos arbitrariamente, pois não é foco tratar uma situação específica de uma usina existente, e sim avaliar o modelo para uma usina genérica.

O cálculo do CVaR é feito com base em 32 retornos passados que formaram os $m$ cenários da equação 4.1.16. A seleção desses retornos pode ser considerada altamente subjetiva e sujeita à interferência do analista. No presente caso os cenários foram escolhidos arbitrariamente, porém é possível determinar critérios econômicos para escolha desses cenários. 


\section{MOMENTO 1: Dados do Brasil}

Para o momento histórico 1, a Figura 4.3.27, evidencia o comportamento esperado do modelo, onde só é possível ter menor risco aceitando um retorno menor.

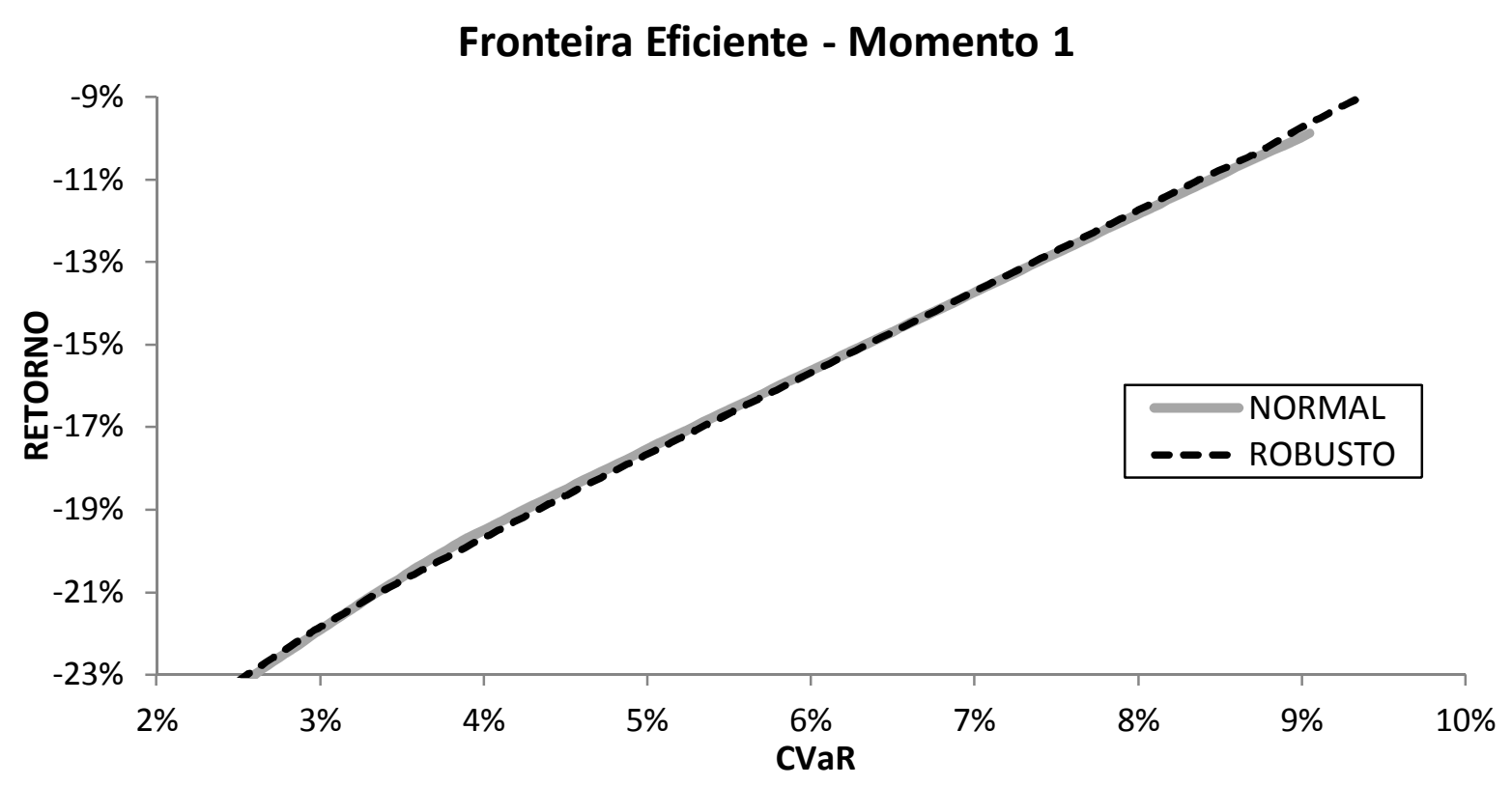

Figura 4.3.27 - Fronteira eficiente no momento 1 - dados Brasil

\section{Decisão 1: Mix de Produção (Momento 1 - Brasil)}

Diferentemente do mercado de milho, a matéria prima do mercado sucroalcooleiro não é uma commodity negociável. Isso faz com ela só possa ser transformada em um subproduto sem a possibilidade de estocagem ou venda no instante imediato após a colheita.

A relação de risco e retorno e incerteza e retorno do momento 1 , foi comumente encontrada por um longo período no Brasil, onde as margens auferidas com o etanol eram negativas ou muito baixas e sempre menores que as margens do açúcar, além disso o risco de mercado e a incerteza associada ao etanol sempre superavam os do açúcar, como mostram as figuras 4.3.28 e 4.3.29. 
Relação Risco e Retorno

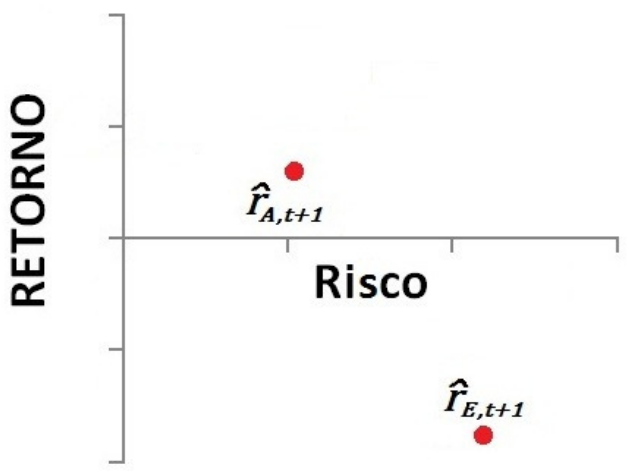

Figura 4.3.28 - Relação risco e retorno no momento 1 - dados Brasil
Relação Incerteza e Retorno

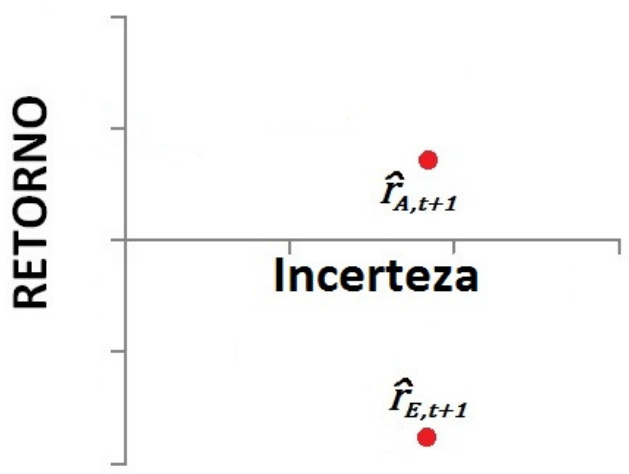

Figura 4.3.29 - Relação incerteza e retorno no momento 1 - dados Brasil

Como esperado o modelo não robusto e robusto apontaram a mesma solução, a de produzir somente açúcar em qualquer nível de risco assumido, ver figuras 4.3 .30 e 4.3 .31 .

Proporção a Produzir - Açúcar

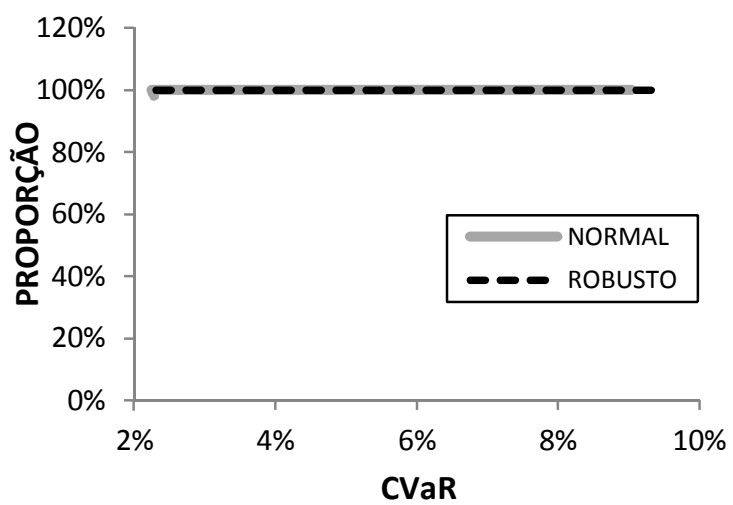

Figura 4.3.30 - Proporção a produzir de Açúcar no momento 1 - dados Brasil
Proporção a Produzir - Etanol

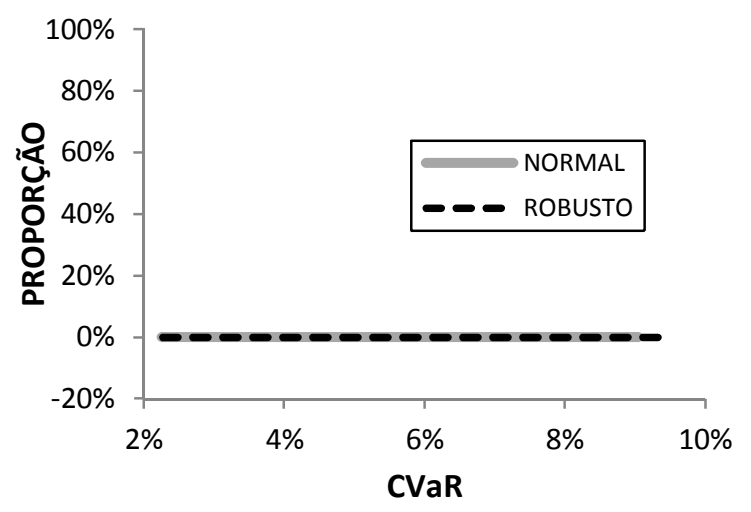

Figura 4.3.31 - Proporção a produzir de Etanol no momento 1 - dados Brasil

\section{Decisão 2: Estocagem e Comercialização (Momento 1 - Brasil)}

Como as margens de estocagem e venda um período a frente superam as margens de venda no período corrente, tanto para o açúcar quanto para o etanol, seria de esperar que o modelo não robusto aumentasse a decisão de estocar conforme a tolerância ao risco aumentasse. Já o modelo robusto deveria fazer o 
mesmo, porém evitando mais os estoques para o mesmo nível de risco, pois considera a incerteza inerente a decisão de estocar.

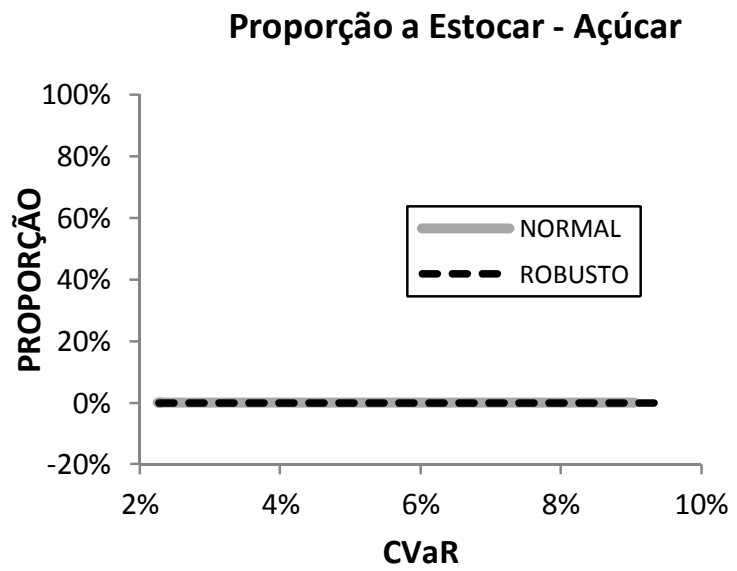

Figura 4.3.32 - Proporção a estocar de Açúcar no momento 1 - dados Brasil

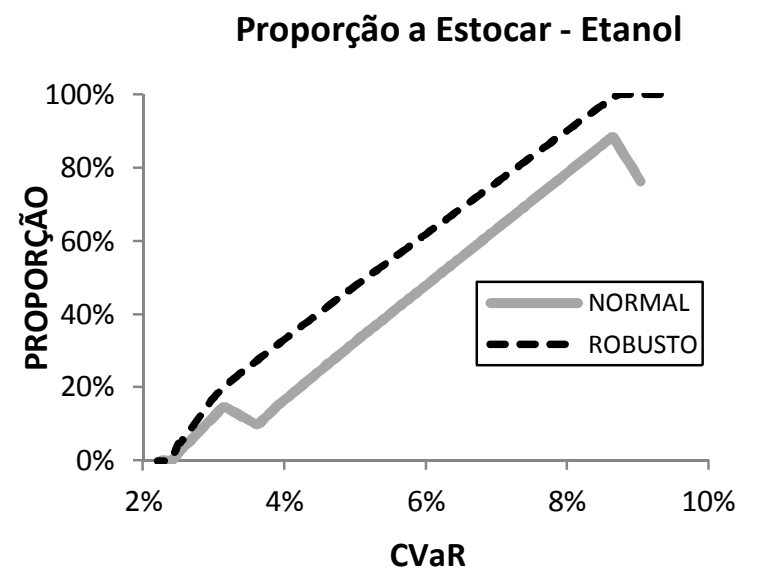

Figura 4.3.33 - Proporção a estocar de Etanol no momento 1 - dados Brasil

Contudo de modo pouco previsível ambos os modelos seguiram com decisões pouco intuitivas, no caso do açúcar, mesmo as margens de estocagens sendo maiores, os modelos robusto e não robusto apontaram para a venda de todo o açúcar disponível no mercado à vista no período corrente independentemente do nível de risco tolerado, ver figura 4.3.32.

Para o etanol disponível o modelo apontou uma solução oposta ao esperado, sendo que a solução do modelo robusto utiliza mais estoque que a solução do modelo não robusto, ver figura 4.3.33. Só é possível compreender esse comportamento do modelo quando visualizamos a decisão de hedge e percebemos que o modelo robusto se utiliza dos estoques como instrumento de proteção, ao invés, dos contrato futuros.

\section{Decisão 3: Hedge (Momento 1 - Brasil)}

Vale lembrar que no caso do mercado sucroalcooleiro brasileiro os contratos futuros de etanol não possuem liquidez, e os contratos futuros de etanol do mercado norte americano não possuem correlação imediata com os preços domésticos. Dessa forma, toda a proteção seria feita através de contratos futuros de açúcar do mercado norte americano. 


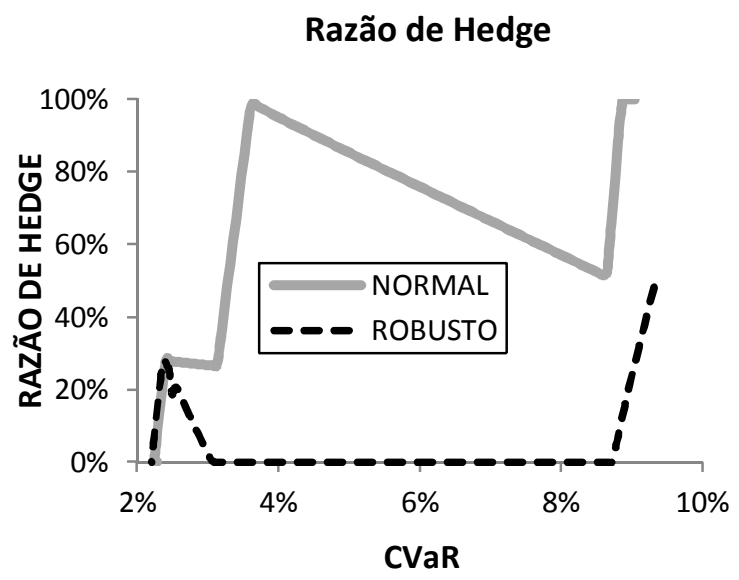

Figura 4.3.34 - Razão de hedge no

momento 1 - dados Brasil

Apesar de o momento escolhido, a priori, parecer de fácil decisão, o modelo proposto é capaz de apresentar combinações pouco intuitivas, como é o caso da estratégia de hedge com contratos futuros, em especial o modelo robusto. O modelo robusto conseguiu construir uma solução que gerou a mesma fronteira eficiente, porém sem a utilização de contratos futuros (ver figura 4.3.34) e controlando os riscos e a incerteza através dos estoques de etanol.

\section{MOMENTO 2: Dados do Brasil}

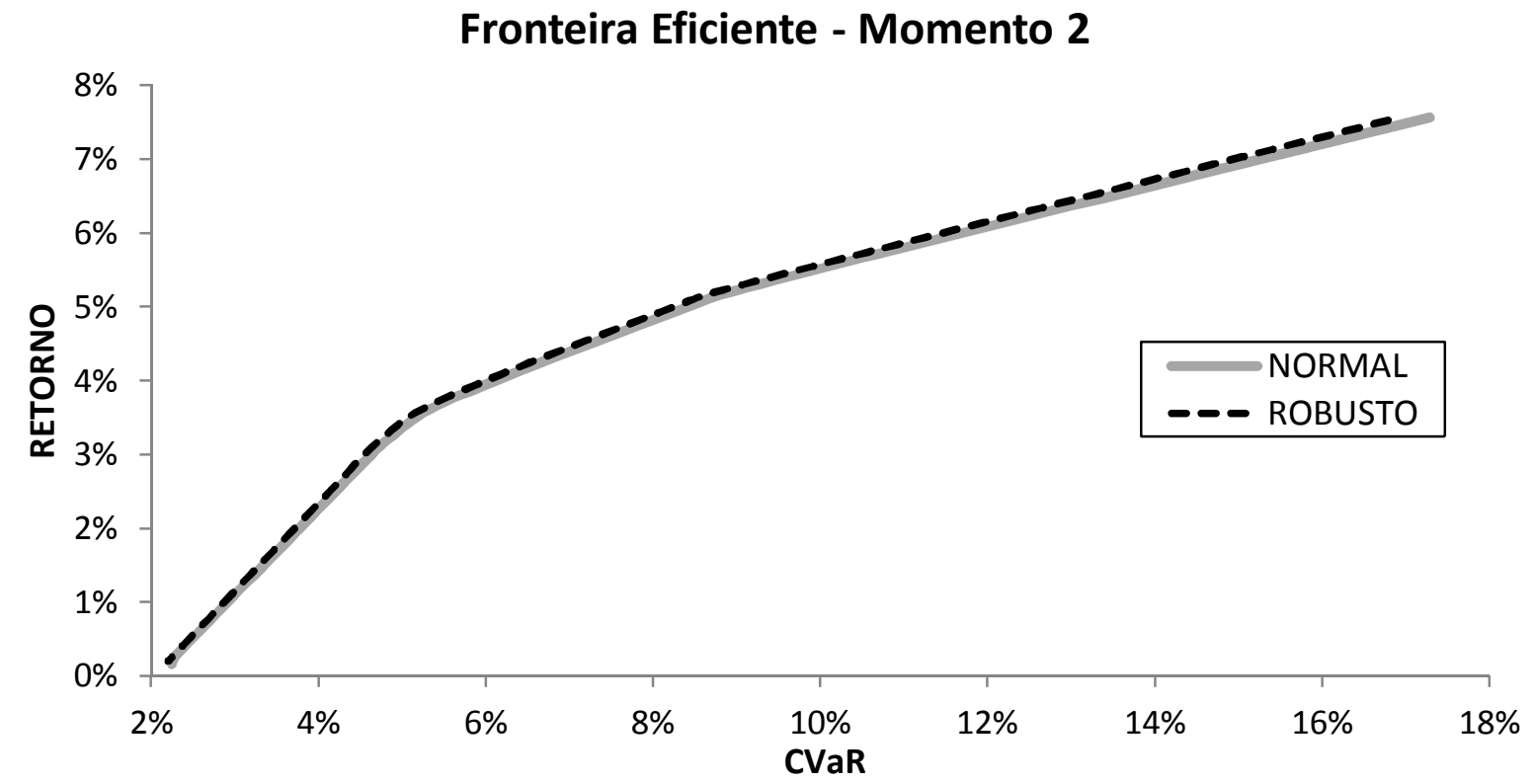

Figura 4.3.35 - Fronteira eficiente no momento 2 - dados Brasil 
Para o momento 2, novamente a fronteira eficiente gerada pelos modelos não robusto e robusto coincidiram, ver figura 4.3.35.

\section{Decisão 1: Mix de Produção (Momento 2 - Brasil)}

Para a decisão de mix de produção, o modelo não robusto apontou a decisão de migrar para a produção de etanol conforme aumentava a tolerância ao risco, uma vez que o etanol apresentava maior margem e maior risco que o açúcar, ver figuras 4.3.36, 4.3.38 e 4.3.39.

Relação Risco e Retorno

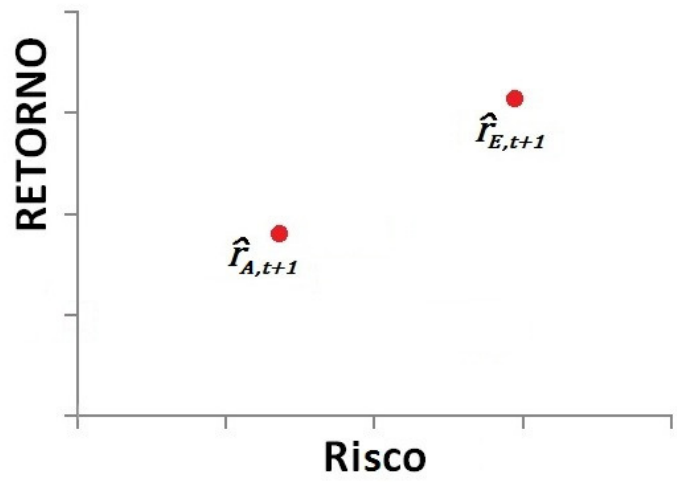

Figura 4.3.36 - Relação risco e retorno no momento 2 - dados Brasil

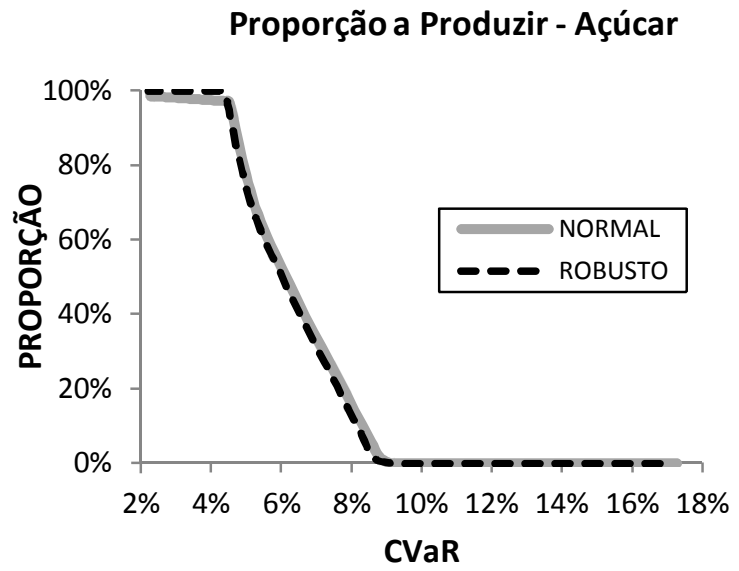

Figura 4.3.38 - Proporção a produzir de Açúcar no momento 2 - dados Brasil
Relação Incerteza e Retorno

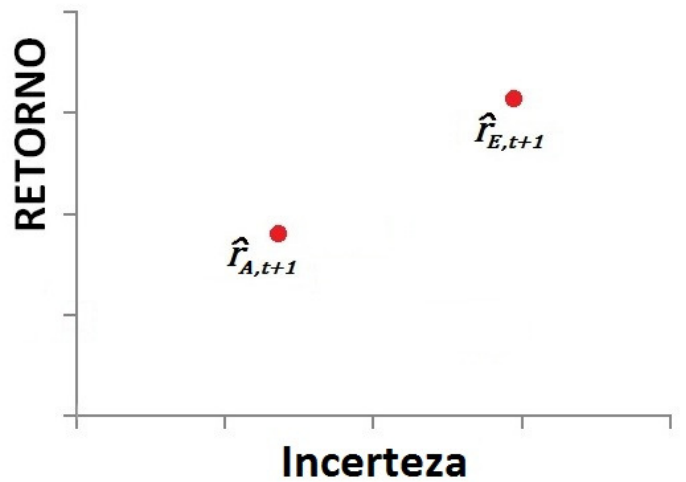

Figura 4.3.37 - Relação incerteza e retorno no momento 2 - dados Brasil

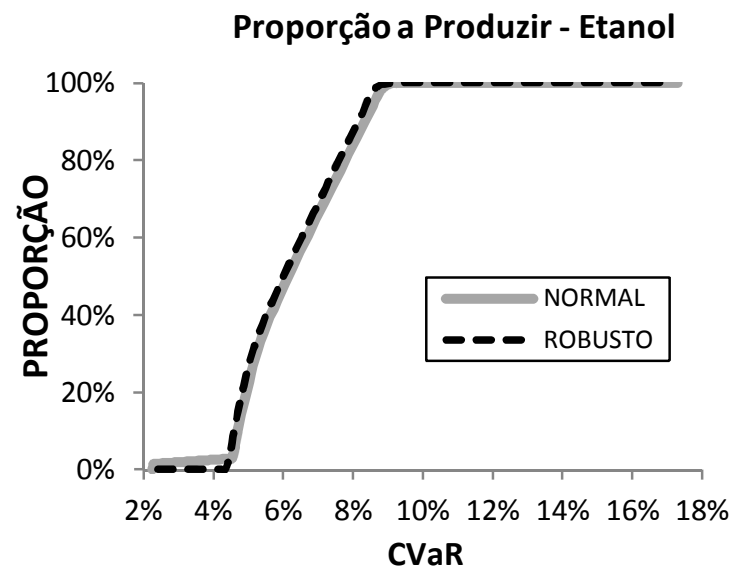

Figura 4.3.39 - Proporção a produzir de Etanol no momento 2 - dados Brasil

Já o modelo robusto, apesar da maior incerteza associada ao etanol (ver figura 4.3.37), não gerou uma solução diferente da apontada pelo modelo não robusto. 


\section{Decisão 2: Estocagem e Comercialização (Momento 2 - Brasil)}

A decisão de estocagem deveria também ocorrer conforme a tolerância para o risco aumentasse, tanto para o açúcar quanto para o etanol disponível, e assim ocorreu, dado que as margens de estocagem superavam as margens de venda no período corrente, ver figuras 4.3.38 e 4.3.39.

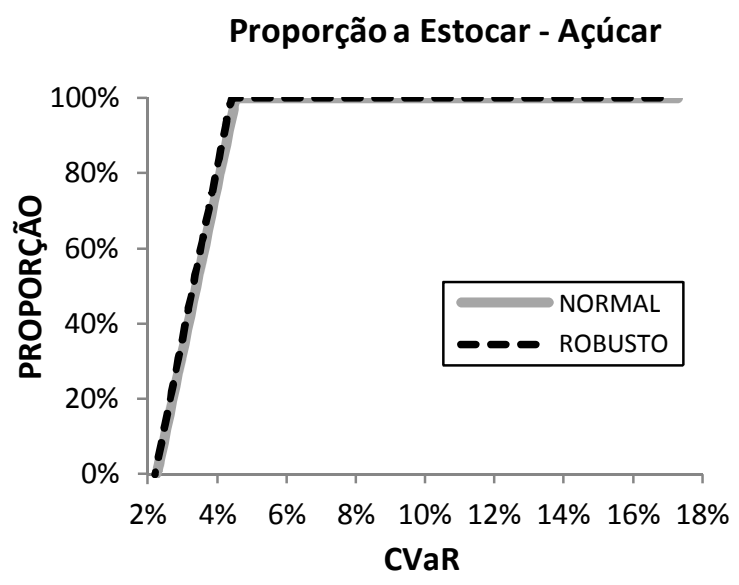

Figura 4.3.40 - Proporção a estocar de Açúcar no momento 2 - dados Brasil

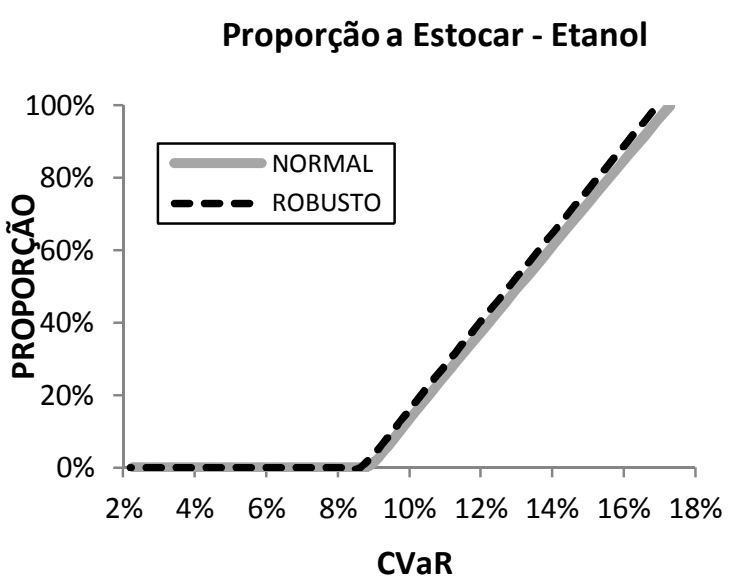

Figura 4.3.41 - Proporção a estocar de Etanol no momento 2 - dados Brasil

Curiosamente apesar de existir incerteza associada a decisão de estocar, o modelo robusto não buscou evitar os estoques, gerando uma solução praticamente idêntica da do modelo não robusto. Novamente esse fenômeno só pode ser entendido quando nos atentamos a decisão de hedge.

\section{Decisão 3: Hedge (Momento 2 - Brasil)}

Os modelos robusto e não robusto conseguiram desenhar a fronteira eficiente, através do mix de produção e do controle de estoques, evitando assim o risco e a incerteza associados aos contratos futuros, ver figuras 4.3.40. 
Razão de Hedge

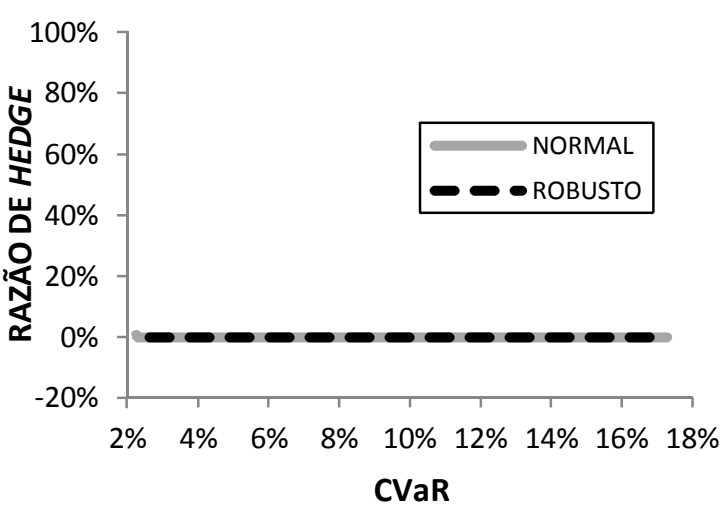

Figura 4.3.42 - Razão de hedge no momento 2 - dados Brasil 


\subsection{Conclusões Acerca do Modelo de Decisão}

O modelo de decisão proposto é capaz de orientar o produtor em decisões não intuitivas, definindo diversas variáveis simultaneamente e ainda considerando incertezas relacionadas ao próprio processo de previsão de preços.

Para o mercado norte-americano o efeito positivo da utilização do modelo de decisão robusto se mostrou mais evidente. Nos dois momentos históricos avaliados a consideração da incerteza de previsão de preços levou a decisões bem diferentes de estocagem, mix de produção e razão de hedge. Em todas as situações as respostas não são intuitivas evidenciando o benefício do modelo proposto.

Para o mercado sucroalcooleiro brasileiro o modelo robusto se mostrou menos relevante para a decisão de mix de produção, uma vez que dentro do período avaliado as margens do açúcar foram muito superiores as do etanol. Por outro lado o modelo robusto mostrou a possibilidade de se reduzir a exposição ao risco e a incerteza através de estoques, evitando contratos futuros.

O modelo se mostrou de grande valia para o entendimento de qual a ordem em que as decisões são tomadas, como ocorreu no momento histórico 2 para o mercado brasileiro, onde três regiões formadas por dois pontos de inflexão representam momentos diferentes em que as decisões para alterar a relação risco/retorno se apresentam de modo separado. Isso permite ao produtor ter um ideia de preferência e impacto relativo de cada decisão.

O modelo também permite ao produtor avaliar a efetividade do mercado futuro em que ele busca se proteger através de hedge. O modelo é capaz de tratar ineficiências, como a utilização de contratos futuros de outro mercado, como foi o caso da simulação feita com o mercado sucroalcooleiro brasileiro, onde se utilizou contratos futuros de açúcar da bolsa ICE de Nova lorque. 


\section{CONCLUSÕES}

Os problemas estudados nessa pesquisa foram as decisões tomadas por produtores de commodities agrícolas diversificáveis, ou seja, aquelas que podem ser transformadas em diferentes subprodutos. Em especial foi dada atenção a commodities ligadas ao setor de alimentos e energia, como é o caso da cana-deaçúcar e do milho, que podem gerar alimentos ou biocombustíveis. Países como Brasil e Estados Unidos já utilizam combustíveis renováveis oriundos de commodities agrícolas, como é o caso do etanol e do biodiesel. O assunto vem ganhando relevância em âmbito mundial e outros países estão direcionando esforços na criação de matrizes renováveis baseadas em biocombustíveis, o que deve estender o problema da diversificação para produtores de outras culturas.

O objetivo central do trabalho é a proposição de um modelo para suporte a tomada de decisão dos produtores de commodities agrícolas que possuem a capacidade de diversificação. O modelo suporta decisões de como dividir a matéria prima entre os diversos subprodutos possíveis, além de definir a estratégia comercial que maximiza o retorno e a estratégia de hedge que protege o produtor contra oscilações indesejadas.

O presente trabalho traz algumas contribuições, entre elas um modelo híbrido para previsão de preços de commodities agrícolas, ou seja, um modelo composto de dois modelos interligados, sendo o primeiro baseado no filtro de Kalman e o segundo na teoria de redes neurais. Os resultados do testes com dados reais do mercado sucroalcooleiro brasileiro e indiano permitem atestar o potencial preditivo do modelo proposto em aplicações diretamente ligadas às commodities agrícolas com interferência dos efeitos da diversificação em sua dinâmica de preços.

A segunda contribuição está ligada ao próprio modelo de decisão de produção, comercialização, estocagem e hedge. São analisados:

1. mix de produção;

2. comercialização dos subprodutos no mercado à vista;

3. posição dos estoques dos subprodutos, e

4. estratégias proteção ou hedge considerando o mercado futuro. 
A definição dos quatro parâmetros é feita utilizando para isso um modelo de seleção de portfólio. O modelo de otimização busca minimizar o risco, nesse caso o CVaR (Conditional Value at Risk), que é considerado uma medida de risco coerente.

A associação de um modelo de previsão de preços eficaz para commodities agrícolas diversificáveis com o modelo de decisão proposto cobre um espaço que existia na literatura no suporte a tomada de decisão dos produtores dessas commodities.

Uma terceira contribuição adiciona ao modelo de decisão de produção, comercialização, estocagem e hedge a capacidade de lidar com incerteza em parâmetros cruciais para a tomada de decisão, em especial os retornos futuros, que são definidos a partir do modelo de previsão de preços. Dessa forma o modelo passa a ter a capacidade de considerar a incerteza associada a previsão de preços, utilizando técnicas de otimização robusta, o que pode ser mais ou menos útil dependendo do cenário econômico enfrentado. Durante o teste com dados reais do mercado sucroalcooleiro brasileiro foi possível notar que por muitos meses a incerteza na previsão não chegava a afetar algumas decisões do produtor, uma vez que as margens do açúcar se mantinham muito acima das margens do etanol. Já para os testes com os dados reais do mercado de milho, etanol e biodiesel dos Estados Unidos, a consideração da incerteza se mostrou essencial no processo de decisão do produtor, uma vez que essa era capaz de alterar as relações de risco e retorno.

Em especial o modelo de decisão robusto apontou soluções com menor utilização do hedge para gerenciamento do risco, substituindo esse mecanismo por melhor diversificação e gerenciamento dos estoques. No caso da utilização de diversos contratos futuros o modelo é capaz de utilizar o crosshedge, ou seja, se utilizar de um contrato futuro de uma commodity para proteger outra commodity e de modo não intuitivo encontrar a melhor composição da carteira para o produtor.

É esperado que mais e mais commodities agrícolas assumam a característica de diversificação para a geração de energia renovável, o que deve elevar o interesse dos produtores agrícolas em ferramentas de suporte à decisão.

Modelos para seleção de portfólio de commodities, determinação de estoques e de estratégias de proteção, apesar de raros, não são inéditos na literatura, porém são apresentados de modo isolado e somente para commodities 
sem a característica de diversificação, e em geral não consideram parâmetros incertos em seus processos de otimização.

O presente estudo resultou na elaboração de um modelo de qualidade superior, congregando diversas técnicas matemáticas recentes para abranger diversos aspectos do processo decisório. O resultado do estudo não só é uma ferramenta para tomada de decisão como é uma ferramenta para avaliação de aspectos diversos, como efetividade do uso do mercado futuro, sensibilidade do processo decisório a determinadas variáveis, e avaliação do impacto da incerteza nas decisões.

Como continuidade do estudo o modelo pode ser aplicado para outras commodities, assim como pode ser modificado afim de considerar efeitos de longo prazo e considerações sobre a logística envolvida, o que podem afetar as decisões de estoque. Parâmetros relacionados ao processo de aquisição de matéria-prima podem ser adicionados afim de modelar mercados onde a matéria-prima não faz parte do controle do produtor de subprodutos. 


\section{REFERÊNCIAS BIBLIOGRÁFICAS}

AITSAHLIA, F.; WANG, C.; CABRERA V. E.; URYASEV, S. e FRAISSE, C. W. Optimal crop planting schedules and financial hedging strategies under ENSO-based climate forecasts. Annals of Operations Research, 2009, DOI: 10.1007 / s10479-009-0551-2.

AJANOVIC, A. Biofuels versus food production: does biofuels production increase food prices? Energy, 2010, Vol.36, n.4, p.2070-2076.

AKRAM, Q.F. Commodity prices, interest rates and the dollar. Energy Economics, 2009, 31, p.838-851.

ALADAG, C. H.; EGRIOGLU, E. e KADILAR, C. Forecasting nonlinear time series with a hybrid methodology. Applied Mathematics, 2009, Letters 22 , p. 1467-1470.

ALLEN, P. G. Economic Forecast in Agriculture. International Journal of Forecasting, 1994, Vol.10, pp. 81-135.

AOUAM, T.; RARDIN, R. e ABRACHE, J. Robust strategies for natural gas procurement. European Journal of Operational Research, 2010, Vol.205, pp. 151-158.

ARTZNER, PH., DELBAEN, F., EBER, J.M. e HEATH, D. Coherent measures of risk. Mathematical Finance, 1999, Vol.9, n.3, p.203-228.

BAFFES, J. Oil spills on other commodities, Resources Policy, 2007, Vol. 32, p.126-134.

BALAT, M. \& BALAT, H. Recent trends in global production and utilization of bio-ethanol fuel. Applied Energy, 2009, n.86, p. 2273-2282.

BASTIAN-PINTO. C.; BRANDÃO, L. e HAHN, W. J. Flexibility as a source of value in the production of alternative fuels: The ethanol case. Energy Economics, 2009, V.31, p.411-422.

BEN-TAL, A. AND NEMIROVSKI, A. Robust solutions of Linear Programming problems contaminated with uncertain data, Math. Program., 2000, Vol.88, pp. 411-424.

BERTRAND, J.W.M.; FRANSOO, J.C. Modeling and Simulation: Operations Management research methodologies using quantitative modeling. International Journal of Operations \& Production Management, 2002, Vol.22, №2, pp 241-264.

BILDIRICIA, M. e ERSIN, Ö. Ö., Improving forecasts of GARCH family models with the artificial neural networks: An application to the daily 
returns in Istanbul Stock Exchange. Expert Systems with Applications, 2009, Vol. 36, n.4, p. 7355-7362.

BM\&F. Operações de Hedge no Mercado Futuro, Apostila do curso oferecido pelo Instituto Educacional BM\&F, São Paulo, 2006.

BORGES, J. M. O cenário econômico mundial e o negócio de açúcar e álcool, Revista Opiniões, 2009, n.19.

BRENNAN, M.J. AND SCHWARTZ, E.S. Evaluating natural resource investments, The Journal of Business, 1985, Vol.58, p.135-157.

CHA, K. S.; BAE, J. H. Dynamic impacts of high oil prices on the bioethanol and feedstock markets, Energy Policy, 2011, n.39, p. 753-760.

CHEN, S. S.; LEE, C.F.; SHRESTHA, K. Futures hedge ratios: a review. The Quarterly Review of Economics and Finance, 2003, n.43, p. 433-465.

CHEN, A; LEUNG, M.T. e DAOUK, H. Application of neural networks to an emerging financial market. Forecasting and trading the Taiwan Stock Index, 2003, Vol.30, n.6, p.901-923.

CHEN, X e SIMCHI-LEVI, D. Coordinating inventory control and pricing strategies: The continuous review model. Operations Research Letters, 2006, Vol.34, p.323-332.

CHEN, Y., ROGOFF, K. e ROSSI, B. Can exchange rates forecast commodity prices?, Quarterly Journal of Economics, 2010, Vol.125, n.3, p.1145-1194.

CIGIZOGLU, H. K. e KISI, O. Flow prediction by three back propagation techniques using k-fold partitioning of neural network training data, Nordic Hydrology, 2005, Vol.36, p.49-64.

CO, H. C. e BOOSARAWONGSE, R. Forecasting Thailand's rice export: Statistical techniques vs. artificial neural networks, Computers \& Industrial Engineering, 2007, Vol. 53, p.610-627.

CORSANO, G.; VECCHIETTI, A. R. e MONTAGNA, J. M. Optimal design for sustainable bioethanol supply chain considering detailed plant performance model. Computers and Chemical Engineering, 2010, doi:10.1016 / j.compchemeng. 2011.01.008.

COSTA, O. L. V. e ASSUNÇÃO, H. G. V. Análise de Risco e Retorno em Investimentos Financeiros. São Paulo, Ed. Manole, v.1, 2005.

COSTA, O. L. V. e PAIVA, A. C. Robust portfolio selection using linear matrix inequalities. Journal of Economic Dynamics and Control, 2002, v.26, p.889-909. 
CRAGO, C. L.; KHANNA, M.; BARTON, J.; GIULIANI, E. e AMARAL, W. Competitiveness of Brazilian sugarcane ethanol compared to US corn ethanol. Energy Policy, 2010, Vol. 38, pp 7404-7415.

DICLEMENTE, A. The empirical value at risk-expected return frontier: A useful tool of Market risk managing. Working Paper, 2002, n.11. Universita' di Roma.

DOOLEY, G. e LENIHAN, H. An assessment of time series methods in metal price forecasting. Resources Policy, 2005, Vol. 30, No 3, pp 208-217.

DUXBURY, D. e SUMMERS, B. Financial risk perception. Are individuals variance averse or loss averse? Economics Letters, 2004, Vol.84, p.21-28.

EL-BAKRY, M. Y. Feed forward neural networks modeling for K-P interactions, Chaos, Solutons \& Fractals, 2003, Vol.18, p.995-1000.

ELLIOT, R. J. \& HYNDMAN C.B. Parameter estimation in commodity markets: a filtering approach. Journal of Economic Dynamics and Control, 2007, Vol. 31, n.7, p.2350-2373.

ELOBEID, A., TOKGOZ, S. Removing distortions in the U.S. ethanol market: what does it imply for the United States and Brazil? American Journal of Agricultural Economic, 2008, Vol.90, n.4, p.918-932.

ENGEL, C. e WEST, D. Exchange rates and fundamentals, The Journal of Political Economy, 2005, Vol.113, p.485-517.

ESMAEILI, A.; SHOKOOHI, Z. Assessing the effect of oil price on world food prices: Application of principal component analysis, Energy Policy, 2011, n.39, p.1022-1025.

ERS (United States Department of Agriculture Economic Research Service), Feed Grains Database, 2010. Disponível em: www.ers.usda.gov.

FABOZZI, F. J.; KOLM, P. N.; PACHAMANOVA, D. A. e FOCARDI, S. M. Robust portfolio optimization and management. 1st ed., Editora: John Wiley \& Sons. Ltd, 2007.

FAMA, E. \& FRENCH. K. Commodity Futures Prices: Some Evidence on Forecast Power, Journal of Business, 1987, Vol. 60, p. 55-74.

FARINELLI, B.; CARTER, C. A.; LIN, C. C. Y. \& SUMNER, D. A. Import demand for Brazilian ethanol: a cross-country analysis. Journal of Cleaner Production, 2009. No Prelo.

FIGUEIRA, S.R. Os programas de álcool como combustíveis nos EUA, no Japão e na União Européia e as possibilidades de exportação do Brasil. Escola Superior de Agricultura da Universidade de São Paulo "Luiz de Queiroz", Tese de Doutorado, 2005, p.246. 
FILENI, D. H.; MACHADO, H. M. e MARQUES, P. V. O risco de base e a efetividade do hedge para o agronegócio do café em Minas Gerais. Revista de Administração da UFLA, Universidade Federal de Lavras, 1999, Vol.1, n.1, p.90-107.

FONTES, R. E.; CASTRO JUNIOR, L. G. e AZEVEDO, A. F. Estratégia de Comercialização em Mercados Derivativos - Descobrimento de Base e Risco de Base da Cafeicultura em Diversas Localidades de Minas Gerais e São Paulo. Ciência e Agrotecnologia, Lavras, 2005, v. 29, n. 2, p. 382-389.

FRECHETTE, D. L. e FACKLER, P. L. What causes commodity price backwardation?, American Journal of Agricultural Economics, 1999, Vol.81, p.761-771.

FUNAHASHI, K. On the approximate realization of continuous mappings by neural networks. Neural Networks, 1989, n.2, p.183-192.

GAUDER, M., GRAEFF-HÖNNINGER, S. e CLAUPEIN, W. The impact of a growing bioethanol industry on food production in Brazil, Applied Energy, 2011, n.88, p.672-679.

GBEP. Global Bioenergy Partnership - white paper. GBEP, 2005.

GEMAN, S., BIENENSTOCK, E. e DOURSAT, R. Neural networks and the bias/variance dilemma, Neural Computation, 1992, Vol. 4, p.1-58.

GEMAN, H. Commodities and commodity derivatives. 1st ed., Editora: John Wiley \& Sons. Ltd, 2005.

GEMAN, H. e OHANA, S. Time-consistency in managing a commodity portfolio: A dynamic risk measure approach. Journal of Banking Finance, 2008, Vol. 32, n.10, p.1991-2005.

GEMAN, H. e OHANA, S. Forward curves, scarcity and price volatility in oil and natural gas markets, Energy Economics, 2009, Vol.31, p.576-585.

GIBSON, R. e SCHWARTZ, E. S. Stochastic convenience yield and the pricing of oil contingent claims. Journal of Finance, 1990, Vol. 45, n.3, p959976.

GIL, D. F. ; MARCHIOTTO, D. M.; LEBEDENCO, F. V. e SILVA, T. O. Custo de dois sistemas de estocagem um estudo comparativo na usina alto alegre. Monografia, Faculdade de Ciências Econômicas d Administrativas de Presidente Prudente, 2005.

GOLDEMBERG, J. e MOREIRA, J. R. The alcohol program. Energy Policy, 1999, 27, 229 - 245. 
GUPTA, S. e DUTTA, K. Modeling of financial supply chain, European Journal of Operational Research, 2010, doi:10.1016/j.ejor.2010.11.005.

HAGAN, M.T. e MENHAJ, M.B. Training feed forward networks with the Marquardt algorithm, IEEE Transactions Neural Networks, 1994, Vol.6, p.861867.

HAMID, S. A. e IQBAL, Z. Using neural networks for forecasting volatility of S\&P500 Index Futures Prices. Journal of Business Research, 2004, Vol. 57, p1116-1125.

HARVEY, A. C. Forecasting, Structural Time Series Models and the Kalman Filter. 1st ed., Cambridge University Press, 1989.

HIRA, A. Sugar rush: prospects for a global ethanol market. Energy Policy, 2010, doi:10.1016/j.enpol.2010.05.035.

HORNIK, K., STINCHCOMBE, M., e WHITE, H. Universal approximation of an unknown mapping and its derivatives using multilayer neural networks. Neural Networks, 1990, n.3, p.551-560.

HOWE, M. A. e RUSTEM, B. A robust hedging algorithm. Journal of Economic Dynamics and Control, 1997, v.21, p.1065-1092.

HOWE, M. A., RUSTEM, B. e SELBY, M. J. P. Multi-period minimax hedging strategies. European Journal of Operational Research, 1996, v.93, p.185-204.

HU, M. Y. e TSOUKALAS, C. Combining conditional volatility forecasts using neural networks: an application to the Ems exchange rates. Journal of International Financial Markets, 1999, Vol. 9, p.407-422.

HULL, J, C. Options, Futures and Others Derivatives. 6⿳亠 ed. New Jersey: Prentice Hall, 2006.

JAIN, A. e KUMAR, A. M. Hybrid neural network models for hydrologic time series forecasting, Applied Soft Computing, 2007, Vol.7, p.585-592.

$\mathrm{KISI}$, O. Multi-layer perceptrons with Levenberg-Marquardt training algorithm for suspended sediment concentration prediction and estimation, Hydrological Sciences - Journal des Sciences Hydrologiques, 2005, Vol.49, p.1025-1040.

KLEINDORFER, P. e LI, L. Multi-period VaR-constrained portfolio optimization in electric power. The Energy Journal, 2005, pp. 1-26.

KOSTIN, A. M.; GUILLÉN-GOSÁLBEZ, G.; MELE, F. D.; BAGAJEWICZ, M. J. e JIMÉNEZ, L. Integrating pricing policies in the strategic planning of supply chains: a case study of the sugar cane industry in Argentina. Computer Aided Chemical Engineering, 2010, vol.28, p.103-108. 
LAPAN, H.; MOSCHINI, G. e HANSON S.D. Production Hedging and Speculative Decisions with Options and Future Markets. American Journal of Agricultural Economics, 1991, Vol. 73, n. 1, pp. 66-74.

LEBOREIRO, J. e HILALY, A. K. Biomass transportation model and optimum plant size for the production of ethanol. Bioresource Technology, 2011, Vol. 102, pp. 2712-2723.

LEVENBERG, K. A Method for the Solution of Certain Problems in Least Squares. Quart. Appl. Math., 1944, Vol. 2, p. 164-168.

LUENBERGER, D.G. Investment Science. 1st ed., Oxford University Press, 1998.

MANOLIU, M. e TOMPAIDIS, S. Energy futures prices: term structure models with Kalman filter estimation, Journal of Applied Mathematical Finance, 2002, Vol.9, n.1, p.21-43.

MARKOWITZ, H. M. Portfolio Selection. Journal of Finance, 1952, Vol.7, p.7791.

MARQUARDT, D. An Algorithm for Least-Squares Estimation of Nonlinear Parameters. SIAM J. Appl. Math., 1963, Vol. 11, pp 431-441.

MARTÍNEZ-DE-ALBÉNIZ, V. e SIMCHI-LEVI, D. Mean-Variance Trade-offs in Supply Contracts. Naval Research Logistics, 2006, n.53, p.603-616.

MAS, M. D.; GIAROLA, S.; ZAMBONI, A. e BEZZO, F. Capacity planning and financial optimization of the bioethanol supply chain under pride uncertainty. Computer Aided Chemical Engineering, 2010, Vol.28, p.97-102.

MORAES, M. A. F. D. As profundas mudanças institucionais ao longo da história da agroindústria canavieira e os desafios atuais, Economia aplicada, 2007, Vol.11, n.4, p.555-557.

MUSSATTO, S.I. ET AL., Technological trends, global market, and challenges of bio-ethanol production-R1, Biotechnology Advances, 2010, Vol.28, n.6, p.817-830.

NAZLIOGLU, S. e SOYTAS, U. World oil prices and agricultural commodity prices: Evidence from an emerging market. Energy Economics, 2010, Vol.33, n.3, p.488-496.

PEREIRA, L. M. Modelo de formação de preços de commodities agrícolas aplicado ao mercado de açúcar e álcool, Tese de Doutorado, Universidade de São Paulo, 2009.

PISHVAEE, M. S.; RABBANI, M. e TORABI, S. A. A robust optimization approach to closed-loop supply chain network design under uncertainty, Applied Mathematical Modelling, 2011, Vol. 35, p. 637-649. 
PRECHELT, L. Automatic early stopping using cross validation: quantifying the criteria, Neural Networks, 1998, Vol.11, p.761-767.

QUARANTA, A. G. e ZAFFARONI, A. Robust Optimization of conditional value at risk and portfolio selection, Journal of Banking and Finance, 2008, Vol.32, p.2046-2056.

RIBEIRO, C. O. e FERREIRA, L. A. S. Uma contribuição ao problema de composição de carteiras de mínimo valor em risco. Gestão e Produção, 2005, Vol.12, p.235-304.

RIBEIRO, C. O.; SOSNOSKI, A. A. B. e WIDONSCK, C. A. Redes neurais aplicadas à previsão de preços de soja no mercado futuro, XLIII congresso da SOBER, Ribeirão Preto, 2005.

RIBEIRO, C, O.; MIRANDA, B. e WIDONSCK, C. A. Redes neurais aplicadas à previsão de volatilidade do mercado futuro de álcool, XXV ENEGEP, Porto Alegre, 2005.

RIBEIRO, C, O.; SOSNOSKI, A.A.B. \& MIRANDA, B., C.A. Brazilian agricultural commodities prices forecast: a hierarchical model on neural networks, $14^{\text {th }}$ EUROMA International Annual Conference, Ankara, 2007.

RIBEIRO, C. O.; OLIVEIRA, S. M. e GUEDES, M. C. M. Modelo híbrido para previsão de preços de commodities do sector sucroalcooleiro, XVII Congresso da Sociedade Portuguesa de Estatística, Lisboa, 2009.

RIBEIRO, C. O. e OLIVEIRA, S. M. A hybrid commodity price-forecasting model applied to sugar-alcohol sector, Australian Journal of Agricultural and Economics, 2011, v.55, p.180-198.

RIBEIRO, C. O.; SOSNOSKI, A. A. K. B. e OLIVEIRA, S. M. Um modelo hierárquico para previsão de preços de commodities agrícolas, Revista Produção Online, 2010, v.10, n.4, p.719-733.

ROCKAFELLAR, R.T. e URYASEV, S. Conditional value at risk for general loss distributions, Journal of Banking and Finance, 2002, V.26, p.1443-1447.

RUSTEM, B. e HOWE, M. Algorithms for worst-case design and applications to risk management. New Jersey: Princeton University Press, 2002.

SCHOUCHANA, F. e MICELI, W. M. Introdução aos mercados futuros e de opções agropecuários no Brasil. 3.ed. São Paulo: Bolsa de Mercadorias \& Futuros, 2004.

SCHWARTZ, E. S. The Stochastic Behavior of Commodity Prices: Implications for Valuation and Hedging. Journal of Finance, 1997, Vol. 52, n.3, p.923-973. 
SCHWARTZ, E. S. Valuing long-term commodity assets. Financial Management, 1998, Vol. 27, n.1, p.57-66.

SCHWARTZ, E. S. \& SMITH, J.E. Short-term variations and long-term dynamics in commodity prices. Management Science, 2000, Vol. 46, n.7, p.893-911.

SERRA, T.; ZILBERMAN, D.; GIL, J.M.; GOODWIN, B.K., Price Transmission in the US ethanol market. Natural Resource Management and Policy, 2010, Vol. 33, pp. 55-72.

SMITH, C. W.; BETRÁN, J. \& RUNGE, E. C. A. Corn: orign, history, technology, and production. 1st ed., Editora: John Wiley \& Sons. Ltd, 2004.

SOUZA, E. L.; SAES, M. S. M.; AZEVEDO, P. F. Competitividade do sistema agroindustrial do milho. Competitividade da agroindústria brasileira. PensaIpea, CD-ROM, 1998.

SOYSTER, A. L. Convex programming with set-inclusive constraints and applications to inexact linear programming, Operational Research, 1973, Vol. 21, p. 1154-1157.

THOMPSON, W.; MEYER, S. \& WESTHOFF, P. How does petroleum price and corn yield volatility affect ethanol markets with and without an ethanol use mandate? Energy Policy, 2009, n. 37, p. 745-749.

TSENG, C. H.; CHENG, S. T.; WANG, Y.H. e PENG, J. T. Artificial neural network model of the hybrid EGARCH volatility of the Taiwan stock index option prices. Physica A: Statistical Mechanics and its Applications, 2008, Vol. 387, n.13, p.3192-3200.

TU, J. V. Advantages and disadvantages of using artificial neural networks versus logistic regression for predicting medical outcomes. Journal of Clinical Epidemiology, 1996, n.49, p.1225-1231.

UNGER, G. Hedging strategy and electricity contract engineering. Swiss Federal Institute Of Technology, Zurich, Tese de Doutorado, 2002.

UNICA. União da Indústria de Cana-de-açúcar. Metade da frota nacional em 2012 será de bicombustíveis, 2009.

VIAN, C. E. F. e QUINTINO, D. D. Crítica à teoria dos mercados futuros à luz do desenvolvimento recente dos contratos futuros de açúcar e álcool da BM\&F. Pesquisa \& Debate, 2007, Vol.18, n.2 (32), p. 307-328.

WANG, Y. H. Nonlinear neural network forecasting model for stock index option price: Hybrid GJR-GARCH approach. Expert Systems with Applications, 2009, Vol. 36, n.1, p. 564-570. 
WANG, Z.; MASSIMO, C. D.; THAM, M. Z. e MORRIS, S. J. A Procedure for Determining the Topology of Multilayer Feedforward Neural Networks. Neural Networks, 1994, Vol. 7, n 2, p. 291-300.

WELCH, G \& BISHOP, G. An Introduction to the Kalman Filter, 1st ed., Siggraph, 2001.

WORKING, Holbrook. Theory of the inverse carrying charge in futures markets. Journal of Farm Economics, 1948, Vol. 30, n. 1, p. 1-28.

YOU, L. e DAIGLER, R. Downside Four-Moment Tail Risk and its Effect on Financial and Commodity Diversification, Probabilistic Constrained Optimization, 2000, p.272-281.

ZHANG, G. P. Time Series Forecasting Using a Hybrid ARIMA and Neural Network Model. Neurocomputing, 2003, Vol 50, p. 159-175.

ZHANG, G. P. e QI, M. Neural network forecasting for seasonal trend series. European Journal of Operational Research, 2005, Vol. 160, n.2, p.501-514.

ZHANG, Z., LOHR, L., ESCALANTE, C. e WETZSTEIN, M. Food versus fuel: What do prices tell us? Energy Policy, 2010, Vol.38, p.445-451.

ZOU, H.F.; XIA, G.P.; YANG, F.T.; WANG H.Y. An investigation and comparison of artificial neural networks and time series models for Chinese food grain prices. Neurocomputing, 2007, Vol. 70, p. 2913-2923.

ZUNINO, L.; TABAK, B. M.; SERINALDI, F.; ZANIN M.; PÉREZ, D. G. e ROSSO, $O$. A. Commodity predictability analysis with a permutation information theory approach. Physica A, 2011, Vol. 390, p. 876-890. 


\section{ANEXO 1: Tabelas}

Tabela A.1 - Fatores de transformação em bushels de milho

\begin{tabular}{lc}
\hline Produtos & bushel de milho \\
\hline 1.0 galão de Etanol & 0.36101 \\
1.0 galão de Biodiesel & 6.66667 \\
\hline
\end{tabular}

Fonte: National Biodiesel Board, 2008

Tabela A.2 - Resultado do modelo por processos estocásticos e Filtro de Kalman para os dados do mercado de milho, etanol e biodiesel dos Estados Unidos

\begin{tabular}{lcccccccc}
\hline \multirow{2}{*}{$\begin{array}{l}\text { Medidas } \\
\text { de Erro }\end{array}$} & \multicolumn{2}{c}{ Milho } & & \multicolumn{2}{c}{ Etanol } & & \multicolumn{2}{c}{ Biodiesel } \\
\cline { 2 - 3 } \cline { 8 - 9 } & Base & $\begin{array}{c}\text { Filtro de } \\
\text { Kalman }\end{array}$ & & Base & $\begin{array}{c}\text { Filtro de } \\
\text { Kalman }\end{array}$ & & Base & $\begin{array}{c}\text { Filtro de } \\
\text { Kalman }\end{array}$ \\
\hline MAE & 0.2632 & 0.0905 & & 0.2655 & 0.0899 & & 0.2333 & 0.1338 \\
MSE & 0.1232 & 0.0167 & & 0.1184 & 0.0132 & & 0.0934 & 0.0288 \\
MAPE (\%) & 5.22 & 1.93 & & 4.86 & 1.73 & & 6.42 & 3.85 \\
Variância & 0.1185 & 0.0167 & & 0.1134 & 0.0136 & & 0.0864 & 0.0297 \\
\hline
\end{tabular}

Tabela A.3 - Matriz $\boldsymbol{r}$ de retornos esperados (EUA)

\begin{tabular}{|c|c|c|c|c|c|c|c|c|c|c|c|}
\hline 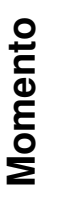 & $\stackrel{\sim}{*}$ & $\Sigma^{*}$ & $\stackrel{\vec{\theta}}{a}$ & $\underset{\Delta=}{ \pm}$ & $\stackrel{\overrightarrow{7}}{\stackrel{+1}{ \pm 0}}$ & 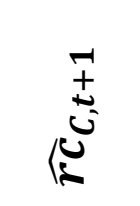 & $\underbrace{ \pm}_{i}$ & 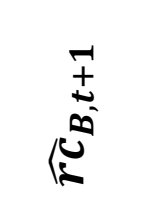 & 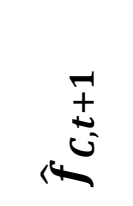 & $\underbrace{+1}_{4}$ & $\stackrel{+7}{ \pm}$ \\
\hline 1 & $47.1 \%$ & $44.4 \%$ & $78.8 \%$ & $57.1 \%$ & $85.5 \%$ & $59.8 \%$ & $51.9 \%$ & $81.3 \%$ & $-7.8 \%$ & $1.7 \%$ & $-10.4 \%$ \\
\hline 2 & $55.2 \%$ & $51.4 \%$ & $84.0 \%$ & $65.0 \%$ & $90.0 \%$ & $59.4 \%$ & $59.9 \%$ & $85.9 \%$ & $15.1 \%$ & $1.3 \%$ & $5.3 \%$ \\
\hline
\end{tabular}

Em que:

$r_{C, t}$ é a margem obtida com a venda do milho no mercado à vista no instante $t$;

$r_{E, t}$ é a margem obtida com a venda do etanol no mercado à vista no instante $t$;

$r_{B, t}$ é a margem obtida com a venda do biodiesel no mercado à vista no instante $t$;

$\hat{r}_{E, t+1}$ é a margem prevista com a venda do etanol no mercado à vista no instante $t+1$; 
$\hat{r}_{B, t+1}$ é a margem prevista com a venda do biodiesel no mercado à vista no instante $t+1$

$\widehat{r c}_{C, t+1}$ é a margem prevista com a venda do milho, no instante $t+1$, estocado por um mês;

$\widehat{r c}_{E, t+1}$ é a margem prevista com a venda do etanol, no instante $t+1$, estocado por um mês;

$\widehat{r} c_{B, t+1}$ é a margem prevista com a venda do biodiesel, no instante $t+1$, estocado por um mês;

$\hat{f}_{C, t+1}$ é o retorno esperado com a posição vendida no mercado futuro de milho entre os períodos $t$ e $t+1$;

$\hat{f}_{E, t+1}$ é o retorno esperado com a posição vendida no mercado futuro de etanol entre os períodos $t$ e $t+1$;

$\hat{f}_{o, t+1}$ é o retorno esperado com a posição vendida no mercado futuro de petróleo entre os períodos $t$ e $t+1$;

Tabela A.4 - Matriz $s$ de níveis de incerteza (EUA)

\begin{tabular}{|c|c|c|c|c|c|c|c|c|c|c|c|}
\hline 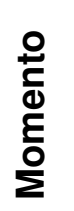 & $s_{C, t}$ & $\boldsymbol{s}_{E, t}$ & $s_{B, t}$ & $\widehat{s}_{E, t+1}$ & $\widehat{s}_{B, t+1}$ & $\hat{\boldsymbol{s}}_{C, t+1}$ & $\widehat{\boldsymbol{s}}_{E, t+1}$ & $\widehat{s}_{B, t+1}$ & $\widehat{s}_{C, t+1}$ & $\widehat{s}_{E, t+1}$ & $\hat{\boldsymbol{s}}_{B, t+1}$ \\
\hline 1 & $0 \%$ & $0 \%$ & $0 \%$ & $5.6 \%$ & $3.6 \%$ & $5.6 \%$ & $5.6 \%$ & $3.6 \%$ & $5.6 \%$ & $5.6 \%$ & $3.6 \%$ \\
\hline 2 & $0 \%$ & $0 \%$ & $0 \%$ & $7.1 \%$ & $4.3 \%$ & $6.4 \%$ & $7.1 \%$ & $4.3 \%$ & $6.4 \%$ & $7.1 \%$ & $4.3 \%$ \\
\hline
\end{tabular}

Em que:

$s_{C, t}$ é a incerteza associada a margem do milho no instante $t$;

$s_{E, t}$ é a incerteza associada a margem do etanol no instante $t$;

$s_{B, t}$ é a incerteza associada a margem do biodiesel no instante $t$;

$\hat{s}_{C, t+1}$ é a incerteza associada a margem prevista do milho no instante $t+1$;

$\hat{s}_{E, t+1}$ é a incerteza associada a margem prevista do etanol no instante $t+1$;

$\hat{s}_{B, t+1}$ é a incerteza associada a margem prevista do biodiesel no instante $t+1$; 
Tabela A.5 - Quantidades e Capacidade de Estoque (EUA)

\begin{tabular}{|c|c|c|c|c|c|c|c|c|c|c|}
\hline 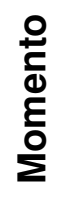 & $Q_{C, t}$ & $Q_{E, t}$ & $Q_{B, t}$ & $S T_{C, t}$ & $S T_{E, t}$ & $S T_{B, t}$ & $\operatorname{Cst}_{C}$ & $\operatorname{Cst}_{E}$ & $C s t_{B}$ & $Q_{\text {Total }, t}$ \\
\hline 1 & 100 & 100 & 10 & 100 & 100 & 40 & 500 & 200 & 200 & 450 \\
\hline 2 & 100 & 100 & 10 & 100 & 100 & 40 & 500 & 200 & 200 & 450 \\
\hline
\end{tabular}

$Q_{C, t}$ é a quantidade de milho disponível, no processo, no instante $t$;

$Q_{E, t}$ é a quantidade de etanol disponível, no processo, no instante $t$;

$Q_{B, t}$ é a quantidade de biodiesel disponível, no processo, no instante $t$;

$S T_{C, t}$ é a quantidade de milho disponível em estoque no instante $t$;

$S T_{E, t}$ é a quantidade de etanol disponível em estoque no instante $t$;

$S T_{B, t}$ é a quantidade de biodiesel disponível em estoque no instante $t$;

$C s t_{C}$ é a capacidade de estocagem de milho;

$C_{S} t_{E}$ é a capacidade de estocagem de etanol;

$C s t_{B}$ é a capacidade de estocagem de biodiesel, e

$Q_{\text {Total,t }}$ é a quantidade de milho disponível, nas mais diversas formas (milho, etanol ou biodiesel), no instante $t$.

Tabela A.6 - Fatores de transformação em equivalentes ATR

\begin{tabular}{lc}
\hline Produtos & kg de ATR \\
\hline $1.0 \mathrm{~kg}$ de Açúcar Branco & 1.04950 \\
1.0 It de Etanol Hidratado & 1.69130 \\
\hline
\end{tabular}

Fonte: CONSECANA, 2008 
Tabela A.7 - Custos de Produção do Setor Sucroalcooleiro

\begin{tabular}{lcc}
\hline \multirow{2}{*}{ Safra } & Açúcar Branco & Etanol Hidratado \\
\cline { 2 - 3 } & $\mathbf{R} \$ /$ ton & $\mathbf{R} \$ \mathbf{m}^{\mathbf{3}}$ \\
\hline $2007 / 2008$ & 472.40 & 744.29 \\
2008 / 2009 & 535.47 & 803.44 \\
2009 / 2010 & 686.30 & 906.36 \\
$2010 / 2011$ & 706.66 & 916.30 \\
\hline
\end{tabular}

Fonte: Pecege - ESALQ

Tabela A.8 - Resultado do modelo por processos estocásticos e Filtro de Kalman para os dados do mercado Sucroalcooleiro Brasileiro

\begin{tabular}{lccccc}
\hline \multirow{2}{*}{$\begin{array}{l}\text { Medidas } \\
\text { de Erro }\end{array}$} & \multicolumn{2}{c}{ Açúcar } & & \multicolumn{2}{c}{ Etanol } \\
\cline { 2 - 3 } \cline { 5 - 6 } & Base & $\begin{array}{c}\text { Filtro de } \\
\text { Kalman }\end{array}$ & & Base & $\begin{array}{c}\text { Filtro de } \\
\text { Kalman }\end{array}$ \\
\hline MAE & 0.3919 & 0.0905 & & 0.2432 & 0.0011 \\
MSE & 6.1320 & 1.9314 & & 2.5383 & 1.3205 \\
MAPE (\%) & 8.33 & 5.91 & & 9.53 & 8.10 \\
Variância & 6.0471 & 1.9453 & & 2.5076 & 1.3357 \\
\hline
\end{tabular}

Tabela A.9 - Matriz $\boldsymbol{r}$ de retornos esperados (Brasil)

\begin{tabular}{|c|c|c|c|c|c|c|c|}
\hline 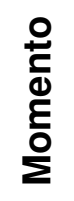 & $r_{A, t}$ & $r_{E, t}$ & $\hat{\boldsymbol{r}}_{A, t+1}$ & $\hat{\boldsymbol{r}}_{E, t+1}$ & $\widehat{r c}_{A, t+1}$ & $\widehat{\boldsymbol{r c}}_{E, t+1}$ & $\widehat{f}_{A, t+1}$ \\
\hline 1 & $18.7 \%$ & $-112.5 \%$ & $20.9 \%$ & $-67.6 \%$ & $20.1 \%$ & $-70.7 \%$ & $7.9 \%$ \\
\hline 2 & $-5.0 \%$ & $1.8 \%$ & $3.9 \%$ & $11.0 \%$ & $2.8 \%$ & $8.9 \%$ & $-18.1 \%$ \\
\hline
\end{tabular}

Tabela A.10 - Matriz $s$ de níveis de incerteza (Brasil)

\begin{tabular}{|c|c|c|c|c|c|c|c|}
\hline 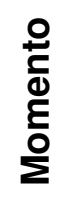 & $s_{A, t}$ & $s_{E, t}$ & $\hat{\boldsymbol{s}}_{\boldsymbol{A}, \boldsymbol{t}+\mathbf{1}}$ & $\widehat{s}_{E, t+1}$ & $\hat{\boldsymbol{s}}_{A, t+1}$ & $\hat{\boldsymbol{s}}_{E, t+1}$ & $\hat{s}_{A, t+1}$ \\
\hline 1 & $0 \%$ & $0 \%$ & $2.4 \%$ & $2.5 \%$ & $2.4 \%$ & $2.5 \%$ & $2.4 \%$ \\
\hline 2 & $0 \%$ & $0 \%$ & $1.0 \%$ & $3.5 \%$ & $1.0 \%$ & $3.5 \%$ & $1.0 \%$ \\
\hline
\end{tabular}


Tabela A.11 - Quantidades e Capacidade de Estoque (Brasil)

\begin{tabular}{|c|c|c|c|c|c|c|c|c|}
\hline 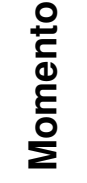 & $Q_{A, t}$ & $Q_{E, t}$ & $S T_{A, t}$ & $S T_{E, t}$ & $Q_{\text {Base }, t}$ & $C s t_{A}$ & $C s t_{E}$ & $Q_{\text {Total }, t}$ \\
\hline 1 & 100 & 100 & 100 & 100 & 200 & 500 & 500 & 600 \\
\hline 2 & 100 & 100 & 100 & 100 & 200 & 500 & 500 & 600 \\
\hline
\end{tabular}

